This PDF is a selection from a published volume from the National Bureau of Economic Research

Volume Title: Measuring Capital in the New Economy

Volume Author/Editor: Carol Corrado, John Haltiwanger and Dan Sichel, editors

Volume Publisher: University of Chicago Press

Volume ISBN: 0-226-11612-3

Volume URL: http://www.nber.org/books/corr05-1

Conference Date: April 26-27, 2002

Publication Date: August 2005

Title: Issues in the Measurement of Capital Services, Depreciation, Asset Price Changes, and Interest Rates

Author: W. Erwin Diewert

URL: http://www.nber.org/chapters/c10628

Chapter pages in book: $(479-556)$ 


\title{
Issues in the Measurement of Capital Services, Depreciation, Asset Price Changes, and Interest Rates
}

\author{
W. Erwin Diewert
}

\subsection{Introduction}

In this chapter, we discuss some of the problems involved in constructing price and quantity series for both capital stocks and the associated flows of services when there are general and asset-specific price changes in the economy. ${ }^{1}$

In section 12.2, we present the basic equations relating stocks and flows of capital assuming that data on the prices of vintages of a homogeneous capital good are available. This framework is not applicable under all circumstances, but it is a framework that will allow us to disentangle the effects of general price change, asset-specific price change, and depreciation.

Section 12.3 continues the theoretical framework that was introduced in section 12.2. We show how information on vintage asset prices, vintage rental prices, and vintage depreciation rates are all equivalent under certain assumptions; that is, knowledge of any one of these three sequences or profiles is sufficient to determine the other two.

Section 12.4 discusses alternative sets of assumptions on nominal interest rates and anticipated asset price changes. We specify three different sets

W. Erwin Diewert is professor of economics at the University of British Columbia and a research associate of the National Bureau of Economic Research.

The author is indebted to Carol Corrado, Kevin Fox, John Haltiwanger, Peter Hill, Ning Huang, Ulrich Kohli, Alice Nakamura, Paul Schreyer, Dan Sichel, and Frank Wykoff for helpful comments. This research was supported by a SSHRC research grant. None of the parties acknowledged here are responsible for any errors or opinions expressed in the paper. A longer version of the present paper, including the data used, is available as Department of Economics Discussion Paper 04-10, University of British Columbia, Vancouver, Canada.

1. We cover some of the same issues discussed in the recent paper by R. J. Hill and Hill (2003). However, Hill and Hill did not deal with the problems associated with adjusting nominal interest rates for general inflation. 
of assumptions that we will use in our empirical illustration of the suggested methods.

Section 12.5 discusses the significance of our assumptions made in the previous section and relates them to controversies in national income accounting. In particular, we discuss whether anticipated asset price decline should be an element of depreciation as understood by national income accountants.

Section 12.6 discusses the problems involved in aggregating over vintages of capital, both in forming capital stocks and capital services. Instead of the usual perpetual inventory method for aggregating over vintages, which assumes perfectly substitutable vintages of the same stock, we suggest the use of a superlative index number formula to do the aggregation.

Sections 12.7 to 12.10 show how the general algebra presented in sections 12.2 and 12.3 can be adapted to deal with four specific models of depreciation. The four models considered are the one-hoss-shay model, the straight-line depreciation model, the geometric model of depreciation, and the linear efficiency decline model. In section 12.11, we show how these models differ empirically by computing the corresponding stocks and flows using Canadian data on two asset classes. The details of the computations and the data used may be found in Diewert (2004).

Section 12.12 shows how our framework can be modified to model the treatment of some forms of intangible capital, such as investments in research and development.

Section 12.13 concludes with some observations on how statistical agencies might be able to use the material presented in this chapter.

\subsection{The Fundamental Equations Relating Stocks and Flows of Capital}

Before we begin with our algebra, it seems appropriate to explain why accounting for the contribution of capital to production is more difficult than accounting for the contributions of labor or materials. The main problem is that when a reproducible capital input is purchased for use by a production unit at the beginning of an accounting period, we cannot simply charge the entire purchase cost to the period of purchase. Since the benefits of using the capital asset extend over more than one period, the initial purchase cost must be distributed somehow over the useful life of the asset. This is the fundamental problem of accounting.

In a noninflationary environment, the value of an asset at the beginning of an accounting period is equal to the discounted stream of future rental payments that the asset is expected to yield. Thus, the stock value of the asset is equal to the discounted future service flows ${ }^{2}$ that the asset is expected

2. Walras (1954; first edition published in 1874) was one of the earliest economists to state that capital stocks are demanded because of the future flow of services that they render. Al- 
to yield in future periods. Let the price of a new capital input purchased at the beginning of period $t$ be $P_{0}^{t}$. In a noninflationary environment, it can be assumed that the (potentially observable) sequence of (cross-sectional) vintage rental prices prevailing at the beginning of period $t$ can be expected to prevail in future periods. Thus, in this no-general-inflation case, there is no need to have a separate notation for future expected rental prices for a new asset as it ages. However, in an inflationary environment, it is necessary to distinguish between the observable rental prices for the asset at different ages at the beginning of period $t$ and future expected rental prices for assets of various ages. ${ }^{3}$ Thus let $f_{0}^{t}$ be the (observable) rental price of a new asset at the beginning of period $t$, let $f_{1}^{t}$ be the (observable) rental price of a one-period-old asset at the beginning of period $t$, let $f_{2}^{t}$ be the (observable) rental price of a two-period-old asset at the beginning of period $t$, and so on. Then the fundamental equation relating the stock value of a new asset at the beginning of period $t, P_{0}^{t}$ to the sequence of cross-sectional rental prices for assets of age $n$ prevailing at the beginning of period $t,\left\{f_{n}^{t} ; n=0\right.$, $1,2, \ldots\}^{4}$ is

$$
P_{0}^{t}=f_{0}^{t}+\left(\frac{1+i_{1}^{t}}{1+r_{1}^{t}}\right) f_{1}^{t}+\left[\frac{\left(1+i_{1}^{t}\right)\left(1+i_{2}^{t}\right)}{\left(1+r_{1}^{t}\right)\left(1+r_{2}^{t}\right)}\right] f_{2}^{t}+\ldots
$$

In the above equation, $1+i_{1}^{t}$ is the rental price escalation factor that is expected to apply to a one-period-old asset going from the beginning of period $t$ to the end of period $t$ (or, equivalently, to the beginning of period $t+$ $1),\left(1+i_{1}^{t}\right)\left(1+i_{2}^{t}\right)$ is the rental price escalation factor that is expected to apply to a two-period-old asset going from the beginning of period $t$ to the beginning of period $t+2$, etc. Thus, the $i_{n}^{t}$ are expected rates of price change for used assets of varying ages $n$ that are formed at the beginning of period $t$. The term $1+r_{1}^{t}$ is the discount factor that makes a dollar received at the beginning of period $t$ equivalent to a dollar received at the beginning of period $t+1$, the term $\left(1+r_{1}^{t}\right)\left(1+r_{2}^{t}\right)$ is the discount factor that makes a dollar received at the beginning of period $t$ equivalent to a dollar received at the beginning of period $t+2$, and so on. Thus, the $r_{n}^{t}$ are one-period nominal interest rates that represent the term structure of interest rates at the beginning of period $t .^{5}$

though he was perhaps the first economist to formally derive a user cost formula, as we shall see, he did not work out the explicit discounting formula that Böhm-Bawerk (1891, p. 342) was able to derive.

3 . Note that these future expected rental prices are not generally observable due to the lack of futures markets for these future period rentals of the assets of varying ages.

4. The sequence of (cross-sectional) vintage rental prices $\left(f_{n}^{t}\right)$ is called the age-efficiency profile of the asset.

5. Peter Hill has noted a major problem with the use of equation (1) as the starting point of our discussion: namely, unique assets will by definition not have used versions of the same asset in the marketplace during the current period, and so the cross-sectional rental prices $f_{n}^{t}$ for assets of age $n$ in period $t$ will not exist for these assets! In this case, the $f_{n}^{t}$ should be 
We now generalize equation (1) to relate the stock value of an n-periodold asset at the beginning of period $t, P_{n}^{t}$, to the sequence of cross-sectional vintage rental prices prevailing at the beginning of period $t,\left\{f_{n}^{t}\right\}$; thus, for $n=0,1,2, \ldots$, we assume

$$
P_{n}^{t}=f_{n}^{t}+\left(\frac{1+i_{1}^{t}}{1+r_{1}^{t}}\right) f_{n+1}^{t}+\left[\frac{\left(1+i_{1}^{t}\right)\left(1+i_{2}^{t}\right)}{\left(1+r_{1}^{t}\right)\left(1+r_{2}^{t}\right)}\right] f_{n+2}^{t}+\ldots
$$

Thus, older assets discount fewer terms in the above sum; thus, as $n$ increases by one, we have one less term on the right-hand side of equation (2). However, note that we are applying the same price escalation factors $(1+$ $\left.i_{1}^{t}\right),\left(1+i_{1}^{t}\right)\left(1+i_{2}^{t}\right), \ldots$, to escalate the cross-sectional rental prices prevailing at the beginning of period $t, f_{1}^{t}, f_{2}^{t}, \ldots$, and to form estimates of future expected rental prices for each vintage of the capital stock that is in use at the beginning of period $t$.

The rental prices prevailing at the beginning of period $t$ for assets of various ages, $f_{0}^{t}, f_{1}^{t}, \ldots$ are potentially observable. ${ }^{6}$ These cross-section rental prices reflect the relative efficiency of the various vintages of the capital good that are still in use at the beginning of period $t$. It is assumed that these rentals are paid (explicitly or implicitly) by the users at the beginning of period $t$. Note that the sequence of asset stock prices for various ages at the beginning of period $t, P_{0}^{t}, P_{1}^{t}, \ldots$ is not affected by general inflation provided that the general inflation affects the expected asset rates of price change $i_{n}^{t}$ and the nominal interest rates $r_{n}^{t}$ in a proportional manner. We will return to this point later.

The physical productivity characteristics of a unit of capital of each age are determined by the sequence of cross-sectional rental prices. Thus, a brand-new asset is characterized by the vector of current rental prices for assets of various ages, $\boldsymbol{f}_{0}^{t}, \boldsymbol{f}_{1}^{t}, \boldsymbol{f}_{2}^{t}, \ldots$, which are interpreted as "physical" contributions to output that the new asset is expected to yield during the current period $t$ (this is $f_{0}^{t}$ ), the next period (this is $f_{1}^{t}$ ), and so on. An asset that is one period old at the start of period $t$ is characterized by the vector $\boldsymbol{f}_{1}^{t}, \boldsymbol{f}_{2}^{t}, \ldots$, and so on. ${ }^{7}$

We have not explained how the expected rental price rates of price

interpreted as expected future rentals that the unique asset is expected to generate at today's prices. The $\left(1+i_{n}^{t}\right)$ terms then summarize expectations about the amount of asset-specific price change that is expected to take place. This reinterpretation of equation (1) is more fundamental, but we chose not to make it our starting point because it does not lead to a completely objective method for national statisticians to form reproducible estimates of these future rental payments. However, in many situations (e.g., the valuation of a new movie), the statistician will be forced to attempt to implement P. Hill's (2000) more general model. In section 12.12 below, we apply a variant of the expected rentals interpretation of our equations to value intangible capital.

6. This is the main reason that we use this escalation of cross-sectional rental prices approach to capital measurement rather than the more fundamental discounted future expected rentals approach advocated by Hill.

7. Triplett (1996, p. 97) used this characterization for capital assets of various vintages. 
change $i_{n}^{t}$ are to be estimated. We shall deal with this problem in section 12.4. However, it should be noted that there is no guarantee that our expectations about the future course of rental prices are correct.

At this point, we make some simplifying assumptions about the expected rates of rental price change for future periods $i_{n}^{t}$ and the interest rates $r_{n}^{t}$. We assume that these anticipated specific price change escalation factors at the beginning of each period $t$ are all equal; that is, we assume

$$
i_{n}^{t}=i^{t} ; \quad n=1,2, \ldots
$$

We also assume that the term structure of (nominal) interest rates at the beginning of each period $t$ is constant; that is, we assume

$$
r_{n}^{t}=r^{t} ; \quad n=1,2, \ldots
$$

However, note that as the period $t$ changes, $r^{t}$ and $i^{t}$ can change.

Using assumptions (3) and (4), we can rewrite equation (2), which relates the sequence or profile of stock prices of age $n$ at the beginning of period $t$ $\left\{P_{n}^{t}\right\}$ to the sequence or profile of (cross-sectional) rental prices for assets of age $n$ at the beginning of period $t\left\{f_{n}^{t}\right\}$, as follows:

$$
\begin{aligned}
& P_{0}^{t}=f_{0}^{t}+\left(\frac{1+i^{t}}{1+r^{t}}\right) f_{1}^{t}+\left(\frac{1+i^{t}}{1+r^{t}}\right)^{2} f_{2}^{t}+\left(\frac{1+i^{t}}{1+r^{t}}\right)^{3} f_{3}^{t}+\ldots \\
& P_{1}^{t}=f_{1}^{t}\left(\frac{1+i^{t}}{1+r^{t}}\right) f_{2}^{t}+\left(\frac{1+i^{t}}{1+r^{t}}\right)^{2} f_{3}^{t}+\left(\frac{1+i^{t}}{1+r^{t}}\right)^{3} f_{4}^{t}+\ldots \\
& P_{2}^{t}=f_{2}^{t}\left(\frac{1+i^{t}}{1+r^{t}}\right) f_{3}^{t}+\left(\frac{1+i^{t}}{1+r^{t}}\right)^{2} f_{4}^{t}+\left(\frac{1+i^{t}}{1+r^{t}}\right)^{3} f_{5}^{t}+\ldots \\
& P_{n}^{t}=f_{n}^{t}\left(\frac{1+i^{t}}{1+r^{t}}\right) f_{n+1}^{t}+\left(\frac{1+i^{t}}{1+r^{t}}\right)^{2} f_{n+2}^{t}+\left(\frac{1+i^{t}}{1+r^{t}}\right)^{3} f_{n+3}^{t}+\ldots
\end{aligned}
$$

On the left-hand side of equations (5), we have the sequence of period- $t$ asset prices by age starting with the price of a new asset, $P_{0}^{t}$, moving to the price of an asset that is one period old at the start of period $t, P_{1}^{t}$, then moving to the price of an asset that is two periods old at the start of period $t$, $P_{2}^{t}$, and so on. On the right-hand side of equations (5), the first term in each equation is a member of the sequence of rental prices by age of asset that prevails in the market (if such markets exist) at the beginning of period $t$. Thus, $f_{0}^{t}$ is the rent for a new asset, $f_{1}^{t}$ is the rent for an asset that is one period old at the beginning of period $t, f_{2}^{t}$ is the rent for an asset that is two periods old, and so on. This sequence of current market rental prices for the assets of various vintages is then extrapolated out into the future using the anticipated price escalation rates $\left(1+i^{t}\right),\left(1+i^{t}\right)^{2},\left(1+i^{t}\right)^{3}$, and so on, and then these future expected rentals are discounted back to the beginning of period $t$ using the nominal discount factors $\left(1+r^{t}\right),\left(1+r^{t}\right)^{2}$, 
$\left(1+r^{t}\right)^{3}$, and so on. Note that given the period- $t$ expected asset inflation rate $i^{t}$ and the period- $t$ nominal discount rate $r^{t}$, we can go from the (crosssectional) sequence of vintage rental prices $\left\{f_{n}^{t}\right\}$ to the (cross-sectional) sequence of vintage asset prices $\left\{P_{n}^{t}\right\}$ using equations (5). We shall show below how this procedure can be reversed; that is, we shall show how, given the sequence of cross-sectional asset prices, we can construct estimates for the sequence of cross-sectional rental prices.

Böhm-Bawerk (1891, p. 342) considered a special case of equations (5) where all service flows $f_{n}$ were equal to 100 for $n=0,1, \ldots, 6$ and equal to 0 thereafter, where the asset inflation rate was expected to be 0 and where the interest rate $r$ was equal to .05 or 5 percent. ${ }^{8}$ This is a special case of what has come to be known as the one-hoss-shay model, and we shall consider it in more detail in section 12.7 .

Note that equations (5) can be rewritten as follows: ${ }^{9}$

$$
\begin{aligned}
& P_{0}^{t}=f_{0}^{t}+\left(\frac{1+i^{t}}{1+r^{t}}\right) P_{1}^{t} ; \\
& P_{1}^{t}=f_{1}^{t}+\left(\frac{1+i^{t}}{1+r^{t}}\right) P_{2}^{t} ; \\
& P_{2}^{t}=f_{2}^{t}+\left(\frac{1+i^{t}}{1+r^{t}}\right) P_{3}^{t} ; \\
& \ldots \\
& P_{n}^{t}=f_{n}^{t}+\left(\frac{1+i^{t}}{1+r^{t}}\right) P_{n+1}^{t} ; \ldots
\end{aligned}
$$

The first equation in equations (6) says that the value of a new asset at the start of period $t, P_{0}^{t}$, is equal to the rental that the asset can earn in period $t, f_{0}^{t},{ }^{10}$ plus the expected asset value of the capital good at the end of period $t,\left(1+i^{t}\right) P_{1}^{t}$, but this expected asset value must be divided by the discount factor, $\left(1+r^{t}\right)$, in order to convert this future value into an equivalent beginning-of-period- $t$ value. ${ }^{11}$

8. Böhm-Bawerk (1891, p. 343) went on to construct the sequence of vintage asset prices using his special case of equations (5).

9. Christensen and Jorgenson $(1969$, p. 302) do this for the geometric depreciation model, except that they assume that the rental is paid at the end of the period rather than the beginning. Variants of the system of equations (6) were derived by Christensen and Jorgenson (1973), Jorgenson (1989, p. 10), Hulten (1990, p. 128) and Diewert and Lawrence (2000, p. 276). Irving Fisher (1908, pp. 32-33) also derived these equations in words.

10. Note that we are implicitly assuming that the rental is paid to the owner at the beginning of period $t$.

11. Another way of interpreting say the first equation in equations (6) runs as follows: the purchase cost of a new asset $P_{0}^{t}$ less the rental $f_{0}^{t}$ (which is paid immediately at the beginning of period $t$ ) can be regarded as an investment, which must earn the going rate of return $r^{t}$. Thus, we must have $\left(P_{0}^{t}-f_{0}^{t}\right)\left(1+r^{t}\right)=\left(1+i^{t}\right) P_{1}^{t}$, which is the (expected) value of the asset at the end of period $t$. This line of reasoning can be traced back to Walras (1954, p. 267). 
Now it is straightforward to solve equations (6) for the sequence of period- $t$ cross-sectional rental prices, $\left\{f_{n}^{t}\right\}$, in terms of the cross-sectional asset prices, $\left\{P_{n}^{t}\right\}$ :

$$
\begin{aligned}
& f_{0}^{t}=P_{0}^{t}-\left(\frac{1+i^{t}}{1+r^{t}}\right) P_{1}^{t}=\left(1+r^{t}\right)^{-1}\left[P_{0}^{t}\left(1+r^{t}\right)-\left(1+i^{t}\right) P_{1}^{t}\right] \\
& f_{1}^{t}=P_{1}^{t}-\left(\frac{1+i^{t}}{1+r^{t}}\right) P_{2}^{t}=\left(1+r^{t}\right)^{-1}\left[P_{1}^{t}\left(1+r^{t}\right)-\left(1+i^{t}\right) P_{2}^{t}\right] \\
& f_{2}^{t}=P_{2}^{t}-\left(\frac{1+i^{t}}{1+r^{t}}\right) P_{3}^{t}=\left(1+r^{t}\right)^{-1}\left[P_{2}^{t}\left(1+r^{t}\right)-\left(1+i^{t}\right) P_{3}^{t}\right] \\
& \ldots \\
& f_{n}^{t}=P_{n}^{t}-\left(\frac{1+i^{t}}{1+r^{t}}\right) P_{n+1}^{t}=\left(1+r^{t}\right)^{-1}\left[P_{n}^{t}\left(1+r^{t}\right)-\left(1+i^{t}\right) P_{n+1}^{t}\right] ; \ldots
\end{aligned}
$$

Thus, equations (5) allow us to go from the sequence of rental prices by age $n\left\{f_{n}^{t}\right\}$ to the sequence of asset prices by age $n\left\{P_{n}^{t}\right\}$, while equations (7) allow us to reverse the process.

Equations (7) can be derived from elementary economic considerations. Consider the first equation in equations (7). Think of a production unit as purchasing a unit of the new capital asset at the beginning of period $t$ at a cost of $P_{0}^{t}$ and then using the asset throughout period $t$. However, at the end of period $t$, the producer will have a depreciated asset that is expected to be worth $\left(1+i^{t}\right) P_{1}^{t}$. Since this offset to the initial cost of the asset will only be received at the end of period $t$, it must be divided by $\left(1+r^{t}\right)$ to express the benefit in terms of beginning-of-period- $t$ dollars. Thus the expected net $\cos ^{12}$ of using the new asset for period $t$ is $P_{0}^{t}-\left[\left(1+i^{t}\right) /\left(1+r^{t}\right)\right] P_{1}^{t}$.

The above equations assume that the actual or implicit period $t$ rental payments $f_{n}^{t}$ for assets of different ages $n$ are made at the beginning of period $t$. It is sometimes convenient to assume that the rental payments are made at the end of each accounting period. Thus, we define the endof-period-t rental price or user cost for an asset that is $n$ periods old at the beginning of period $t, u_{n}^{t}$, in terms of the corresponding beginning-ofperiod-t rental price $f_{n}^{t}$ as follows:

$$
u_{n}^{t} \equiv\left(1+r^{t}\right) f_{n}^{t} ; \quad n=0,1,2, \ldots
$$

Thus, if the rental payment is made at the end of the period instead of the beginning, then the beginning of the period rental $f_{n}^{t}$ must be escalated by the interest rate factor $\left(1+r^{t}\right)$ in order to obtain the end-of-period user $\operatorname{cost} u_{n}^{t}$.

12. This explains why the rental prices $f_{n}^{t}$ are sometimes called $u$ ser costs. This derivation of a user cost was used by Diewert (1974, p. 504; 1980, pp. 472-73; 1992b, p. 194) and by Hulten (1996, p. 155). 
Using equations (8) and the second set of equations in (7), it can readily be shown that the sequence of end-of-period- $t$ user costs $\left\{u_{n}^{t}\right\}$ can be defined in terms of the period- $t$ sequence of asset prices by age $\left\{P_{n}^{t}\right\}$ as follows:

$$
\begin{gathered}
u_{0}^{t}=P_{0}^{t}\left(1+r^{t}\right)-\left(1+i^{t}\right) P_{1}^{t} \\
u_{1}^{t}=P_{1}^{t}\left(1+r^{t}\right)-\left(1+i^{t}\right) P_{2}^{t} \\
u_{2}^{t}=P_{2}^{t}\left(1+r^{t}\right)-\left(1+i^{t}\right) P_{3}^{t} \\
\ldots \\
u_{n}^{t}=P_{n}^{t}\left(1+r^{t}\right)-\left(1+i^{t}\right) P_{n+1}^{t} ; \ldots
\end{gathered}
$$

Equations (9) can also be given a direct economic interpretation. Consider the following explanation for the user cost for a new asset, $u_{0}^{t}$. At the end of period $t$, the business unit expects to have an asset worth $\left(1+i^{t}\right) P_{1}^{t}$. Offsetting this benefit is the beginning-of-period asset purchase cost, $P_{0}^{t}$. However, in addition to this cost, the business must charge itself either the explicit interest cost that occurs if money is borrowed to purchase the asset or the implicit opportunity cost of the equity capital that is tied up in the purchase. Thus, offsetting the end-of-period benefit $\left(1+i^{t}\right) P_{1}^{t}$ is the initial purchase cost and opportunity interest cost of the asset purchase, $P_{0}^{t}\left(1+r^{t}\right)$, leading to an end-of-period- $t$ net cost of $P_{0}^{t}\left(1+r^{t}\right)-\left(1+i^{t}\right) P_{1}^{t}$ or $u_{0}^{t}$.

It is interesting to note that in both the accounting and financial management literature of the past century, there was a reluctance to treat the opportunity cost of equity capital tied up in capital inputs as a genuine cost of production. ${ }^{13}$ However, more recently there is an acceptance of an imputed interest charge for equity capital as a genuine cost of production. ${ }^{14}$

In the following section, we will relate the asset price profiles $\left\{P_{n}^{t}\right\}$ and the user cost profiles $\left\{u_{n}^{t}\right\}$ to depreciation profiles. However, before turning to the subject of depreciation, it is important to stress that the analysis presented in this section is based on a number of restrictive assumptions, particularly on future price expectations. Moreover, we have not explained how these asset price expectations are formed, and we have not explained how the period- $t$ nominal interest rate is to be estimated (we will address these topics in section 12.7). We have not explained what should be done if the sequence of secondhand asset prices $\left\{P_{n}^{t}\right\}$ is not available and the sequences of vintage rental prices or user costs, $\left\{f_{n}^{t}\right\}$ or $\left\{u_{n}^{t}\right\}$, are also not available (we will address this problem in later sections as well). We have also assumed that asset values and user costs are independent of how intensively the assets are used. Finally, we have not modeled uncertainty (about future prices and the useful lives of assets) and attitudes toward risk

13. This literature is reviewed in Diewert and Fox (1999, pp. 271-74).

14. Stern Stewart and Co. has popularized the idea of charging for the opportunity cost of equity capital and has called the resulting income concept economic value added (EVA). 
on the part of producers. Thus, the analysis presented in this chapter is only a start on the difficult problems associated with measuring capital input.

\subsection{Cross-Section Depreciation Profiles}

Recall that in the previous section, $P_{n}^{t}$ was defined to be the price of an asset that was $n$ periods old at the beginning of period $t$. Generally, the decline in asset value as we go from one vintage to the next oldest is called $d e-$ preciation. More precisely, we define the cross-section depreciation $D_{n}^{t 15}$ of an asset that is $n$ periods old at the beginning of period $t$ as

$$
D_{n}^{t} \equiv P_{n}^{t}-P_{n+1}^{t} ; \quad n=0,1,2, \ldots
$$

Thus, $D_{n}^{t}$ is the value of an asset that is $n$ periods old at the beginning of period $t, P_{n}^{t}$, minus the value of an asset that is $n+1$ periods old at the beginning of period $t, P_{n+1}^{t}$.

Obviously, given the sequence of period- $t$ cross-section asset prices $\left\{P_{n}^{t}\right\}$, we can use equations (10) to determine the period- $t$ sequence of declines in asset values by age, $\left\{D_{n}^{t}\right\}$. Conversely, given the period- $t$ crosssection depreciation sequence or profile, $\left\{D_{n}^{t}\right\}$, we can determine the period- $t$ asset prices by age $n$ by adding up amounts of depreciation:

$$
\begin{gathered}
P_{0}^{t}=D_{0}^{t}+D_{1}^{t}+D_{2}^{t}+\ldots \\
P_{1}^{t}=D_{1}^{t}+D_{2}^{t}+D_{3}^{t}+\ldots \\
\ldots \\
P_{n}^{t}=D_{n}^{t}+D_{n+1}^{t}+D_{n+2}^{t}+\ldots
\end{gathered}
$$

Rather than working with first differences of asset prices by age, it is more convenient to reparameterize the pattern of cross-section depreciation by defining the period-t depreciation rate $\delta_{n}^{t}$ for an asset that is $n$ periods old at the start of period $t$ as follows:

$$
\delta_{n}^{t} \equiv 1-\left(\frac{P_{n+1}^{t}}{P_{n}^{t}}\right)=\frac{D_{n}^{t}}{P_{n}^{t}} ; \quad n=0,1,2, \ldots
$$

In the above definitions, we require $n$ to be such that $P_{n}^{t}$ is positive. ${ }^{16}$

Obviously, given the sequence of period- $t$ asset prices by age $n,\left\{P_{n}^{t}\right\}$, we

15. This terminology is due to P. Hill (1999), who distinguished the decline in secondhand asset values due to aging (cross-section depreciation) from the decline in an asset value over a period of time (time series depreciation). Triplett (1996, pp. 98-99) uses the cross-section definition of depreciation (calling it deterioration) and shows that it is equal to the concept of capital consumption in the national accounts, but he does this under the assumption of no expected real asset price change. We will examine the relationship of cross-section to time series depreciation in section 12.5 below.

16. This definition of depreciation dates back to Hicks (1939, p. 176) at least and was used extensively by Edwards and Bell (1961, p. 175), Hulten and Wykoff (1981a,b), who call it deterioration, Diewert (1974, p. 504), and Hulten (1990, p. 128; 1996, p. 155). 
can use equations (12) to determine the period- $t$ sequence of cross-section depreciation rates, $\left\{\delta_{n}^{t}\right\}$. Conversely, given the cross-section sequence of period- $t$ depreciation rates, $\left\{\delta_{n}^{t}\right\}$, as well as the price of a new asset in period $t, P_{0}^{t}$, we can determine the period- $t$ asset prices by age as follows:

$$
\begin{aligned}
P_{1}^{t} & =\left(1-\delta_{0}^{t}\right) P_{0}^{t} \\
P_{2}^{t} & =\left(1-\delta_{0}^{t}\right)\left(1-\delta_{1}^{t}\right) P_{0}^{t} \\
& \ldots \\
P_{n}^{t}= & \left(1-\delta_{0}^{t}\right)\left(1-\delta_{1}^{t}\right) \ldots\left(1-\delta_{1}^{t}\right) P_{0}^{t}, \ldots
\end{aligned}
$$

The interpretation of equations (13) is straightforward. At the beginning of period $t$, a new capital good is worth $P_{0}^{t}$. An asset of the same type but that is one period older at the beginning of period $t$ is less valuable by the amount of depreciation $\delta_{0}^{t} P_{0}^{t}$ and hence is worth $\left(1-\delta_{0}^{t}\right) P_{0}^{t}$, which is equal to $P_{1}^{t}$. An asset that is two periods old at the beginning of period $t$ is less valuable than a one-period-old asset by the amount of depreciation $\delta_{1}^{t} P_{1}^{t}$ and hence is worth $P_{2}^{t}=\left(1-\delta_{1}^{t}\right) P_{1}^{t}$, which is equal to $\left(1-\delta_{1}^{t}\right)\left(1-\delta_{0}^{t}\right) P_{0}^{t}$ using the first equation in equations (13), and so on. Suppose $L-1$ is the first integer that is such that $\delta_{L-1}^{t}$ is equal to one. Then $P_{n}^{t}$ equals zero for all $n \geq$ $L$; that is, at the end of $L$ periods of use, the asset no longer has a positive rental value. If $L=1$, then a new asset of this type delivers all of its services in the first period of use and the asset is in fact a nondurable asset.

Now substitute equations (12) into equations (9) in order to obtain the following formulas for the sequence of the end-of-period-t user costs by age $n,\left\{u_{n}^{t}\right\}$, in terms of the price of a new asset at the beginning of period $t, P_{0}^{t}$, and the sequence of cross-section depreciation rates, $\left\{\delta_{n}^{t}\right\}$ :

$$
\begin{aligned}
& u_{0}^{t}=\left[\left(1+r^{t}\right)-\left(1+i^{t}\right)\left(1-\delta_{0}^{t}\right)\right] P_{0}^{t} \\
& u_{1}^{t}=\left(1-\delta_{0}^{t}\right)\left[\left(1+r^{t}\right)-\left(1+i^{t}\right)\left(1-\delta_{1}^{t}\right)\right] P_{0}^{t} \\
& u_{n}^{t}=\left(1-\delta_{0}^{t}\right) \ldots\left(1-\delta_{n-1}^{t}\right)\left[\left(1+r^{t}\right)-\left(1+i^{t}\right)\left(1-\delta_{n}^{t}\right)\right] P_{0}^{t} ; \ldots
\end{aligned}
$$

Thus, given $P_{0}^{t}$ (the beginning-of-period- $t$ price of a new asset), $i^{t}$ (the nominal rate of new asset price change that is expected at the beginning of pe$\operatorname{riod} t$ ), $r^{t}$ (the one-period nominal interest rate that the business unit faces at the beginning of period $t$ ) and given the sequence of cross-section vintage depreciation rates prevailing at the beginning of period $t\left(\right.$ the $\left.\delta_{n}^{t}\right)$, then we can use equations (14) to calculate the sequence of the end-of-period user costs for period $t$, the $u_{n}^{t}$. Of course, given the $u_{n}^{t}$, we can use equations (8) to calculate the beginning-of-period user costs (the $f_{n}^{t}$ ) and then use the $f_{n}^{t}$ to calculate the sequence of asset prices by age $P_{n}^{t}$ using equations (5), and finally, given the $P_{n}^{t}$, we can use equations (12) in order to calculate the sequence of depreciation rates for assets of age $n$ at the beginning of period 
$t$, the $\delta_{n}^{t}$. Thus, given any one of these sequences or profiles, all of the other sequences are completely determined. This means that assumptions about depreciation rates, the pattern of user costs by age of asset, or the pattern of asset prices by age of asset cannot be made independently of each other. ${ }^{17}$

It is useful to look more closely at the first equation in equations (14), which expresses the user cost or rental price of a new asset at the end of period $t, u_{0}^{t}$, in terms of the depreciation rate $\delta_{0}^{t}$, the one-period nominal interest rate $r^{t}$, the new asset inflation rate $i^{t}$ that is expected to prevail at the beginning of period $t$, and the beginning-of-period- $t$ price for a new asset, $P_{0}^{t}$.

$$
u_{0}^{t}=\left[\left(1+r^{t}\right)-\left(1+i^{t}\right)\left(1-\delta_{0}^{t}\right)\right] P_{0}^{t}=\left[r^{t}-i^{t}+\left(1+i^{t}\right) \delta_{0}^{t}\right] P_{0}^{t} .
$$

Thus, the user cost of a new asset $u_{0}^{t}$ that is purchased at the beginning of period $t$ (and the actual or imputed rental payment is made at the end of the period) is equal to $r^{t}-i^{t}$ (a nominal interest rate minus an asset inflation rate that can be loosely interpreted ${ }^{18}$ as a real interest rate) times the initial asset cost $P_{0}^{t}$ plus $\left(1+i^{t}\right) \delta_{0}^{t} P_{0}^{t}$, which is depreciation on the asset at beginning-of-period prices, $\delta_{1}^{t} P_{0}^{t}$, times one plus the expected rate of asset price change, $\left(1+i^{t}\right) \cdot{ }^{19}$ If we further assume that the expected rate of asset price change $i^{t}$ is 0 , then equation (15) further simplifies to:

$$
u_{0}^{t}=\left[r^{t}+\delta_{0}^{t}\right] P_{0}^{t} .
$$

Under these assumptions, the user cost of a new asset is equal to the interest rate plus the depreciation rate times the initial purchase price. ${ }^{20}$ This is essentially the user cost formula that was obtained by Walras (1954, pp. 268-69) in 1874.

However, the basic idea that a durable input should be charged a period

17. This point was first made explicitly by Jorgenson and Griliches (1967, p. 257); see also Jorgenson and Griliches (1972, pp. 81-87). Much of the above algebra for switching from one method of representing vintage capital inputs to another was first developed by Christensen and Jorgenson (1969, pp. 302-5; 1973) for the geometrically declining depreciation model. The general framework for an internally consistent treatment of capital services and capital stocks in a set of vintage accounts was set out by Jorgenson (1989) and Hulten (1990, pp. 12729; 1996, pp. 152-60).

18. We will provide a more precise definition of a real interest rate later.

19. This formula was obtained by Christensen and Jorgenson $(1969$, p. 302) for the geometric model of depreciation, but it is valid for any depreciation model. Griliches (1963, p. 120) also came very close to deriving this formula in words: "In a perfectly competitive world the annual rent of a machine would equal the marginal product of its services. The rent itself would be determined by the interest costs on the investment, the deterioration in the future productivity of the machine due to current use, and the expected change in the price of the machine (obsolescence)."

20. Using equations (13) and (14) and the assumption that the asset inflation rate $i^{t}=0$, it can be shown that the user cost of an asset that is $n$ periods old at the start of period $t$ can be written as $u_{n}^{t}=\left(r^{t}+\delta_{n}^{t}\right) P_{n}^{t}$, where $P_{n}^{t}$ is the beginning of period- $t$ secondhand market price for the asset. 
price that is equal to a depreciation term plus a term that would cover the cost of financial capital goes back to Babbage (1835, p. 287) and others. ${ }^{21}$

Babbage did not proceed further with the user cost idea. Walras seems to have been the first economist who formalized the idea of a user cost into a mathematical formula. However, the early industrial engineering literature also independently came up with the user cost idea; Church (1901, pp. 734 and 907-8) in particular gave a very modern exposition of the ingredients needed to construct user costs or machine rents.

Church was well aware of the importance of determining the "right" rate to be charged for the use of a machine in a multiproduct enterprise. This information is required not only to price products appropriately but to determine whether an enterprise should make or purchase a particular commodity. Babbage (1835, p. 203) and Canning (1929, pp. 259-60) were also aware of the importance of determining the right machine rate charge. ${ }^{22}$

The above equations relating asset prices by age $n, P_{n}^{t}$, beginning-ofperiod user costs by age $n, f_{n}^{t}$, end-of-period user costs, $u_{n}^{t}$, and the (crosssection) depreciation rates $\delta_{n}^{t}$ are the fundamental ones that we will specialize in subsequent sections in order to measure both wealth capital stocks and capital services under conditions of inflation. In the following section, we shall consider several options that could be used in order to determine empirically the interest rates $r^{t}$ and the expected asset rates of price change $i^{t}$.

\subsection{The Empirical Determination of Interest Rates and Rates of Asset Price Change}

We consider initially three broad approaches ${ }^{23}$ to the determination of the nominal interest rate $r^{t}$ that is to be used to discount future period value flows by the business units in the aggregate under consideration:

21. Solomons (1968, pp. 9-17) indicates that interest was regarded as a cost for a durable input in much of the nineteenth-century accounting literature. The influential book by Garcke and Fells (1893) changed this.

22. Under moderate inflation, the difficulties with traditional cost accounting based on historical cost, and no proper allowance for the opportunity of capital, the proper pricing of products becomes very difficult. Diewert and Fox (1999, pp. 271-74) argued that this factor contributed to the great productivity slowdown that started around 1973 and persisted to the early 1990s. The traditional method of cost accounting can be traced back to a book first published in 1887 by the English accountants Garcke and Fells (1893, pp. 70-71). Their rather crude approach to cost accounting should be compared to the masterful analysis of Church. Garcke and Fells (pp. 72-73) endorsed the idea that depreciation was an admissible item of cost that should be allocated in proportion to the prime cost (i.e., labor and materials cost) of manufacturing an article but they explicitly ruled out interest as a cost. The aversion of accountants to including interest as a cost can be traced back to the influence of Garcke and Fells.

23. Other methods for determining the appropriate interest rates that should be inserted into user cost formulas are discussed by Harper, Berndt, and Wood (1989) and in chapter 5 of Schreyer (2001). Harper, Berndt, and Wood evaluate empirically five alternative rental price formulas using geometric depreciation but making different assumptions about the interest 
- Use the ex post rate of return that will just make the sum of the user costs exhaust the gross operating surplus of the production sectors for the aggregate under consideration.

- Use an aggregate of nominal interest rates that the production sectors in the aggregate might be facing at the beginning of each period.

- Take a fixed real interest rate and add to it actual ex post consumer price inflation or anticipated consumer price inflation.

The first approach was used for the entire private production sector of the economy by Jorgenson and Griliches (1967, p. 267) and for various sectors of the economy by Christensen and Jorgenson (1969, p. 307). It is also widely used by statistical agencies. It has the advantage that the value of output for the sector will exactly equal the value of input in a consistent accounting framework. It has the disadvantages that it is subject to measurement error and it is an ex post rate of return, which may not reflect the economic conditions facing producers at the beginning of the period. This approach (incorrectly in our view) transforms pure profits (or losses) into a change in the opportunity cost of financial capital.

The second approach suffers from aggregation problems. There are many interest rates in an economy at the beginning of an accounting period, and the problem of finding the right aggregate of these rates is not a trivial one.

The third approach works as follows. Let the consumer price index for the economy at the beginning of period $t$ be $c^{t}$, say. Then the ex post general consumer inflation rate for period $t$ is $\rho^{t}$, defined as

$$
1+\rho^{t} \equiv \frac{c^{t+1}}{c^{t}}
$$

Let the production units under consideration face the real interest rate $r^{* t}$. Then, by the Fisher (1896) effect, the relevant nominal interest rate that the producers face should be approximately equal to $r^{t}$, defined as follows:

$$
r^{t} \equiv\left(1+r^{* t}\right)\left(1+\rho^{t}\right)-1 .
$$

The Australian Bureau of Statistics assumes that producers face a real interest rate of 4 percent. This is consistent with long-run observed economywide real rates of return for most Organization for Economic Cooperation and Development (OECD) countries, which fall in the 3 to 5 percent range. We shall choose this third method for defining nominal interest rates and choose the real rate of return to be 4 percent per annum; that is, we assume that the nominal rate $r^{t}$ is defined by equation (18) with the real rate defined by

rate and the treatment of asset price change. They show (as we will later) that the choice of formula matters. 


$$
r^{* t} \equiv .04,
$$

assuming that the accounting period chosen is a year. ${ }^{24}$

We turn now to the determination of the asset expected rates of price change, ${ }^{25}$ the $i^{t}$, which appear in most of the formulas derived in the preceding sections of this chapter. There are three broad approaches that can be used in this context:

- Use actual ex post rates of price change for a new asset over each period.

- Assume that each asset rate of price change is equal to the general inflation rate for each period.

- Estimate anticipated rates of asset price change for each period.

In what follows, we will compute cross-sectional user costs using Canadian data on investments for two broad classes of assets (nonresidential construction and machinery and equipment) for four different sets of assumptions about depreciation or the relative efficiency of assets by age. We will undertake these computations in an inflationary environment and make each of the three sets of assumptions about the asset inflation rates listed above for each of the four depreciation models, giving twelve models in all that will be compared. If the various models give very different results, this indicates that the statistical agency computing capital stocks and service flows under inflation must choose its preferred model with some care.

When we assume that the rate of price change for each asset is equal to the general inflation rate $\rho^{t}$ defined by equation (17), the equations presented earlier simplify. Thus, if we replace $1+i^{t}$ with $1+\rho^{t}$ and $1+r^{t}$ with $\left(1+r^{*}\right)\left(1+\rho^{t}\right)$, equations (5), which relate the period- $t$ asset prices by age $n P_{n}^{t}$ to the rental prices $f_{n}^{t}$, become

$$
\begin{aligned}
& P_{0}^{t}=f_{0}^{t}+\left(\frac{1}{1+r^{*}}\right) f_{1}^{t}+\left(\frac{1}{1+r^{*}}\right)^{2} f_{2}^{t}+\left(\frac{1}{1+r^{*}}\right)^{3} f_{3}^{t}+\ldots \\
& P_{1}^{t}=f_{1}^{t}+\left(\frac{1}{1+r^{*}}\right) f_{2}^{t}+\left(\frac{1}{1+r^{*}}\right)^{2} f_{3}^{t}+\left(\frac{1}{1+r^{*}}\right)^{3} f_{4}^{t}+\ldots \\
& P_{n}^{t}=f_{n}^{t}+\left(\frac{1}{1+r^{*}}\right) f_{n+1}^{t}+\left(\frac{1}{1+r^{*}}\right)^{2} f_{n+2}^{t}+\left(\frac{1}{1+r^{*}}\right)^{3} f_{n+3}^{t}+\ldots
\end{aligned}
$$

Note that only the constant real interest rate $r^{*}$ appears in these equations.

If we replace $1+i^{t}$ with $1+\rho^{t}$ and $1+r^{t}$ with $\left(1+r^{*}\right)\left(1+\rho^{t}\right)$, equations

24. If we are in a high-inflation situation so that the accounting period becomes a quarter or a month, then $r^{* t}$ must be chosen to be appropriately smaller.

25 . These are sometimes called revaluation terms in user cost formulas. 
(14), which relate the end-of-period user costs $u_{n}^{t}$ to the depreciation rates $\delta_{n}^{t}$, become

$$
\begin{aligned}
& u_{0}^{t}=\left(1+\rho^{t}\right)\left[\left(1+r^{*}\right)-\left(1-\delta_{0}^{t}\right)\right] P_{0}^{t}=\left(1+\rho^{t}\right)\left[r^{*}+\delta_{0}^{t}\right] P_{0}^{t} \\
& u_{1}^{t}=\left(1+\rho^{t}\right)\left(1-\delta_{0}^{t}\right)\left[\left(1+r^{*}\right)-\left(1-\delta_{1}^{t}\right)\right] P_{0}^{t} \\
&=\left(1+\rho^{t}\right)\left(1-\delta_{0}^{t}\right)\left[r^{*}+\delta_{1}^{t}\right] P_{0}^{t} \\
& \ldots \\
& u_{n}^{t}=\left(1+\rho^{t}\right)\left(1-\delta_{0}^{t}\right) \ldots\left(1-\delta_{n-1}^{t}\right)\left[\left(1+r^{*}\right)-\left(1-\delta_{n}^{t}\right)\right] P_{0}^{t} \\
&=\left(1+\rho^{t}\right)\left(1-\delta_{0}^{t}\right) \ldots\left(1-\delta_{n-1}^{t}\right)\left[r^{*}+\delta_{n}^{t}\right] P_{0}^{t} .
\end{aligned}
$$

Now use equations (8) and $1+r^{t}=\left(1+r^{*}\right)\left(1+\rho^{t}\right)$ and substitute into equations (21) to obtain the following equations, which relate the beginning-of-period user costs $f_{n}^{t}$ to the depreciation rates $\delta_{n}^{t}$ :

$$
\begin{gathered}
f_{0}^{t}=\left(1+r^{*}\right)^{-1}\left[r^{*}+\delta_{0}^{t}\right] P_{0}^{t} \\
f_{1}^{t}=\left(1+r^{*}\right)^{-1}\left(1-\delta_{0}^{t}\right)\left[r^{*}+\delta_{1}^{t}\right] P_{0}^{t} \\
\ldots \\
f_{n}^{t}=\left(1+r^{*}\right)^{-1}\left(1-\delta_{0}^{t}\right) \ldots\left(1-\delta_{n-1}^{t}\right)\left[r^{*}+\delta_{n}^{t}\right] P_{0}^{t} .
\end{gathered}
$$

Note that only the constant real interest rate $r^{*}$ appears in equations (22), but equations (21) also have the general inflation rate $\left(1+\rho^{t}\right)$ as a multiplicative factor.

As mentioned above, in our third class of assumptions about rates of asset price change, we want to estimate anticipated rates of asset price change and use these estimates as our $i^{t}$ in the various formulas we have exhibited. Unfortunately, there are any number of forecasting methods that could be used to estimate the anticipated asset rates of price change. We will take a somewhat different approach than a pure forecasting one: we will simply smooth the observed ex post new asset rates of price change and use these smoothed rates as our estimates of anticipated rates. ${ }^{26}$ A similar forecasting problem arises when we use ex post actual consumer price index inflation rates (recall equations [17] and [18] above) in order to generate anticipated general inflation rates. Thus, in our third set of models, we will use both smoothed asset inflation rates and smoothed general inflation rates as our estimates for anticipated rates. In our first class of models, we will use actual ex post rates in both cases.

Before we proceed to consider our four specific depreciation models, we

26. Unfortunately, different analysts may choose different smoothing methods, so there may be a problem of a lack of reproducibility in our estimating procedures. Harper, Berndt, and Wood (1989, p. 351) note that the use of time series techniques to smooth ex post asset inflation rates and the use of such estimates as anticipated price change dates back to Epstein (1977). 
briefly consider in the next section a topic of some current interest: namely, the interaction of (foreseen) obsolescence and depreciation. We also discuss cross-section versus time series depreciation.

\subsection{Obsolescence and Depreciation}

We begin this section with a definition of the time series depreciation of an asset. Define the ex post time series depreciation of an asset that is $n$ periods old at the beginning of period $t, E_{n}^{t}$, to be its secondhand market price at the beginning of period $t, P_{n}^{t}$, less the price of an asset that is one period older at the beginning of period $t+1, P_{n+1}^{t+1}$; that is,

$$
E_{n}^{t} \equiv P_{n}^{t}-P_{n+1}^{t+1} ; \quad n=0,1,2, \ldots
$$

Definition (23) should be contrasted with our earlier definitions in equation (10), which defined the cross-section amounts of depreciation for the same assets at the beginning of period $t, D_{n}^{t} \equiv P_{n}^{t}-P_{n+1}^{t}$.

We can now explain why we preferred to work with the cross-section definition of depreciation, equation (10), over the time series definition, equation (23). The problem with equation (23) is that time series depreciation captures the effects of changes in two things: changes in time (this is the change in $t$ to $t+1)^{27}$ and changes in the age of the asset (this is the change in $n$ to $n+1) .^{28}$ Thus, time series depreciation aggregates together two effects: the asset-specific price change that occurred between time $t$ and time $t+1$ (asset revaluation due to general inflation and asset-specific price change) and the effects of asset aging (depreciation). Thus, the time series definition of depreciation combines together two distinct effects.

The foregoing definition of ex post time series depreciation is the original definition of depreciation, and it extends back to the very early beginnings of accounting theory. ${ }^{29}$

However, what has to be kept in mind that the early authors who used the concept of time series depreciation were implicitly or explicitly assuming that prices were stable across time, in which case, time series and crosssection depreciation coincide.

P. Hill (2000, p. 6) and R. J. Hill and Hill (2003, p. 617) ${ }^{30}$ recently argued that a form of time series depreciation that included expected obsolescence was to be preferred over cross-section depreciation for national accounts purposes. Since the depreciation rates $\delta_{n}^{t}$ defined by equation (12) are cross-

27. This change could be captured by either $P_{n}^{t}-P_{n}^{t+1}$ or $P_{n+1}^{t}-P_{n+1}^{t+1}$.

28. This change could be captured by either $P_{n}^{n}-P_{n+1}^{n}$ or $P_{n}^{n+1}-P_{n+1}^{n+1}$

29. See, for example, Matheson (1910, p. 35) and Hotelling (1925, p. 341).

30. We agree in general with P. Hill (2000) and R. J. Hill and Hill (2003) that expected obsolescence should be added to cross-sectional depreciation to form an overall depreciation charge. However, Hill and Hill assumed that there was no general inflation in their exposition, so some clarification is needed to deal with this complication. 
section depreciation rates and they play a key role in the beginning and end of period- $t$ user costs $f_{n}^{t}$ and $u_{n}^{t}$ defined by equations (14), (21), and (22), it is necessary to clarify their use in the context of P. Hill's point that these depreciation rates should not be used to measure depreciation in the national accounts.

Our response to the Hill critique is twofold:

- Cross-section depreciation rates as we have defined them are affected by anticipated obsolescence in principle, but

- Hill is correct in arguing that cross-section depreciation will not generally equal ex post time series depreciation or anticipated time series depreciation.

Before discussing these two points in detail, it is necessary to discuss the concept of obsolescence in a bit more detail. Wykoff, in his discussion of this chapter (chap. 12 comment in this volume), takes a narrow "technological" definition of obsolescence. In his view, an asset can only become obsolete if a new model of the asset becomes available that can deliver at least the service flow of the old asset at a lower price. In his view, if there is no technological change embodied in the new asset, then by definition there is no obsolescence. However, it is possible to define obsolescence more broadly and include the effects of changes in the economy that reduce the demand for the asset's services to such an extent that its real price falls. ${ }^{31}$ In what follows, we will use the second, broader concept of obsolescence. One more point must be considered at this point. If there is technological obsolescence due to a new and improved model of the asset being made available, then we assume that the price of the new model has been (somehow) quality adjusted so that the quality-adjusted price is measured in quantity units that are comparable to the older models.

Now consider the first bulleted point. Provisionally, we define anticipated obsolescence as a situation where the expected new asset rate of price change (adjusted for quality change) $i^{t}$ is negative. ${ }^{32}$ For example, everyone

31. This broader definition goes back to Church (1917) at least: "Even though a machine is used fairly and uniformly as contemplated when the rate of depreciation was fixed there is another influence that may shorten its period of usefulness in an unexpected way. The progress of the technical art in which it is employed may develop more efficient machines for doing the same work, so that it becomes advisable to scrap it long before it is worn out. The machine becomes obsolete and the loss of value from this cause is called 'obsolescence.' Again, unless the machine is of a very generalized type, such as an engineer's lathe, another type of misfortune may overtake it. If it is a machine that can only be used for certain definite kinds of work or some special article, as for example many of the machines used in automobile and bicycle manufacture, it may happen that changes in demand, or in style, make the manufacture of that special article no longer profitable. In this case, unless the machine can be transformed for another use, it is a dead loss" (192-93).

32. Paul Schreyer and Peter Hill noted a problem with this provisional definition of anticipated obsolescence as a negative value of the expected asset inflation rate: it will not work in a high-inflation environment. In a high-inflation environment, the nominal asset inflation rate 
anticipates that the quality-adjusted price for a new computer next quarter will be considerably lower than it is this quarter. ${ }^{33}$ Now turn back to equations (5), which define the profile of vintage asset prices $P_{n}^{t}$ at the start of period $t$. It is clear that the negative $i^{t}$ plays a role in defining the sequence of vintage asset prices, as does the sequence of vintage rental prices that is observed at the beginning of period $t$, the $f_{n}^{t}$. Thus, in this sense, crosssectional depreciation rates certainly embody assumptions about anticipated obsolescence.

Thus, for an asset that has a finite life, as we move down the rows of equations (5), the number of discounted rental terms declines, and hence asset value declines, which is Griliches's (1963, p. 119) concept of exhaustion. If the cross-sectional rental prices are monotonically declining (due to their declining efficiency), then as we move down the rows of equations (5), the higher rental terms are being dropped one by one so that the asset values will also decline from this factor, which is Griliches's concept of deterioration. Finally, a negative anticipated asset inflation rate will cause all future period rentals to be discounted more heavily, which could be interpreted as Griliches's concept of obsolescence. ${ }^{34}$ Thus, all of these explanatory factors are embedded in equations (5).

Now consider the second bulleted point: that cross-section depreciation is not really adequate to measure time series depreciation in some sense to be determined.

Define the ex ante time series depreciation of an asset that is $n$ periods old at the beginning of period $t, \Delta_{n}^{t}$, to be its secondhand market price at the beginning of period $t, P_{n}^{t}$, less the anticipated price of an asset that is one period older at the beginning of period $t+1,\left(1+i^{t}\right) P_{n+1}^{t}$; i.e.,

$$
\Delta_{n}^{t} \equiv P_{n}^{t}-\left(1+i^{t}\right) P_{n+1}^{t} ; \quad n=0,1,2, \ldots
$$

Thus, anticipated time series depreciation for an asset that is $t$ periods old at the start of period $t, \Delta_{n}^{t}$, differs from the corresponding cross-section de-

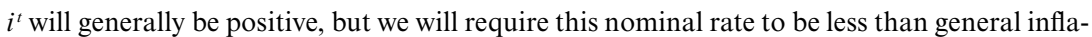
tion in order to have anticipated obsolescence. Thus, our final definition of anticipated obsolescence is that the real asset inflation rate $i^{* t}$ defined later by equation (28) be negative; see the discussion immediately preceding equation (30).

33. Our analysis assumes that the various vintages of capital are adjusted for quality change (if any occurs) as they come on the market. In terms of our Canadian empirical example to follow, we are assuming that Statistics Canada correctly adjusted the published investment price deflators for machinery and equipment and nonresidential construction for quality change. We also need to assume that the form of quality change affects all future efficiency factors (i.e., the $f_{n}^{t}$ ) in a proportional manner. This is obviously only a rough approximation to reality: technical change may increase the durability of a capital input, or it may decrease the amount of maintenance or fuel that is required to operate the asset. These changes can lead to nonproportional changes in the $f_{n}^{t}$.

34. However, it is more likely that what Griliches had in mind was Hill's second point: that time series depreciation will be larger than cross-section depreciation in a situation where $i^{* t}$ is negative. 
preciation defined by equation (10), $D_{n}^{t} \equiv P_{n}^{t}-P_{n+1}^{t}$, in that the anticipated new asset rate of price change, $i^{t}$, is missing from $D_{n}^{t}$. However, note that the two forms of depreciation will coincide if the expected asset rate of price change $\mathrm{i}^{\mathrm{t}}$ is zero.

We can use equations (12) and (13) in order to define the ex ante depreciation amounts $\Delta_{n}^{t}$ in terms of the cross-section depreciation rates $\delta_{n}^{t}$. Thus, using definitions (24), we have

$$
\begin{array}{rlrl}
\Delta_{n}^{t} \equiv P_{n}^{t}-\left(1+i^{t}\right) P_{n+1}^{t} & & n=0,1,2, \ldots \\
= & P_{n}^{t}-\left(1+i^{t}\right)\left(1-\delta_{n}^{t}\right) P_{n}^{t} & & \text { using equation (12) } \\
= & {\left[1-\left(1+i^{t}\right)\left(1-\delta_{n}^{t}\right)\right] P_{n}^{t}} & \\
= & \left(1-\delta_{1}^{t}\right)\left(1-\delta_{2}^{t}\right) \ldots\left(1-\delta_{n-1}^{t}\right) & \\
& \cdot\left[1-\left(1+i^{t}\right)\left(1-\delta_{n}^{t}\right)\right] P_{0}^{t} & \text { using equation (13) } \\
= & \left(1-\delta_{1}^{t}\right)\left(1-\delta_{2}^{t}\right) \ldots\left(1-\delta_{n-1}^{t}\right)\left[\delta_{n}^{t}-i^{t}\left(1-\delta_{n}^{t}\right)\right] P_{0}^{t} .
\end{array}
$$

We can compare the above sequence of ex ante time series depreciation amounts $\Delta_{n}^{t}$ with the corresponding sequence of cross-section depreciation amounts:

$$
\begin{aligned}
D_{n}^{t} & \equiv P_{n}^{t}-P_{n+1}^{t} & & n=0,1,2, \ldots \\
& =P_{n}^{t}-\left(1-\delta_{n}^{t}\right) P_{n}^{t} & & \text { using equation (12) } \\
& =\left[1-\left(1-\delta_{n}^{t}\right)\right] P_{n}^{t} & & \\
& =\left(1-\delta_{1}^{t}\right)\left(1-\delta_{2}^{t}\right) \ldots\left(1-\delta_{n-1}^{t}\right)\left[\delta_{n}^{t}\right] P_{0}^{t} & & \text { using equations (13). }
\end{aligned}
$$

Of course, if the anticipated rate of asset price change $i^{t}$ is zero, then equations (25) and (26) coincide, and ex ante time series depreciation equals cross-section depreciation. If we are in the provisional expected obsolescence case with $i^{t}$ negative, then it can be seen comparing equations (25) and (26) that $\Delta_{n}^{t}>D_{n}^{t}$ for all $n$ such that $D_{n}^{t}>0$; that is, if $i^{t}$ is negative (and $\left.0<\delta_{n}^{t}<1\right)$, then ex ante time series depreciation exceeds cross-section depreciation over all in-use vintages of the asset. If $i^{t}$ is positive so that the rental price of each vintage is expected to rise in the future, then ex ante time series depreciation is less than the corresponding cross-section depreciation for all assets that have a positive price at the end of period $t$. This corresponds to the usual result in the vintage user cost literature where capital gains or an ex post price increase for a new asset leads to a negative term in the user cost formula (plus a revaluation of the cross-section depreciation rate). Here we are restricting ourselves to anticipated capital gains rather than the actual ex post capital gains, and we are focusing on depreciation concepts rather than the full user cost.

This is not quite the end of the story in the high-inflation context. National income accountants often readjust asset values at either the beginning 
or end of the accounting period to take into account general price level change. At the same time, they also want to decompose nominal interest payments into a real interest component and another component that compensates lenders for general price change.

Recall equation (17), which defined the general period- $t$ inflation rate $\rho^{t}$, and equation (18), which related the period- $t$ nominal interest rate $r^{t}$ to the real rate $r^{* t}$ and the inflation rate $\rho^{t}$. We rewrite equation (18) as follows:

$$
1+r^{* t} \equiv \frac{1+r^{t}}{1+\rho^{t}} .
$$

In a similar manner, we define the period- $t$ anticipated rate of real asset price change $i^{* t}$ as follows:

$$
1+i^{* t} \equiv \frac{1+i^{t}}{1+\rho^{t}}
$$

Recall definition (23), which defined the ex ante time series depreciation of an asset that is $n$ periods old at the beginning of period $t, \Delta_{n}^{t}$. The first term in this definition reflects the price level at the beginning of period $t$ while the second term in this definition reflects the price level at the end of period $t$. We now express the second term in terms of the beginning-ofperiod- $t$ price level. Thus, we define the ex ante real time series depreciation of an asset that is $n$ periods old at the beginning of period $t, \Pi_{n}^{t}$, as follows:

$$
\begin{aligned}
& \Pi_{n}^{t} \equiv P_{n}^{t}-\left(1+i^{t}\right) \frac{P_{n+1}^{t}}{1+\rho^{t}} \\
& =P_{n}^{t}-\left(1+i^{t}\right)\left(1-\delta_{n}^{t}\right) \frac{P_{n}^{t}}{1+\rho^{t}} \\
& =\left[\left(1+\rho^{t}\right)-\left(1+i^{* t}\right)\left(1+\rho^{t}\right)\left(1-\delta_{n}^{t}\right)\right] \frac{P_{n}^{t}}{1+\rho^{t}} \text { using equation (28) } \\
& =\left(1-\delta_{0}^{t}\right)\left(1-\delta_{1}^{t}\right) \ldots\left(1-\delta_{n-1}^{t}\right) \\
& \cdot\left[1-\left(1+i^{* t}\right)\left(1-\delta_{n}^{t}\right)\right] P_{0}^{t} \\
& =\left(1-\delta_{0}^{t}\left(1-\delta_{1}^{t}\right) \ldots\left(1-\delta_{n-1}^{t}\right)\left[\delta_{n}^{t}-i^{* t}\left(1-\delta_{n}^{t}\right)\right] P_{0}^{t}\right. \text {. } \\
& n=0,1,2, \ldots
\end{aligned}
$$

The ex ante real time series depreciation amount $\Pi_{n}^{t}$ defined by equations (29) can be compared to its cross-section counterpart $D_{n}^{t}$, defined by equations (25) above. Of course, if the real anticipated asset inflation rate $i^{* t}$ is zero, then equations (29) and (25) coincide, and real ex ante time series depreciation equals cross-section depreciation.

We are now in a position to provide a more satisfactory definition of expected obsolescence, particularly in the context of high inflation. We now 
define expected obsolescence to be the situation where the real rate of asset price change $i^{* t}$ is negative. If this real rate is negative, then it can be seen comparing equations (29) and (26) that

$$
\Pi_{n}^{t}>D_{n}^{t} \quad \text { for all } n \text { such that } D_{n}^{t}>0
$$

that is real anticipated time series depreciation exceeds the corresponding cross-section depreciation provided that $i^{* t}$ is negative.

Thus, the general user cost formulas that we have developed from the vintage accounts point of view can be reconciled to reflect the point of view of national income accountants. We agree with Hill's point of view that cross-section depreciation is not really adequate to measure time series depreciation as national income accountants have defined it since Pigou (1935, pp. 240-41).

Pigou in an earlier work (1924) had a more complete discussion of the obsolescence problem and the problems involved in defining time series depreciation in an inflationary environment. Pigou first pointed out that the national dividend or net annual income (or, in modern terms, real net output) should subtract depreciation or capital consumption (34-35). Pigou then went on to discuss the roles of obsolescence and general price change in measuring depreciation (39-41). Pigou was responsible for many of the conventions of national income accounting that persist down to the present day. He essentially argued that (unanticipated) capital gains or losses be excluded from income and that the effects of general price level change be excluded from estimates of depreciation. He also argued for the inclusion of (foreseen) obsolescence in depreciation. Unfortunately, he did not spell out exactly how all of this could be done in the accounts. Our preceding algebra can be regarded as an attempt to formalize these Pigovian complications.

It should be noted that the early industrial engineering literature also stressed that the possibility of obsolescence meant that depreciation allowances should be larger than those implied by mere wear and tear; see Babbage (1835, p. 285), Matheson (1910, pp. 39-40) and Church (1917, pp. 19293). Both Matheson and Church noted that obsolescence could arise not only from new inventions but also from shifts in demand.

We will end this section by pointing out another important use for the concept of real anticipated time series depreciation. However, before doing this, it is useful to rewrite equations (5), which define the beginning-ofperiod- $t$ asset prices by age $n, P_{n}^{t}$, in terms of the beginning-of-period- $t$ rental prices $f_{n}^{t}$, and equations (7), which define the user $\operatorname{costs} f_{n}^{t}$ in terms of the asset prices $P_{n}^{t}$, using definitions (27) and (28), which define the period- $t$ real interest rate $r^{* t}$ and expected asset inflation rate $i^{* t}$, respectively, in terms of the corresponding nominal rates $r^{t}$ and $i^{t}$ and the general inflation rate $\rho^{t}$. Substituting equations (27) and (28) into equations (5) yields the following system of equations: 


$$
\begin{aligned}
& P_{0}^{t}= f_{0}^{t}+\left[\left(\frac{1+i^{* t}}{1+r^{* t}}\right)\right] f_{1}^{t}+\left[\left(\frac{1+i^{* t}}{1+r^{* t}}\right)\right]^{2} f_{2}^{t}+\left[\left(\frac{1+i^{* t}}{1+r^{* t}}\right)\right]_{3}^{3} f_{3}^{t}+\ldots \\
& P_{1}^{t}=f_{1}^{t}+\left[\left(\frac{1+i^{* t}}{1+r^{* t}}\right)\right] f_{2}^{t}+\left[\left(\frac{1+i^{* t}}{1+r^{* t}}\right)\right]^{2} f_{3}^{t}+\left[\left(\frac{1+i^{* t}}{1+r^{* t}}\right)\right]^{3} f_{4}^{t}+\ldots \\
& P_{n}^{t}=f_{n}^{t}+\left[\left(\frac{1+i^{* t}}{1+r^{* t}}\right)\right] f_{n+1}^{t}+\left[\left(\frac{1+i^{* t}}{1+r^{* t}}\right)\right]^{2} f_{n+2}^{t} \\
&+\left[\left(\frac{1+i^{* t}}{1+r^{* t}}\right)\right]_{n+3}^{3} f_{n+}^{t}+\ldots
\end{aligned}
$$

Similarly, substituting equations (27) and (28) into equations (7) yields the following system of equations:

$$
\begin{gathered}
f_{0}^{t}=P_{0}^{t}-\left(\frac{1+i^{* t}}{1+r^{* t}}\right) P_{1}^{t}=\left(1+r^{* t}\right)^{-1}\left[P_{0}^{t}\left(1+r^{* t}\right)-\left(1+i^{* t}\right) P_{1}^{t}\right] \\
f_{1}^{t}=P_{1}^{t}-\left(\frac{1+i^{* t}}{1+r^{* t}}\right) P_{2}^{t}=\left(1+r^{* t}\right)^{-1}\left[P_{1}^{t}\left(1+r^{* t}\right)-\left(1+i^{* t}\right) P_{2}^{t}\right] \\
\ldots \\
f_{n}^{t}=P_{n}^{t}-\left(\frac{1+i^{* t}}{1+r^{* t}}\right) P_{n+1}^{t}=\left(1+r^{* t}\right)^{-1}\left[P_{n}^{t}\left(1+r^{* t}\right)\right. \\
\left.-\left(1+i^{* t}\right) P_{n+1}^{t}\right]
\end{gathered}
$$

Note that the nominal interest and inflation rates have entirely disappeared from the equations. In particular, the beginning-of-period user $\operatorname{costs} f_{n}^{t}$ can be defined in terms or real variables using equations (32) if this is desired. On the other hand, entirely equivalent formulas for the cross-section user costs can be obtained using the initial set of equations (7), which used only nominal variables. Which set of equations is used in practice can be left up to the judgment of the statistical agency or the user. ${ }^{35}$ The point is that the careful and consistent use of discounting should eliminate the effects of general inflation from our price variables; discounting makes comparable cash flows received or paid out at different points of time.

Recall definition (29), which defined $\Pi_{n}^{t}$ as the ex ante real time series depreciation of an asset that is $n$ periods old at the beginning of period $t$. It is convenient to convert this amount of depreciation into a percentage of the

35. In particular, it is not necessary for the statistical agency to convert all nominal prices into real prices as a preliminary step before "real" user costs are calculated. The above algebra shows that our nominal user costs $f_{n}^{t}$ can also be interpreted as real user costs that are expressed in terms of the value of money prevailing at the beginning of period $t$. 
initial price of the asset at the beginning of period $t, P_{n}^{t}$. Thus, we define the ex ante time series depreciation rate for an asset that is $\mathrm{n}$ periods old at the start of period $\mathrm{t}, \pi_{n}^{t}$, as follows: ${ }^{36}$

$$
\begin{aligned}
\pi_{n}^{t} & \equiv \frac{\Pi_{n}^{t}}{P_{n}^{t}} ; & & n=0,1,2, \ldots \\
& =\frac{P_{n}^{t}-\left(1+i^{t}\right) P_{n+1}^{t} /\left(1+\rho^{t}\right)}{P_{n}^{t}} & & \text { using equations (29) } \\
& =\frac{P_{n}^{t}-\left(1+i^{t}\right)\left(1-\delta_{n}^{t}\right) P_{n}^{t} /\left(1+\rho^{t}\right)}{P_{n}^{t}} & & \text { using equation (12) } \\
& =\left[1-\left(1+i^{* t}\right)\left(1-\delta_{n}^{t}\right)\right] & & \text { using equation (28). }
\end{aligned}
$$

Now substitute definition (12) for the cross-section depreciation rate $\delta_{n}^{t}$ into the $n$th equation of equations (32) and we obtain the following expression for the beginning-of-period- $t$ user cost of an asset that is $n$ periods old at the start of period $t$ :

$$
\begin{array}{rlr}
f_{n}^{t} & =\left(1+r^{* t}\right)^{-1}\left[P_{n}^{t}\left(1+r^{* t}\right)-\left(1+i^{* t}\right) P_{n+1}^{t}\right] \quad n=0,1,2, \ldots \\
& =\left(1+r^{* t}\right)^{-1}\left[P_{n}^{t}\left(1+r^{* t}\right)-\left(1+i^{* t}\right)\left(1-\delta_{n}^{t}\right) P_{n}^{t}\right] \text { using equation (12) } \\
& =\left(1+r^{* t}\right)^{-1}\left[\left(1+r^{* t}\right)-\left(1+i^{* t}\right)\left(1-\delta_{n}^{t}\right)\right] P_{n}^{t} & \\
& =\left(1+r^{* t}\right)^{-1}\left[r^{* t}+\pi_{n}^{t}\right] P_{n}^{t} & \text { using equations (33). }
\end{array}
$$

Thus, the period- $t$ vintage user cost for an asset that is $n$ periods old at the start of period $t, f_{n}^{t}$, can be decomposed into the sum of two terms. Ignoring the discount factor, $\left(1+r^{* t}\right)^{-1}$, the first term is $r^{* t} P_{n}^{t}$, which represents the real interest cost of the financial capital that is tied up in the asset, and the second term is $\pi_{n}^{t}-P_{n}^{t}=\Pi_{n}^{t}$, which represents a concept of national accounts depreciation.

The last line of equations (34) is important if at some stage statistical agencies decide to switch from measures of gross domestic product to measures of net domestic product. If this change occurs, then the user cost for each age $n$ of capital, $f_{n}^{t}$, must be split up into two terms as in equations (34). The first term, $\left(1+r^{* t}\right)^{-1} r^{* t} P_{n}^{t}$ times the number of units of that type

36. To see that there can be a very large difference between the cross-section depreciation rate $\delta_{n}^{t}$ and the corresponding ex ante time series depreciation rate $\pi_{n}^{t}$, consider the case of an asset whose vintages yield exactly the same service for each period in perpetuity. In this case, all of the vintage asset prices $P_{n}^{t}$ would be identical and the cross-section depreciation rates $\delta_{n}^{t}$ would all be zero. Now suppose a marvelous new invention is scheduled to come on the market next period that would effectively drive the price of this class of assets down to zero. In this case, $i^{* t}$ would be -1 and substituting this expected measure of price change into definitions (33) shows that the ex ante time series depreciation rates would all equal one; that is, under these conditions, we would have $\pi_{n}^{t}=1$ and $\delta_{n}^{t}=0$ for all vintages $n$. 
of capital in use, could remain as a primary input charge, while the second term, $\left(1+r^{* t}\right)^{-1} \pi_{n}^{t} P_{n}^{t}$ times the number of units of that age of capital in use (this is real national accounts depreciation), could be treated as an intermediate input charge (similar to the present treatment of imports). The second term would be an offset to gross investment. ${ }^{37}$

This completes our discussion of the obsolescence problem. ${ }^{38}$ In the next section, we turn our attention to the problem of aggregating across ages of the same capital good.

\subsection{Aggregation over Vintages of a Capital Good}

In previous sections, we have discussed the beginning-of-period- $t$ stock price $P_{n}^{t}$ of an asset that is $n$ periods old and the corresponding beginningand end-of-period user costs, $f_{n}^{t}$ and $u_{n}^{t}$. The stock prices are relevant for the construction of real wealth measures of capital, and the user costs are relevant for the construction of capital services measures. We now address the problems involved in obtaining quantity series that will match up with these prices.

Let the period- $t-1$ investment in a homogeneous asset for the sector of the economy under consideration be $I^{t-1}$. We assume that the starting capital stock for a new unit of capital stock at the beginning of period $t$ is $K_{0}^{t}$ and this stock is equal to the new investment in the asset in the previous period; that is, we assume

$$
K_{0}^{t} \equiv I^{t-1} .
$$

Essentially, we are assuming that the length of the period is short enough so that we can neglect any contribution of investment to current production; a new capital good becomes productive only in the period immediately following its construction. In a similar manner, we assume that the capital stock available of an asset that is $n$ periods old at the start of period $t$ is $K_{n}^{t}$ and this stock is equal to the gross investment in this asset class during period $t-n-1$; that is, we assume

$$
K_{n}^{t} \equiv I^{t-n-1} ; \quad n=0,1,2, \ldots
$$

Given these definitions, the value of the capital stock in the given asset class for the sector of the economy under consideration (the wealth capital stock) at the start of period $t$ is

37. Using this methodology, we would say that capital is being maintained intact for the economy if the value of gross investments made during the period (discounted to the beginning of the period) is equal to or greater than the sum of the real national accounts depreciation terms over all assets. This is a maintenance of financial capital concept as opposed to Pigou's (1935, p. 235) maintenance of physical capital concept.

38. It should be noted that our discussion of the obsolescence issue only provides an introduction to the many thorny issues that make this area of inquiry quite controversial. For fur- 


$$
\begin{aligned}
W^{t} & \equiv P_{0}^{t} K_{0}^{t}+P_{1}^{t} K_{1}^{t}+P_{2}^{t} K_{2}^{t}+\ldots \\
& =P_{0}^{t} I^{t-1}+P_{1}^{t} I^{t-2}+P_{2}^{t} I^{t-3}+\ldots \quad \text { using equation (36). }
\end{aligned}
$$

Turning now to the capital services quantity, we assume that the quantity of services that an asset of a particular age at a point in time is proportional (or more precisely, is equal) to the corresponding stock. Thus, we assume that the quantity of services provided in period $t$ by a unit of the capital stock that is $n$ periods old at the start of period $t$ is $K_{n}^{t}$ defined by equation (36) above. Given these definitions, the value of capital services for all vintages of asset in the given asset class for the sector of the economy under consideration (the productive services capital stock) during period $t$ using the end-of-period user costs $u_{n}^{t}$ defined by equations (8) is

$$
\begin{aligned}
S^{t} & \equiv u_{0}^{t} K_{0}^{t}+u_{1}^{t} K_{1}^{t}+u_{2}^{t} K_{2}^{t}+\ldots \\
& =u_{0}^{t} I^{t-1}+u_{1}^{t} I^{t-2}+u_{2}^{t} I^{t-3}+\ldots \quad \text { using equation (36). }
\end{aligned}
$$

Now we are faced with the problem of decomposing the value aggregates $W^{t}$ and $S^{t}$ defined by equations (37) and (38) into separate price and quantity components. If we assume that each new unit of capital lasts only a finite number of periods - $L$, say - then we can solve this value decomposition problem using normal index number theory. Thus, define the period- $t$ stock price and quantity vectors, $\mathbf{P}^{t}$ and $\mathbf{K}^{t}$ respectively, as follows:

$$
\begin{aligned}
\mathbf{P}^{t} & \equiv\left[P_{0}^{t}, P_{1}^{t}, \ldots, P_{L-1}^{t}\right] ; \quad t=0,1, \ldots, T \\
\mathbf{K}^{t} & \equiv\left[K_{0}^{t}, K_{1}^{t}, \ldots, K_{L-1}^{t}\right]=\left[I^{t-1}, I^{t-2}, \ldots, I^{t-L-1}\right] .
\end{aligned}
$$

Fixed-base or chain indexes may be used to decompose value ratios into price change and quantity change components. In the empirical work that follows, we have used the chain principle. ${ }^{39}$ Thus, the value of the capital stock in period $t, W^{t}$, relative to its value in the preceding period, $W^{t-1}$, has the following index number decomposition:

$$
\frac{W^{t}}{W^{t-1}}=P\left(\mathbf{P}^{t-1}, \mathbf{P}^{t}, \mathbf{K}^{t-1}, \mathbf{K}^{t}\right) Q\left(\mathbf{P}^{t-1}, \mathbf{P}^{t}, \mathbf{K}^{t-1}, \mathbf{K}^{t}\right) ; \quad t=1,2, \ldots, T,
$$

where $P$ and $Q$ are bilateral price and quantity indexes, respectively.

In a similar manner, we define the period-t end-of-period user cost price and quantity vectors, $\mathbf{u}^{t}$ and $\mathbf{K}^{t}$, respectively, as follows:

ther discussion, see Oulton (1995), Scott (1995), and Triplett (1996) and the references in these papers.

39. Given smoothly trending price and quantity data, the use of chain indexes will tend to reduce the differences between Paasche and Laspeyres indexes compared to the corresponding fixed-base indexes, and so chain indexes are generally preferred; see Diewert (1978, p. 895) for a discussion. 


$$
\begin{aligned}
\mathbf{u}^{t} & \equiv\left[u_{0}^{t}, u_{1}^{t}, \ldots, u_{L-1}^{t}\right] ; \quad t=0,1, \ldots, T ; \\
\mathbf{K}^{t} & \equiv\left[K_{0}^{t}, K_{1}^{t}, \ldots, K_{L-1}^{t}\right]=\left[I^{t-1}, I^{t-2}, \ldots, I^{t-L-1}\right] .
\end{aligned}
$$

We ask that the value of capital services in period $t, S^{t}$, relative to its value in the preceding period, $S^{t-1}$, have the following index number decomposition:

$$
\frac{S^{t}}{S^{t-1}}=P\left(\mathbf{u}^{t-1}, \mathbf{u}^{t}, \mathbf{K}^{t-1}, \mathbf{K}^{t}\right) Q\left(\mathbf{u}^{t-1}, \mathbf{u}^{t}, \mathbf{K}^{t-1}, \mathbf{K}^{t}\right) ; \quad t=1,2, \ldots, T,
$$

where again $P$ and $Q$ are bilateral price and quantity indexes, respectively.

There is now the problem of choosing the functional form for either the price index $P$ or the quantity index $Q \cdot{ }^{40}$ In the empirical work that follows, we used the Fisher (1922) Ideal price and quantity indexes. These indexes appear to be best from the axiomatic viewpoint ${ }^{41}$ and can also be given strong economic justifications. ${ }^{42}$

It should be noted that our use of an index number formula to aggregate both stocks and services by age is more general than the usual aggregation procedures, which essentially assume that the different vintages of the same capital good are perfectly substitutable so that linear aggregation techniques can be used..$^{43}$ However, as we shall see in subsequent sections, the more general mode of aggregation suggested here frequently reduces to the traditional linear method of aggregation provided that the period prices by age all move in strict proportion over time.

Many researchers and statistical agencies relax the assumption that an asset lasts only a fixed number of periods ( $L$, say) and make assumptions about the distribution of retirements around the average service life, $L$. In our empirical work that follows, for simplicity, we will stick to the suddendeath assumption: that all assets in the given asset class are retired at age $L$. However, this simultaneous retirement assumption can readily be relaxed (at the cost of much additional computational complexity) using a methodology developed by Hulten (1990, p. 125), where he subdivided a vintage into subcomponents, each of which had a different expected length of life.

We now have all of the pieces that are required in order to decompose the capital stock of an asset class and the corresponding capital services into price and quantity components. However, in order to construct price and quantity components for capital services, we need information on the rel-

40. Obviously, given one of these functional forms, we may use equation (40) to determine the other.

41. See Diewert (1992a, pp. 214-23).

42. See Diewert (1976, pp. 129-34).

43. This more general form of aggregation was first suggested by Diewert and Lawrence (2000). For descriptions of the more traditional linear method of aggregation, see Jorgenson (1989, p. 4) or Hulten (1990, pp. 121-27; 1996, pp. 152-65). 
ative efficiencies $f_{n}^{t}$ of the various vintages of the capital input, or, equivalently, we need information on cross-sectional vintage depreciation rates $\delta_{n}^{t}$ in order to use equation (42) above. The problem is that we do not have accurate information on either of these series, so in what follows we will assume a standard asset life $L$ and make additional assumptions on either the pattern of vintage efficiencies or depreciation rates. Thus, in a sense, we are following the same somewhat mechanical strategy that was used by the early cost accountants like Daniels (1933, p. 303).

However, our mechanical strategy is more complex than that used by early accountants in that we translate assumptions about the pattern of cross-section depreciation rates into implications for the pattern of crosssection rental prices and asset prices, taking into account the complications induced by discounting and expected future asset price changes.

In the following sections, we will consider four different sets of assumptions and calculate the resulting aggregate capital stocks and services using Canadian data. We illustrate how the various depreciation models differ from each other using annual Canadian data on two broad classes of asset: $^{44}$

- machinery and equipment

- nonresidential structures

We use Canadian data on gross investment in these two asset classes (in current and in constant dollars) because it extends back to 1926 and hence capital stocks can be formed without making arbitrary starting value assumptions.

Our first problem is to decide on the average age of retirement for each of these asset classes. One source is the OECD (1993), where average service lives for various asset classes were reported for fourteen OECD countries. For machinery and equipment (excluding vehicles) used in manufacturing activities, the average life ranged from eleven years for Japan to twenty-six years for the United Kingdom. For vehicles, the average service lives for passenger cars ranged from two years in Sweden to fourteen years in Iceland, and for road freight vehicles the average life ranged from three years in Sweden to fourteen years in Iceland. For buildings and structures, the average service lives ranged from fifteen years (for petroleum and gas structures in the United States) to eighty years for railway structures in Sweden. Faced with this wide range of possible lives, we decided to follow the example of Angus Maddison (1993) and assume an average service life of fourteen years for machinery and equipment and thirty-nine years for nonresidential structures. The Canadian data that we used may be found in Diewert (2004).

We turn now to our first efficiency and depreciation model.

44. More accurate models would work with more disaggregated investment series. 


\subsection{The One-Hoss-Shay Model of Efficiency and Depreciation}

In section 12.2, we noted that Böhm-Bawerk (1891, p. 342) postulated that an asset would yield a constant level of services throughout its useful life of $L$ years and then collapse in a heap to yield no services thereafter. This has come to be known as the one-hoss-shay or lightbulb model of depreciation. Hulten (1990, p. 124) noted that this pattern of relative efficiencies has considerable intuitive appeal for many assets.

The basic assumptions of this model are that the period- $t$ efficiencies and hence cross-sectional rental prices $f_{n}^{t}$ are all equal to, say, $f^{t}$ for ages $n$ that are less than $L$ periods old, and for older ages the efficiencies fall to zero. Thus, we have

$$
\begin{aligned}
f_{n}^{t} & =f^{t} & & \text { for } n=0,1,2, \ldots, L-1 ; \\
& =0 & & \text { for } n=L, L+1, L+2, \ldots
\end{aligned}
$$

Now substitute equations (43) into the first equation in equations (5) and get the following formula ${ }^{45}$ for the rental price $f^{t}$ in terms of the price of a new asset at the beginning of year $t, P_{0}^{t}$.

$$
f^{t}=\frac{P_{0}^{t}}{1+\left(\gamma^{t}\right)+\left(\gamma^{t}\right)^{2}+\ldots+\left(\gamma^{L}\right)^{L-1}},
$$

where the period- $t$ discount factor $\gamma^{t}$ is defined in terms of the period- $t$ nominal interest rate $r^{t}$ and the period- $t$ expected asset rate of price change $i^{t}$ as follows:

$$
\gamma^{t}=\frac{1+i^{t}}{1+r^{t}}
$$

Now that the period- $t$ rental price $f^{t}$ for an unretired asset has been determined, substitute equations (43) into equations (5) and determine the sequence of period- $t$ asset prices by age $n, P_{n}^{t}$.

$$
\text { (46) } \begin{aligned}
P_{n}^{t} & =f^{t}\left[1+\left(\gamma^{t}\right)+\left(\gamma^{t}\right)^{2}+\ldots+\left(\gamma^{L}\right)^{L-1-n}\right] & & \text { for } n=0,1,2, \ldots, L-1 \\
& =0 & & \text { for } n=L, L+1, L+2, \ldots
\end{aligned}
$$

Finally, use equations (8) to determine the end-of-period- $t$ rental prices, $u_{n}^{t}$, in terms of the corresponding beginning-of-period- $t$ rental prices, $f_{n}^{t}$.

$$
u_{n}^{t}=\left(1+r^{t}\right) f_{n}^{t} ; \quad n=0,1,2, \ldots
$$

45. This formula simplifies to $P_{0}^{t}\left[1-\left(\gamma^{t}\right)^{L}\right] /\left[1-\gamma^{t}\right]$ provided that $\gamma^{t}$ is less than 1 in magnitude. This last restriction does not hold for our Canadian data since, for some years, $i^{t}$ exceeds $r^{t}$. However, equation (44) is still valid under these conditions. 
Given the asset prices defined by equations (46), we could use equations (12) above to determine the corresponding cross-section depreciation rates $\delta_{n}^{t}$. We will not table these depreciation rates since our focus is on constructing measures of the capital stock and of the flow of services that the stocks yield.

We have data in current and constant dollars for investment in nonresidential structures and for machinery and equipment in Canada for the years 1926 to 1999 inclusive; see Diewert (2004) for a description of these data. As was mentioned in the previous section, we follow the example set by Maddison (1993) and assume an average service life of fourteen years for machinery and equipment and thirty-nine years for nonresidential structures. Thus, 1965 is the first year for which we will have data on all thirty-nine types of nonresidential structures. Now it is a straightforward matter to use the asset prices by age defined by equations (46) above (where $L$ equals 39 ) and apply equation (40) in the previous section to aggregate over the thirty-nine types of nonresidential capital using the Fisher (1922) Ideal index number formula and form aggregate price and quantity series for the nonresidential construction (wealth) capital stock, $P_{\mathrm{NR}}^{t}$ and $K_{\mathrm{NR}}^{t}$, for the years 1965-99. These series, along with their annual average (geometric) growth rates, can be found in Diewert at five-year intervals. Similarly, we use equations (46) above (where $L$ equals 14 ) and apply equation (40) in the previous section to aggregate over the fourteen ages of machinery and equipment using the Fisher Ideal index number formula and form aggregate price and quantity series for the machinery and equipment (wealth) capital stock, $P_{\mathrm{ME}}^{t}$ and $K_{\mathrm{ME}}^{t}$, for the years 1965-99. These series, along with their annual average (geometric) growth rates, can also be found in Diewert at five-year intervals. In this first model, we assume that producers exactly anticipate the asset rates of price change, $i_{\mathrm{NR}}^{t}$ and $i_{\mathrm{ME}}^{t}$, for nonresidential construction and for machinery and equipment respectively; these ex post rates of price change are listed in Diewert. Having constructed the aggregate price and quantity of nonresidential capital, $P_{\mathrm{NR}}^{t}$ and $K_{\mathrm{NR}}^{t}$ respectively, and the aggregate price and quantity of machinery and equipment, $P_{\mathrm{ME}}^{t}$ and $K_{\mathrm{ME}}^{t}$ respectively, we may again use the Fisher Ideal formula and aggregate these two series into a single aggregate price and quantity series for the wealth stock, which we denote by $P(1)^{t}$ and $K(1)^{t}$, where the 1 indicates that this is our first model in a grand total of twelve alternative aggregate capital stock models.

Using equations (43), (44), and (47), along with the data tabled in Diewert (2004), we can construct the end-of-period user costs for each of our thirty-nine types of nonresidential construction capital. Now use equation (38) to construct the service flow aggregate for nonresidential construction for each year. Then we use equation (42) in the previous section (where $L$ equals 39) to aggregate over the thirty-nine types of nonresidential capital 
using the Fisher Ideal index number formula and form the aggregate rental price for nonresidential construction, $u_{\mathrm{NR}}^{t}$, and the corresponding services aggregate, $k_{\mathrm{NR}}^{t}$, for the years $1965-99 .{ }^{46}$ These series, along with their annual average (geometric) growth rates, can be found in Diewert (2004) at five-year intervals. Similarly, we use equation (42) above (where $L$ equals 14) and aggregate over the fourteen ages of machinery and equipment using the Fisher Ideal index number formula and form aggregate capital services price and quantity series, $u_{\mathrm{ME}}^{t}$ and $k_{\mathrm{ME}}^{t}$, for the years 1965-99. These series, along with their annual average (geometric) growth rates, can also be found in Diewert at five-year intervals. Having constructed the aggregate price and quantity of nonresidential capital services, $u_{\mathrm{NR}}^{t}$ and $k_{\mathrm{NR}}^{t}$ respectively, and the aggregate price and quantity of machinery and equipment services, $u_{\mathrm{ME}}^{t}$ and $k_{\mathrm{ME}}^{t}$ respectively, we may again use the Fisher Ideal formula and aggregate these two series into a single aggregate price and quantity series for capital services, which we denote by $u(1)^{t}$ and $k(1)^{t}$, where the 1 again indicates that this is our first model in a grand total of twelve alternative aggregate capital stock models. The various data series will be compared graphically in section 12.11 below.

We turn now to our second one-hoss-shay depreciation model. In this model, instead of assuming that producers correctly anticipate each year's ex post asset inflation rates, we assume that producers use the current consumer price index (CPI) inflation rate as estimators of anticipated asset inflation rates. This model turns out to be equivalent to the constant real interest rate model that is frequently used by statistical agencies. ${ }^{47}$ In terms of computations, we simply replace the two ex post asset inflation rates, $i_{\mathrm{NR}}^{t}$ and $i_{\mathrm{ME}}^{t}$, with the CPI inflation rate $\rho^{t}$ listed in Diewert (2004) and then repeat all of the computations made to implement model 1 above.

When we compare the service prices and quantities in model 1, the perfect-foresight model, with the corresponding service prices and quantities in model 2, the constant real interest rate model, a number of things stand out:

- The model 2 user costs are much less volatile (as could be expected).

- The model 1 user costs grow much more quickly.

- The model 2 levels of capital services are much higher.

- The model 1 and 2 average growth rates for capital services are very similar.

46. Since all of the vintage rental prices are equal, it turns out that the aggregate rental price is equal to this common vintage rental price and the service aggregate is equal to the simple sum over the vintages. This result is an application of Hicks's (1939, pp. 312-13) aggregation theorem; that is, if all prices in the aggregate move in strict proportion over time, then any one of these prices can be taken as the price of the aggregate.

47. The nominal interest rate is still used in forming the end-of-period user costs; otherwise, only real interest rates are used in this model. 
Thus, the two models give very different results overall. The average rate of price increase for the model 2 capital services aggregate was 3.29 percent per year, which is much lower than the model 1 estimate of 4.85 percent per year. On the quantity side, the model 2 flow of nonresidential construction capital services increased from $\$ 2,727$ million to $\$ 11,564$ million (constant 1965) Canadian dollars, for an annual average (geometric) growth rate of 4.34 percent, while the model 2 flow of machinery and equipment capital services increased from $\$ 3,588$ million to $\$ 34,556$ million (constant 1965) Canadian dollars, for an annual average growth rate of 6.89 percent. The model 2 capital services aggregate grew at an annual average growth rate of 5.49 percent compared to the model 1 capital services annual average growth rate of 5.61 percent.

We turn now to our third one-hoss-shay depreciation model. In this model (model 3), instead of assuming that producers correctly anticipate each year's ex post asset inflation rates, we assume that they can anticipate the trends in asset inflation rates. In Diewert (2004), we describe in detail how these trends were determined. In terms of computations, we use exactly the same program that we used to implement model 1 except that we replace the rather volatile nominal interest rates $r^{t}$ with the smoothed nominal interest rates that are listed in Diewert. We also replace the two ex post asset inflation rates, $i_{\mathrm{NR}}^{t}$ and $i_{\mathrm{ME}}^{t}$, with their smoothed counterparts listed in Diewert.

Comparing the numbers across the three models, there are some small differences between the capital stocks generated by our three variants of the one-hoss-shay model of depreciation, but the average growth rates are virtually identical. There is more variation across the three models in the movement of the stock prices, with model 1 giving the highest rate of price growth for the capital aggregate ( 4.35 percent per year), followed by model 3 (4.17 percent per year) and then model 2 (3.97 percent per year). The model 1,2 , and 3 aggregate prices, $P(1)-P(3)$, and quantities of capital, $K(1)-K(3)$ respectively, are graphed in figures $12.1-12.6$ in section 12.11 .

The tremendous volatility of the model 1 rental prices, $u(1)$, will become evident from viewing figure 12.7 in section 12.11. Thus, the use of ex post asset inflation rates as ex ante or anticipated inflation rates leads to user costs that are extremely volatile. The model 3 aggregate user costs, $u(3)$, while still more volatile than the constant real interest rate user costs, $u(2)$, are reasonable and smooth out the fluctuations in the $u(1)$ series. The $u(2)$ series lies below the other two user cost series because the constant real interest rate user costs make no allowance for the extra depreciation that arises from the anticipated price declines that are due to obsolescence; that is, the $u(2)$ series ignores the systematic real price declines in the price of machinery and equipment. Thus, while model 2 is acceptable, we prefer model 3 , since this model includes the effects of anticipated obsolescence, whereas model 2 does not. 
Examination of figures 12.4-12.6 in section 12.11 will show that all three one-hoss-shay models give rise to much the same aggregate capital stocks. The constant real interest rate capital stocks $K(2)$ are the biggest, followed by the smoothed anticipated inflation stocks $K(3)$, and the fully anticipated inflation stocks $K(1)$ are the smallest. The aggregate capital services graphed in figures 12.10-12.12 show much the same pattern but with more dispersion. The constant real interest rate aggregated capital services $k(2)$ are the biggest, followed by the smoothed anticipated inflation capital services $k(3)$ and the fully anticipated inflation capital services $k(1)$ are the smallest.

We turn now to our second model of depreciation and efficiency.

\subsection{The Straight-Line Depreciation Model}

The straight-line method of depreciation is very simple in a world without price change: one simply makes an estimate of the most probable length of life for a new asset, $L$ periods, say, and then the original purchase price $P_{0}^{t}$ is divided by $L$ to yield an estimate of period-by-period depreciation for the next $L$ periods. In a way, this is the simplest possible model of depreciation, just as the one-hoss-shay model was the simplest possible model of efficiency decline. ${ }^{48}$ The use of straight-line depreciation dates back to the 1800s at least; see Matheson (1910, p. 55), Garcke and Fells (1893, p. 98), and Canning (1929, pp. 265-66).

We now set out the equations that describe the straight-line model of depreciation in the general case when the anticipated asset rate of price change $i^{t}$ is nonzero. Assuming that the asset has a life of $L$ periods and that the cross-sectional amounts of depreciation $D_{n}^{t} \equiv P_{n}^{t}-P_{n+1}^{t}$ defined by equation (10) above are all equal for the assets in use, then it can be seen that the beginning of period- $t$ vintage asset prices $P_{n}^{t}$ will decline linearly for $L$ periods and then remain at zero; that is, the $P_{n}^{t}$ will satisfy the following restrictions:

$$
\begin{aligned}
P_{n}^{t} & =P_{0}^{t}\left(\frac{L-n}{L}\right) & & n=0,1,2, \ldots, L \\
& =0 & & n=L+1, L+2, \ldots
\end{aligned}
$$

Recall definition (12) above, which defined the cross-sectional depreciation rate for an asset that is $n$ periods old at the beginning of period $t, \delta_{n}^{t}$. Using equations (48) and the $n$th equation in equations (13), we have

48. In fact, it can be verified that if the nominal interest rate $r^{t}$ and the nominal asset inflation rate $i^{t}$ are both zero, then the one-hoss-shay efficiency model will be entirely equivalent to the straight-line depreciation model. 


$$
\left(1-\delta_{0}^{t}\right)\left(1-\delta_{1}^{t}\right) \ldots\left(1-\delta_{n-1}^{t}\right)=\frac{P_{n}^{t}}{P_{0}^{t}}=1-\frac{n}{L} \quad \text { for } n=1,2, \ldots, L .
$$

Using equation (49) for $n$ and $n+1$, it can be shown that

$$
\left(1-\delta_{n}^{t}\right)=\frac{L-(n+1)}{L-n} \quad n=0,1,2, \ldots, L-1 .
$$

Now substitute equations (49) and (50) into the general user cost formula, equations (14), in order to obtain the period-t end-of-period straightline user costs, $u_{n}^{t}: 49$

$$
\begin{aligned}
u_{n}^{t}= & \left(1-\delta_{0}^{t}\right) \ldots\left(1-\delta_{n-1}^{t}\right)\left[\left(1+r^{t}\right)\right. \\
& \left.-\left(1+i^{t}\right)\left(1-\delta_{n}^{t}\right)\right] P_{0}^{t} \quad n=0,1,2, \ldots, L-1 \\
= & \left(1-\frac{n}{L}\right)\left\{\left(1+r^{t}\right)-\left(1+i^{t}\right)\left[\frac{L-(n+1)}{L-n}\right]\right\} P_{0}^{t} .
\end{aligned}
$$

Equations (48) give us the sequence of asset prices by age that are required to calculate the wealth capital stock, while equations (51) give us the user costs by age that are required to calculate capital services for the asset. It should be noted that if the anticipated asset inflation rate $i^{t}$ is large enough compared to the nominal interest rate $r^{t}$, then the user cost $u_{n}^{t}$ can be negative. This means that the corresponding asset becomes an output rather than an input for period $t .^{50}$

At this point, we can proceed in much the same manner as in the previous section. We use the asset prices defined by equations (48) above (where $L$ equals 39 ) and apply equation (40) in section 12.7 to aggregate over the thirty-nine types of nonresidential capital using the Fisher Ideal index number formula, and we form aggregate price and quantity series for the nonresidential construction (wealth) capital stock, $P_{\mathrm{NR}}^{t}$ and $K_{\mathrm{NR}}^{t}$, for the years 1965-99. These series, along with their annual average (geometric) growth rates, can be found in Diewert (2004) at five-year intervals. Similarly, we use equations (48) above (where $L$ equals 14) and apply equation (40) to aggregate over the fourteen types of machinery and equipment using the Fisher Ideal index number formula, and we form aggregate price and quantity series for the machinery and equipment (wealth) capital stock, $P_{\mathrm{ME}}^{t}$ and $K_{\mathrm{ME}}^{t}$, for the years 1965-99. These series, along with their annual average (geometric) growth rates, can also be found in Diewert at fiveyear intervals. In this fourth model, we assume that producers exactly anticipate the ex post asset rates of price change, $i_{\mathrm{NR}}^{t}$ and $i_{\mathrm{ME}}^{t}$, for nonresidential construction and for machinery and equipment, respectively. Having

49. The user costs for $n=L, L+1, L+2, \ldots$ are all zero.

50. However, one is led to wonder if the model is reasonable if some vintages of the asset have negative user costs while other vintages have positive ones. 
constructed the aggregate price and quantity of nonresidential capital, $P_{\mathrm{NR}}^{t}$ and $K_{\mathrm{NR}}^{t}$ respectively, and the aggregate price and quantity of machinery and equipment, $P_{\mathrm{ME}}^{t}$ and $K_{\mathrm{ME}}^{t}$ respectively, we may again use the Fisher Ideal formula and aggregate these two series into a single aggregate price and quantity series for the wealth stock, which we denote by $P(4)^{t}$ and $K(4)^{t}$.

Using equations (51) along with the data tabled in Diewert (2004), we can construct the end-of-period user costs for each of our thirty-nine types of nonresidential construction capital. Now use equation (38) to construct the service flow aggregate for nonresidential construction for each year. Then we use equation (42) in the previous section (where $L$ equals 39) to aggregate over the thirty-nine types of nonresidential capital using the Fisher Ideal index number formula and form the aggregate rental price for nonresidential construction, $u_{\mathrm{NR}}^{t}$, and the corresponding services aggregate, $k_{\mathrm{NR}}^{t}$, for the years $1965-99 .{ }^{51}$ These series, along with their annual average (geometric) growth rates, can be found in Diewert at five-year intervals. Similarly, we use (42) above (where $L$ equals 14 ) and aggregate over the fourteen types of machinery and equipment using the Fisher Ideal index number formula, and we form aggregate capital services price and quantity series, $u_{\mathrm{ME}}^{t}$ and $k_{\mathrm{ME}}^{t}$, for the years 1965-99. These series, along with their annual average (geometric) growth rates, can also be found in Diewert at five-year intervals. Having constructed the aggregate price and quantity of nonresidential capital services, $u_{\mathrm{NR}}^{t}$ and $k_{\mathrm{NR}}^{t}$ respectively, and the aggregate price and quantity of machinery and equipment services, $u_{\mathrm{ME}}^{t}$ and $k_{\mathrm{ME}}^{t}$ respectively, we may again use the Fisher Ideal formula and aggregate these two series into a single aggregate price and quantity series for capital services, which we denote by $u(4)^{t}$ and $k(4)^{t}$.

We turn now to our second straight-line depreciation model. In this model 5 , instead of assuming that producers correctly anticipate each year's ex post asset inflation rates, we assume that producers use the current CPI inflation rate as estimators of anticipated asset rates of price change. In terms of computations, we simply replace the two ex post asset rates of price change, $i_{\mathrm{NR}}^{t}$ and $i_{\mathrm{ME}}^{t}$, by the CPI inflation rate $\rho^{t}$ listed in Diewert (2004) and then repeat all of the computations made to implement model 4 above.

It turns out that the model 5 constant real interest rate capital stocks (and prices) are exactly equal to their model 4 counterparts. This follows from equations (48), which describe the pattern of asset prices by age: in

51. It turned out that some of our rental prices were negative. This may not be a major theoretical problem since in this case the corresponding capital input becomes a net output. However, the computations were carried out using the econometrics computer program SHAZAM, and the index number option fails when any price is negative. In this case, it was necessary to write up a subroutine that would compute the Fisher indexes when some prices were negative. The four inner products that are building blocks into the Fisher indexes must all be positive in order to take the positive square root. This condition was satisfied by the data in all cases. 
both models 4 and 5 (and model 6, to be considered shortly), these asset prices do not depend on $r^{t}$ or $i^{t}$, and hence the resulting asset prices and capital stocks will be identical. Hence, there is no need to table the capital stocks and prices for model 5 . However, the model 5 user costs and capital service flows by age (listed in Diewert 2004 at five-year intervals) are very different from their model 4 counterparts.

We turn now to our third straight-line depreciation model, which we call model 6. In this model, instead of assuming that producers correctly anticipate each year's ex post asset inflation rates, we assume that they can anticipate the trends in asset rates of price change. In terms of computations, we use exactly the same program that we used to implement model 4 except that we replace the rather volatile nominal interest rate $r^{t}$ that is listed in Diewert (2004) with the smoothed nominal interest rate that is listed in Diewert. We also replace the two ex post asset inflation rates, $i_{\mathrm{NR}}^{t}$ and $i_{\mathrm{ME}}^{t}$, with their smoothed counterparts, also listed in Diewert.

As mentioned earlier, the model 6 constant real interest rate capital stocks (and prices) are exactly equal to their model 4 counterparts in table 12.7. Hence, there is no need to table the capital stocks and prices for model 6 . However, the model 6 vintage user costs and capital service flows are very different from their model 4 and 5 counterparts.

On the quantity side, model 6 gives much the same results as the other two straight-line depreciation models, models 4 and 5; see figures 12.1012.12 in section 12.11 for graphs of $k(4)-k(6)$. In particular, the average annual (geometric) rate of growth of aggregate capital services for models 4 , 5 , and 6 was 5.30 percent, 5.08 percent, and 5.24 percent per year, respectively. However, on the user cost side, the three models give very different results. The perfect-foresight model, model 4 , gave the highest annual average growth rate for the aggregate price of capital services, 4.96 percent per year, while the constant real interest rate model, model 5 , gave the lowest average growth rate, 3.61 percent per year. The smoothed anticipated prices model, model 6 , gave an intermediate growth rate for the price of capital services, 4.31 percent per year. As will be seen from figures 12.712.9, the model 5 and 6 aggregate user costs were much smoother than the volatile model 4 user costs.

We turn now to our third class of depreciation and efficiency models.

\subsection{The Declining Balance or Geometric Depreciation Model}

The declining balance method of depreciation dates back to Matheson $(1910$, p. 55$)$ at least. ${ }^{52}$ In terms of the algebra presented in section 12.3 , the

52. Matheson (1910, p. 91) used the term "diminishing value" to describe the method. Hotelling (1925, p. 350) used the term "the reducing balance method," while Canning (1929, p. 276) used the term the "declining balance formula." 
method is very simple: all of the cross-sectional vintage depreciation rates $\delta_{n}^{t}$ defined by equation (12) are assumed to be equal to the same rate $\delta$, where $\delta$ is a positive number less than one; that is, we have for all time periods $t$

$$
\delta_{n}^{t}=\delta \quad n 0,1,2, \ldots
$$

Substitution of equation (52) into equations (14) leads to the following formula for the sequence of period- $t$ vintage user costs:

$$
\begin{aligned}
u_{n}^{t} & =(1-\delta)^{n-1}\left[\left(1+r^{t}\right)-\left(1+i^{t}\right)(1-\delta)\right] P_{0}^{t} & & n=0,1,2, \ldots \\
& =(1-\delta)^{n-1} u_{0}^{t} & & n=1,2, \ldots
\end{aligned}
$$

The second set of equations in equations (53) says that all of the vintage user costs are proportional to the user cost for a new asset. This proportionality means that we do not have to use an index number formula to aggregate over vintages to form a capital services aggregate. To see this, using (53), the period- $t$ services aggregate $S^{t}$ defined earlier by equations (38) can be rewritten as follows:

$$
\begin{aligned}
S^{t} & \equiv u_{0}^{t} K_{0}^{t}+u_{2}^{t} K_{2}^{t}+\ldots \\
& =u_{0}^{t}\left[K_{0}^{t}+(1-\delta) K_{1}^{t}+(1-\delta)^{2} K_{2}^{t}+\ldots\right] \\
& =u_{0}^{t} K_{A}^{t}
\end{aligned}
$$

where the period $t$ capital aggregate $K_{A}^{t}$ is defined as

$$
K_{A}^{t} \equiv K_{0}^{t}+(1-\delta) K_{1}^{t}+(1-\delta)^{2} K_{2}^{t}+\ldots
$$

If the depreciation rate $\delta$ and the vintage capital stocks are known, then $K_{A}^{t}$ can readily be calculated using (55). Then using the last line of equations (54), we see that the value of capital services (summed over all ages), $S^{t}$, decomposes into the price term $u_{0}^{t}$ times the quantity term $K_{A}^{t}$. Hence, it is not necessary to use an index number formula to aggregate over ages of the asset using this depreciation model.

A similar simplification occurs when calculating the wealth stock using this depreciation model. Substitution of equation (52) into equations (13) leads to the following formula for the sequence of period- $t$ asset prices by age $n$ :

$$
P_{n}^{t}=(1-\delta)^{n-1} P_{0}^{t} \quad n=1,2, \ldots
$$

Equations (56) say that all of the period-t asset prices are proportional to the price of a new asset. This proportionality means that, again, we do not have to use an index number formula to aggregate over vintages to form a capital stock aggregate. To see this, using equations (56), the period- $t$ wealth aggregate $W^{t}$ defined earlier by equations (37) can be rewritten as follows: 


$$
\begin{aligned}
W^{t} & \equiv P_{0}^{t} K_{0}^{t}+P_{1}^{t} K_{1}^{t}+P_{2}^{t} K_{2}^{t}+\ldots \\
& =P_{0}^{t}\left[K_{0}^{t}+(1-\delta) K_{1}^{t}+(1-\delta)^{2} K_{2}^{t}+\ldots\right] \\
& =P_{0}^{t} K_{A}^{t}
\end{aligned}
$$

where $K_{A}^{t}$ was defined by equation (55). Thus, $K_{A}^{t}$ can serve as either a capital stock aggregate or a flow-of-services aggregate, which is a major advantage of this model. ${ }^{53}$

There is a further simplification of the model that is useful in applications. If we compare equation (55) for period $t+1$ and period $t$, we see that the following formula results using definitions (39):

$$
K_{A}^{t+1} \equiv K_{0}^{t+1}+(1-\delta) K_{A}^{t} .
$$

Thus, the period- $t+1$ aggregate capital stock, $K_{A}^{t+1}$, is equal to the investment in new assets that took place in period $t$, which is $K_{0}^{t+1}$, plus $1-\delta$ times the period- $t$ aggregate capital stock, $K_{A}^{t}$. This means that, given a starting value for the capital stock, we can readily update it just using the depreciation rate $\delta$ and the new investment in the asset during the prior period.

We now need to address the problem of determining the depreciation rate $\delta$ for a particular asset class. Matheson (1910, pp. 69-91) was perhaps the first engineer to address this problem. On the basis of his experience, he simply postulated some approximate rates that could be applied, ranging from 3 to 20 percent.

The algebra corresponding to Matheson's method for determining $\delta$ was explicitly described by the accountant Canning (1929, p. 276). Let the initial value of the asset be $V_{0}$, and let its scrap value $n$ years later be $V_{n}$. Then $V_{0}, V_{n}$, and the depreciation rate $\delta$ are related by the following equation:

$$
V_{n}=(1-\delta)^{n} V_{0} \text {. }
$$

Canning goes on to explain that $1-\delta$ may be determined by solving the following equation:

$$
\log (1-\delta)=\frac{\log V_{n}-\log V_{0}}{n}
$$

It is clear that Matheson used this framework to determine depreciation rates even though he did not lay out formally the above straightforward algebra.

However, Canning $\left(1929\right.$, p. 276) pointed out that the scrap value, $V_{n}$, which is not determined very accurately from an a priori point of view, is

53. This advantage of the model has been pointed out by Jorgenson $(1996 \mathrm{~b}, 1989)$ and his coworkers. Its early application dates back to Jorgenson and Griliches (1967) and Christensen and Jorgenson $(1969,1973)$. 
the tail that is wagging the dog; that is, this poorly determined value plays a crucial role in the determination of the depreciation rate.

An effective response to Canning's (1929) criticism of the declining balance method of depreciation did not emerge until relatively recently, when Hall (1971), Beidelman (1973, 1976), and Hulten and Wykoff (1981a,b) used an entire array of used asset prices at point in time in order to determine the geometric depreciation rate that best matched up with the data. ${ }^{54}$ Another theoretical possibility would be to use information on rental prices by age of asset in order to deduce the depreciation rate. ${ }^{55}$

This brings us to our next problem: how should we convert our estimated asset lives of thirty-nine years for structures and fourteen years for machinery and equipment into comparable geometric rates?

One possible method for converting an average asset life $-L$ periods, say - into a comparable geometric depreciation rate is to argue as follows. Suppose that we believe that the straight-line model of depreciation is the correct one and the asset under consideration has a useful life of $L$ periods. Suppose further that investment in this type of asset is constant over time at one unit per period and asset prices are constant over time. Under these conditions, the long-run equilibrium capital stock for this asset would be ${ }^{56}$

$$
1+\frac{L-1}{L}+\frac{L-2}{L}+\ldots+\frac{2}{L}+\frac{1}{L}=\frac{L(L+1)}{2 L}=\frac{L+1}{2} .
$$

Under the same conditions, the long-run equilibrium geometric depreciation capital stock would be equal to the following sum:

$$
1+(1-\delta)+(1-\delta)^{2}+\ldots=\frac{1}{1-(1-\delta)}=\frac{1}{\delta} .
$$

Now find the depreciation rate $\delta$ that will make the two capital stocks equal; that is, equate equation (61) to equation (62) and solve for $\delta$. The resulting $\delta$ is

$$
\delta=\frac{2}{L+1} .
$$

Obviously, there are a number of problematical assumptions that were made in order to derive the depreciation rate $\delta$ that corresponds to the

54. Jorgenson (1996a) has a nice review of most of the empirical studies of depreciation. It should be noted that Beidelman $(1973,1976)$ and Hulten and Wykoff $(1981 \mathrm{a}, 1996$, p. 22) showed that equation (59) must be adjusted to correct for the early retirement of assets. The accountant Schmalenbach (1959, p. 91; first German edition published in 1919) also noticed this problem.

55. This possibility is mentioned by Hulten and Wykoff (1996, p. 15).

56. Recall equations (48), which imply that the vintage asset prices are proportional. Hence, Hicks's Aggregation Theorem will imply that the capital aggregate will be the simple sum on the left-hand side of equation (61). 
length of life $L,{ }^{57}$ but equation (63) gives us at least a definite method of conversion from one model to the other.

Since we assumed that the average length of life for nonresidential construction was $L$ equal to thirty-nine years, applying the conversion formula given by equation (63) implies that $\delta_{\mathrm{NR}}$ equals .05; that is, we assume that the declining balance or geometric depreciation rate for nonresidential construction in Canada is 5 percent. Similarly, our assumed life of fourteen years for machinery and equipment translates into a $\delta_{\mathrm{ME}}$ equal to a $13^{1 / 3}$ percent geometric depreciation rate for this asset class.

There is one remaining problem to deal with, and then we can proceed to table the results for three geometric depreciation models for Canada. The problem is this: before 1926, we do not have reliable investment data, but the effects of investments made prior to 1926 live on forever in the infinite-lived geometric depreciation model that we considered in equations (54) to (58) above. In the case of machinery and equipment investments made before 1926, by the time we get to 1965 , what is left of the original investments is negligible. However, in the case of a $\$ 1,000$ investment in nonresidential structures made in $1925, \$ 128.50$ of it would still be available as a productive input in 1965 , assuming a 5 percent geometric depreciation rate. Hence, we need a method for estimating the geometric capital stock that is available at the start of 1926 in order to not bias downward our estimates of the geometric capital stock for nonresidential construction for the period 1965-99. We decided to assume that nonresidential investment for the period prior to 1926 grew at the same rate that it grew during the years 1926-99.58 Thus, for the years 1927 to 1999, we took investment in nonresidential construction during the current year divided by the corresponding investment in the prior year (both in constant dollars) as our dependent variable and regressed this variable on a constant. The estimated constant turned out to be 1.0509. Hence, for the period prior to 1926, we assumed that investments in nonresidential construction grew at the rate $g$ $\equiv .05$ (i.e., a 5 percent growth rate). Thus if $I_{\mathrm{NR}}^{1926}$ was the investment in 1926 , we assumed that the investments in prior years were

57. The two assumptions that are the least justified are (a) the assumption that the straightline depreciation model is the correct model to do the conversion and (b) the assumption that investment has been constant back to minus infinity. Hulten and Wykoff (1996, p. 16) made the following suggestions for converting an $L$ into a $\delta$ : "Information is available on the average service life, $L$, from several sources. The rate of depreciation for non-marketed assets can be estimated using a two step procedure based on the 'declining balance' formula $\delta=X / L$. Under the 'double declining balance' formula, $X=2$. The value of $X$ can be estimated using the formula $X=\delta L$ for those assets for which these estimates are available. In the HultenWykoff studies, the average value of $X$ for producer's durable equipment was found to be 1.65 (later revised to 1.86). For nonresidential structures, $X$ was found to be 0.91 . Once $X$ is fixed, $\delta$ follows for other assets whose average service life is available."

58. This method for obtaining a starting value for the geometric capital stock is due to Kohli (1982); see also Fox and Kohli (1998). 


$$
\frac{I_{\mathrm{NR}}^{1926}}{1+g}, \frac{I_{\mathrm{NR}}^{1926}}{(1+g)^{2}}, \frac{I_{\mathrm{NR}}^{1926}}{(1+g)^{3}}, \ldots
$$

Using assumption (64), we can calculate an estimate of the starting capital stock for nonresidential construction at the start of 1927 as

$$
\begin{aligned}
K_{\mathrm{NR}}^{1927} & \equiv I_{\mathrm{NR}}^{1926}\left[1+\left(\frac{1-\delta}{1+g}\right)+\left(\frac{1-\delta}{1+g}\right)^{2}+\left(\frac{1-\delta}{1+g}\right)^{3}+\ldots\right] \\
& =I_{\mathrm{NR}}^{1926}\left\{\frac{1}{1-[(1-\delta) /(1+g)}\right\} \\
& =I_{\mathrm{NR}}^{1926}\left(\frac{1+g}{g+\delta}\right),
\end{aligned}
$$

where $g=.05$ and $\delta=.05$. Now we can use formula (58), starting at the year $t=1927$, to build up the capital stock for each of our two asset classes. For nonresidential construction, our starting 1927 capital stock was defined by equations (65), and for machinery and equipment, it was simply the 1926 investment in machinery and equipment $-I_{\mathrm{ME}}^{1926}$, say.

At this point, we can proceed in much the same manner as in the previous section. We have already explained how we can use equations (58) to form the aggregate capital stocks for nonresidential construction and machinery and equipment. From equations (57), it can be seen that the corresponding capital stock price is $P_{0}^{t}$, the price of a new vintage at the beginning of year $t$. These series, along with their annual average (geometric) growth rates, can be found in table 11 of Diewert (2004) at five-year intervals. In this seventh model, having constructed the aggregate price and quantity of nonresidential capital, $P_{\mathrm{NR}}^{t}$ and $K_{\mathrm{NR}}^{t}$ respectively, and the aggregate price and quantity of machinery and equipment, $P_{\mathrm{ME}}^{t}$ and $K_{\mathrm{ME}}^{t}$ respectively, we may again use the Fisher Ideal formula and aggregate these two series into a single aggregate price and quantity series for the wealth stock, which we denote by $P(7)^{t}$ and $K(7)^{t}$.

Comparing the capital stock prices for model 7 with those of model 4 , we find that these numbers are exactly the same. This is because in both the straight-line depreciation model and the geometric model, the price of a new asset acts as the aggregate stock price over all vintages. However, when we use the Fisher formula to aggregate the two types of capital prices together to get either $P(4)$ or $P(7)$, we get slightly different numbers because the aggregate quantities of the two types of asset differ in the two models. The Fisher Ideal aggregate price for these two capital stock components increased from 1 to 3.6243 over this period. The price of a unit of nonresidential construction capital increased by 5.08 percent per year, and the price of a unit of machinery and equipment capital increased by only 1.37 percent per year on average for model 7 . The average rate of price increase 
for the model 7 capital aggregate was 3.86 percent per year. This should be compared to the average rate of price increase for the one-hoss-shay capital aggregate, which was much higher at 4.35 percent per year. On the quantity side, the stock of nonresidential construction capital increased from $\$ 32.8$ billion to $\$ 115.9$ billion (constant 1965) Canadian dollars, for an annual average (geometric) growth rate of 3.78 percent (3.85 percent for the straight-line model), while the stock of machinery and equipment capital increased from $\$ 19.1$ billion to $\$ 199.7$ billion (constant 1965) Canadian dollars, for an annual average growth rate of 7.15 percent $(7.19$ percent for the straight-line model). The model 7 declining balance capital aggregate grew at an annual average growth rate of 4.85 percent. The corresponding aggregate growth rates for the one-hoss-shay and straight-line models were 4.95 percent and 4.88 percent per year, respectively.

We turn now to the service flow part of our seventh model, where we assume that producers exactly anticipate the asset rates of price change, $i_{\mathrm{NR}}^{t}$ and $i_{\mathrm{ME}}^{t}$, for nonresidential construction and for machinery and equipment, respectively; these ex post rates are listed in table A2 of Diewert (2004). The user cost for a new asset at the start of period $t, u_{0}^{t}$, is defined in equations (53). Equations (54) show that this user cost matches up with the corresponding aggregated over ages capital stock so the computations are simplified in this model. Denote these user costs by $u_{\mathrm{NR}}^{t}$ and $u_{\mathrm{ME}}^{t}$ for our two assets and denote the corresponding service aggregates by $k_{\mathrm{NR}}^{t}$ and $k_{\mathrm{ME}}^{t}$, respectively. We renormalize these series so that both user costs are unity in $1965 .{ }^{59}$ These series, along with their annual average (geometric) growth rates, can be found in table 12 of Diewert at five-year intervals. Having constructed the aggregate price and quantity of nonresidential capital services, $u_{\mathrm{NR}}^{t}$ and $k_{\mathrm{NR}}^{t}$ respectively, and the aggregate price and quantity of machinery and equipment services, $u_{\mathrm{ME}}^{t}$ and $k_{\mathrm{ME}}^{t}$ respectively, we may again use the Fisher Ideal formula and aggregate these two series into a single aggregate price and quantity series for capital services, which we denote by $u(7)^{t}$ and $k(7)^{t} .60$

Comparison of the declining balance growth rates with the corresponding straight-line growth rates shows that there are some substantial differences. For example, the average annual geometric rate of growth for the user cost of machinery and equipment was 3.40 percent per year for the straight-line model versus 2.75 percent per year for the geometric model. The geometric model rate of capital services price growth of 4.51 percent per year should be compared to the straight-line model rate of capital services price growth of 4.96 percent per year, which in turn can be compared to the average rate of price increase for the one-hoss-shay capital services

59. Before normalization, the service flow aggregates $k_{\mathrm{NR}}^{t}$ and $k_{\mathrm{ME}}^{t}$ are exactly equal to the corresponding stock aggregates. Thus the rates of growth of the corresponding stock and flow variables will be the same.

60. These series are plotted in figures 12.7 and 12.10 in section 12.11 . 
aggregate, which was somewhat higher at 4.85 percent per year. The use of ex post asset inflation rates again leads to user costs that are extremely volatile; see figure 12.7 below. On the quantity side, the model 7 flow of nonresidential construction capital services increased from $\$ 1,916$ million to $\$ 6,764$ million (constant 1965) Canadian dollars, for an annual average (geometric) growth rate of 3.78 percent, while the flow of machinery and equipment capital services increased from $\$ 3,069$ million to $\$ 32,069$ million (constant 1965) Canadian dollars, for an annual average growth rate of 7.15 percent. The capital services aggregate grew at an annual average growth rate of 5.55 percent, compared to the 4.85 percent annual average growth rate for the aggregate capital stock. The geometric model average rate of capital services growth rate of 5.55 percent per year can be compared to the straight-line growth rate of capital services of 5.30 percent per year and to the average rate of growth for the one-hoss-shay capital services aggregate of 5.61 percent per year.

We turn now to our second geometric depreciation model, which will eliminate the volatility problem mentioned in the last paragraph. In this model 8 , instead of assuming that producers correctly anticipate each year's ex post asset rates of price change, it is assumed that producers use the current CPI inflation rate as estimators of anticipated asset price change. In terms of computations, we simply replace the two ex post asset rates of price change, $i_{\mathrm{NR}}^{t}$ and $i_{\mathrm{ME}}^{t}$, with the CPI inflation rate $\rho^{t}$ listed in table A2 of Diewert (2004) and then repeat all of the computations made to implement model 7 above.

It turns out that the model 8 constant real interest rate capital stocks (and prices) are exactly equal to their model 7 counterparts in table 11 of Diewert (2004). This follows from equations (57), which show that the aggregate (over ages) stock price is equal to the price of a new asset, which in turn does not depend on our assumptions about interest rates or expected asset inflation rates. Hence, there is no need to table the capital stocks and prices for model 8 (or model 9 below). However, the model 8 vintage user costs and capital service flows are very different from their model 2 counterparts and slightly different from their model 5 counterparts. Table 13 in Diewert (2004) lists the model 8 rental prices and flows of capital services for the geometric depreciation (constant real interest rate) Canadian capital stocks at five-year intervals over the period 1965-99.

The overall annual rate of growth for capital services for the straight-line model was 5.08 percent per year, compared to 5.37 percent per year for the geometric model, where both models assumed constant real interest rates. This is not a large difference. In figures 12.7 and 12.8 in section 12.11 , it can be seen that the user costs that correspond to the geometric model with constant real interest rates, $u(8)$, is much less volatile than the corresponding geometric model that assumes perfect foresight, $u(7)$.

We turn now to our third geometric depreciation model, which we call 
model 9. In this model, instead of assuming that producers correctly anticipate each year's ex post asset rates of price change, we assume that they can anticipate the trends in these rates. In terms of computations, we use exactly the same program that we used to implement model 7 except that we replace the rather volatile nominal interest rate $r^{t}$ that was listed in table A2 of Diewert (2004) with the smoothed nominal interest rate that is listed in table A3 of Diewert. We also replace the two ex post asset rates of price change, $i_{\mathrm{NR}}^{t}$ and $i_{\mathrm{ME}}^{t}$, with their smoothed counterparts listed in table $\mathrm{A} 3$ of Diewert.

As mentioned earlier, the model 9 constant real interest rate capital stocks (and prices) are exactly equal to their model 7 counterparts in table 7 in Diewert (2004). Hence, there is no need to table the capital stocks and prices for model 9 . However, the model 9 vintage user costs are somewhat different from their model 7 and 8 counterparts. Table 14 in Diewert lists the model 9 rental prices and flows of capital services for the Canadian capital stock at five-year intervals over the period 1965-99.

When we compare the two capital services, $k_{\mathrm{NR}}^{t}$ and $k_{\mathrm{ME}}^{t}$, across the three declining balance models, they turn out to be identical; hence, so are their growth rates. Hence, when we aggregate across these two assets to form the model 7,8 , and 9 capital services aggregates, we find that the average annual geometric growth rates are quite similar: 5.55 percent, 5.37 percent, and 5.52 percent, respectively. However, the corresponding rental price series for each type of asset, $u_{\mathrm{NR}}^{t}$ and $u_{\mathrm{ME}}^{t}$, are no longer identical across the two models. The geometric aggregate rental price grew at an annual geometric rate of 3.88 percent per year, while the straight-line aggregate rental price grew at a 4.31 percent per year rate. In figures 12.7 and 12.9 in section 12.11, it can be seen that the user cost that corresponds to the geometric model with smoothed asset inflation rates, $u(9)$, is much less volatile than the corresponding geometric model that assumes perfect foresight, $u$ (7), but the trend in each series is similar.

We turn now to our fourth and final class of depreciation and relative efficiency models.

\subsection{The Linear Efficiency Decline Model}

Recall that our first class of models (the one-hoss-shay models) assumed that the efficiency (or cross-section user cost) of the asset remained constant over the useful life of the asset. In our second class of models (the straight-line depreciation models), we assumed that the cross-section depreciation of the asset declined at a linear rate. In our third class of models (the geometric depreciation models), we assumed that cross-section depreciation declined at a geometric rate. Comparing the third class with the second class of models, it can be seen that geometric depreciation is more $a c$ celerated than straight-line depreciation; that is, depreciation is relatively 
large for new vintages compared to older ones. In this section, we will consider another class of models that gives rise to an accelerated pattern of depreciation: the class of models that exhibit a linear decline in efficiency. ${ }^{61}$

It is relatively easy to develop the mathematics of this model. Let $f_{0}^{t}$ be the period- $t$ rental price for an asset that is new at the beginning of period $t$. If the useful life of the asset is $L$ years and the efficiency decline is linear, then the sequence of period- $t$ cross-sectional user $\operatorname{costs} f_{n}^{t}$ is defined as follows:

$$
\begin{array}{rlrl}
f_{n}^{t} & \equiv f_{0}^{t}\left(\frac{L-n}{L}\right) & n=0,1,2, \ldots, L-1 \\
& \equiv 0 & n & =L, L+1, L+2, \ldots
\end{array}
$$

Now substitute equations (66) into the first equation in equations (5) and get the following formula for the rental price $f_{0}^{t}$ in terms of the price of a new asset at the beginning of year $t, P_{0}^{t}$ :

$$
f_{0}^{t}=\frac{L P_{0}^{t}}{L+(L-1)\left(\gamma^{t}\right)+(L-2)\left(\gamma^{t}\right)^{2}+\ldots+1\left(\gamma^{t}\right)^{L-1}},
$$

where the period- $t$ discount factor $\gamma^{t}$ is defined in terms of the period- $t$ nominal interest rate $r^{t}$ and the period- $t$ expected asset rate of price change $i^{t}$ in the usual way:

$$
\gamma^{t} \equiv \frac{1+i^{t}}{1+r^{t}}
$$

Now that $f_{0}^{t}$ has been determined, substitute equation (67) into equations (66), substitute the resulting equations into equations (5), and determine the sequence of period- $t$ asset prices by age $n, P_{n}^{t}$ :

$$
\begin{aligned}
P_{n}^{t}=P_{0}^{t}\left[\frac{(L-n)+(L-n-1)\left(\gamma^{t}\right)+\ldots+1\left(\gamma^{t}\right)^{L-1-n}}{L+(L-1)\left(\gamma^{t}\right)+\ldots+1\left(\gamma^{t}\right)^{L-1}}\right] & \\
& \text { for } n=0,1,2, \ldots, L-1 \\
& \text { for } n=L, L+1, L+2, \ldots
\end{aligned}
$$

Finally, use equations (8) to determine the end-of-period- $t$ rental prices, $u_{n}^{t}$, in terms of the corresponding beginning-of-period- $t$ rental prices, $f_{n}^{t}$ :

$$
u_{n}^{t}=\left(1+r^{t}\right) f_{n}^{t} \quad n=0,1,2, \ldots
$$

Given the asset prices by age $n$ defined by equations (69), we could use equations (12) above to determine the corresponding cross-section depre-

61. Diewert (2004) showed how linear efficiency decline models can be derived from onehoss-shay models where maintenance expenditures are expected to increase linearly over time. 
ciation rates $\delta_{n}^{t}$. We will not table these depreciation rates, since our focus is on constructing measures of the capital stock and of the flow of services that the stocks yield. However, we will note that if we recall definition (10) for the period- $t$ cross-section depreciation of an asset of vintage $n, D_{n}^{t} \equiv$ $P_{n}^{t}-P_{n+1}^{t}$, and assume that the nominal interest rate $r^{t}$ and the nominal asset rate of price change $i^{t}$ are both zero, then using equations (69), it can be shown that

$$
D_{n}^{t} \equiv P_{n}^{t}-P_{n+1}^{t}=P_{0}^{t}\left[\frac{L-n}{L(L+1) / 2}\right] \text { for } n=0,1,2, \ldots, \mathrm{L}
$$

that is, when $r^{t}=i^{t}=0$, depreciation declines at a linear rate for the linear efficiency decline model. When depreciation declines at a linear rate, the resulting formula for depreciation is called the sum of the year digits formula.$^{62}$ Thus, just as the one-hoss-shay and straight-line depreciation models coincide when $r^{t}=i^{t}=0$, so too do the linear efficiency decline and sum of the year digits depreciation models.

In our tenth model, we assume that producers exactly anticipate the asset rates of price change, $i_{\mathrm{NR}}^{t}$ and $i_{\mathrm{ME}}^{t}$, for nonresidential construction and for machinery and equipment, respectively. We use the Fisher Ideal index to aggregate over ages using formula (69) above for the asset prices by age. Having constructed the aggregate price and quantity of nonresidential capital, $P_{\mathrm{NR}}^{t}$ and $K_{\mathrm{NR}}^{t}$ respectively, and the aggregate price and quantity of machinery and equipment, $P_{\mathrm{ME}}^{t}$ and $K_{\mathrm{ME}}^{t}$ respectively, we may again use the Fisher Ideal formula and aggregate these two series into a single aggregate price and quantity series for the wealth stock, which we denote by $P(10)^{t}$ and $K(10)^{t}$. The average rate of price increase for the linear efficiency decline capital stock aggregate was 4.13 percent per year, which is lower than the corresponding rate of aggregate price increase for the one-hoss-shay aggregate of 4.35 percent per year; see table 15 in Diewert (2004). On the quantity side, the stock of nonresidential construction capital increased from $\$ 29.6$ billion to $\$ 98.5$ billion (constant 1965) Canadian dollars, for an annual average (geometric) growth rate of 3.60 percent, while the stock of machinery and equipment capital increased from $\$ 15.0$ billion to $\$ 166.6$ billion (constant 1965) Canadian dollars, for an annual average growth rate of 7.33 percent. Of course, the levels of the capital aggregate are only about two-thirds to three-quarters of the corresponding one-hoss-shay levels due to the accelerated form of depreciation for the former model. The linearly declining efficiency capital aggregate grew at an annual average growth rate of 4.74 percent, which is lower than the corresponding rate of growth for the one-hoss-shay aggregate of 4.95 percent.

Using equations (66), (67), and (70) along with the data tabled in tables

62. Canning $(1929,277)$ describes the method in some detail, so it was already in common use by that time. 
A1 and A2 of Diewert (2004), we can construct the end-of-period user costs for each of our thirty-nine types of nonresidential construction capital. As usual, use equation (38) to construct the service flow aggregate for nonresidential construction for each year. Then we use equation (42), where $L$ equals 39 , to aggregate over the thirty-nine types of nonresidential capital using the Fisher Ideal index number formula and form the aggregate rental price for nonresidential construction, $u_{\mathrm{NR}}^{t}$, and the corresponding services aggregate, $k_{\mathrm{NR}}^{t}$, for the years $1965-99 .{ }^{63}$ These series, along with their annual average (geometric) growth rates, can be found in table 16 of Diewert at five-year intervals. Similarly, we use equation (42), where $L$ equals 14 , and aggregate over the fourteen types of machinery and equipment using the Fisher Ideal index number formula and form aggregate capital services price and quantity series, $u_{\mathrm{ME}}^{t}$ and $k_{\mathrm{ME}}^{t}$, for the years 1965-99. These series, along with their annual average (geometric) growth rates, can also be found in table 16 of Diewert at five-year intervals. Having constructed the aggregate price and quantity of nonresidential capital services, $u_{\mathrm{NR}}^{t}$ and $k_{\mathrm{NR}}^{t}$ respectively, and the aggregate price and quantity of machinery and equipment services, $u_{\mathrm{ME}}^{t}$ and $k_{\mathrm{ME}}^{t}$ respectively, we may again use the Fisher Ideal formula and aggregate these two series into a single aggregate price and quantity series for capital services, which we denote by $u(10)^{t}$ and $k(10)^{t} .{ }^{64}$

Table 16 in Diewert (2004) shows that the price of a unit of nonresidential construction capital services increased by 6.32 percent per year and the price of a unit of machinery and equipment capital services increased by 2.54 percent per year on average. The average rate of price increase for the linearly declining efficiency capital services aggregate was 4.32 percent per year, which is much less than the corresponding rate of price increase for the one-hoss-shay aggregate capital services price, which was 4.85 percent per year. On the quantity side, the flow of nonresidential construction capital services increased from $\$ 2,066$ million to $\$ 7,467$ million (constant 1965) Canadian dollars, for an annual average (geometric) growth rate of 3.85 percent, while the flow of machinery and equipment capital services increased from $\$ 3,162$ million to $\$ 33,554$ million (constant 1965) Canadian dollars, for an annual average growth rate of 7.19 percent. The capital services aggregate grew at an annual average growth rate of 5.56 percent, compared to the 5.61 percent annual average growth rate for the corresponding one-hoss-shay capital services. As usual, the linear efficiency decline user costs $u(10)$ that are based on the assumption of perfect foresight are very volatile; see figure 12.7 in section 12.11 .

We turn now to our second linear efficiency decline model, which will

63. Since all of the rental prices by age of asset are proportional to each other, again Hicks's (1939, p. 312-13) aggregation theorem implies that all of the usual indexes are equal to each other.

64. These series are plotted in figures 12.7 and 12.10 . 
eliminate the volatility problem mentioned in the last paragraph. In this model 11, instead of assuming that producers correctly anticipate each year's ex post asset rates of price change, it is assumed that producers use the current CPI inflation rate as estimators of these rates. This model turns out to be equivalent to the constant real interest rate model. As usual, in terms of computations, we simply replace the two ex post asset rates of price change, $i_{\mathrm{NR}}^{t}$ and $i_{\mathrm{ME}}^{t}$, with the CPI inflation rate $\rho^{t}$ listed in table A2 of Diewert (2004) and then repeat all of the computations made to implement model 10 above.

The model 11 capital stock quantities are very similar to the model 10 quantities. The overall average growth rate for the price of the aggregate stock is a bit higher for model 10 (4.13 percent per year) than for model 11 (3.94 percent per year).

The one-hoss-shay capital services aggregate that assumes constant real interest rates, $k(2)$, is quite close to the linear efficiency decline capital services aggregate that assumes constant real interest rates, $k(11)$, and their average annual geometric growth rates are also close: 5.49 percent for $k(2)$ versus 5.43 percent for $k(11)$. However, $k(11)$ is 15 to 20 percent bigger in levels than the first linear efficiency decline capital services aggregate $k(10)$, which assumed that anticipated asset inflation rates were equal to ex post rates. The average annual geometric growth rate for $k(10)$ was somewhat higher, at 5.56 percent per year.

We turn now to our third linear efficiency decline model. In this model (model 12), instead of assuming that producers correctly anticipate each year's ex post asset rates of price change, we assume that they can anticipate the trends in these rates. In terms of computations, we use exactly the same program that we used to implement model 10 except that we replace the rather volatile nominal interest rates $r^{t}$ that are listed in table A2 of Diewert (2004) with the smoothed nominal interest rates that are listed in table A3 of Diewert. We also replace the two ex post asset inflation rates, $\mathrm{i}_{\mathrm{NR}}^{t}$ and $\mathrm{i}_{\mathrm{ME}}^{t}$, with their smoothed counterparts listed in table A3 of Diewert. It turns out that there are some small differences between the capital stocks generated by our three variants of the linear efficiency decline model, but the average growth rates are virtually identical. There is more variation across the three models in the movement of the stock prices, with model 10 giving the highest rate of price growth for the capital aggregate (4.13 percent per year), followed by model 12 (4.04 percent per year) and then model 11 (3.94 percent per year). However, there are large differences in the levels and small differences in the growth rates for capital services generated by the three models: the average annual geometric growth rates for $k(10), k(11)$, and $k(12)$ are 5.56 percent, 5.43 percent, and 5.55 percent per year. The average annual geometric growth rates for $K(10), K(11)$, and $K(12)$ are 4.74 percent, 4.72 percent, and 4.74 percent per year, respectively. However, there is much more variation across the three models in the 
movement of the service prices, with model 10 giving the highest rate of price growth for the capital services aggregate (4.32 percent per year), followed by model 12 (3.78 percent per year) and then model 11 (3.27 percent per year).

When we view figures $12.7-12.9$ in section 12.11 , the aggregate linear efficiency decline user cost series $u(10)$, which assumes that anticipated asset inflation rates are equal to the actual ex post rates, is the highest very volatile curve. Smoothing these volatile asset inflation rates leads to the $u(12)$ curve, which is much smoother and captures the trend in $u(10)$. The constant real interest rate user cost series, $u(11)$, lies far below the other two aggregate user cost series for much of the sample period.

Figures 12.10-12.12 in section 12.11 plot the three linear efficiency decline aggregate capital services series, $k(10)-k(12)$. Each of these series is reasonably smooth, but note that they are spread out much more than the corresponding aggregate capital stock series, $K(10)-K(12)$, that are plotted in figures 12.4-12.6. Thus, the different assumptions on anticipated asset price movements generate substantially different measures of capital services for these linear efficiency decline models. The constant real interest rate series, $k(11)$, is the top curve, followed by the smoothed asset inflation rates model, $k(12)$, and the ex post asset inflation rates model, $k(10)$, is the lowest curve.

In the following section, we make some graphical comparisons across our twelve models.

\subsection{A Comparison of the Twelve Models}

In this section, we will compare stock prices and user costs across our four types of model that are based on alternative assumptions about the structure of depreciation or asset efficiency, holding constant our assumptions about nominal interest rates and anticipated asset price movements. We will also compare capital stocks and service flows across depreciation and relative efficiency models, holding constant our assumptions about nominal interest rates and anticipated asset price movements.

Figure 12.1 plots the aggregate capital stock prices generated by our four depreciation and efficiency models, assuming that ex post asset price movements are perfectly anticipated. Note the volatility of these series. The onehoss-shay stock prices $P(1)$ are the highest, followed by the linear efficiency decline prices $P(10)$. The straight-line and geometric depreciation prices, $P(4)$ and $P(7)$, are the lowest and are very close to each other.

Figure 12.2 plots the aggregate capital stock prices generated by our four depreciation and efficiency models, assuming that ex post asset price changes are equal to changes in the CPI. This model assumes a constant real interest rate of 4 percent. These stock prices are much smoother than those exhibited in figure 12.1, and they are also much closer to each other. 


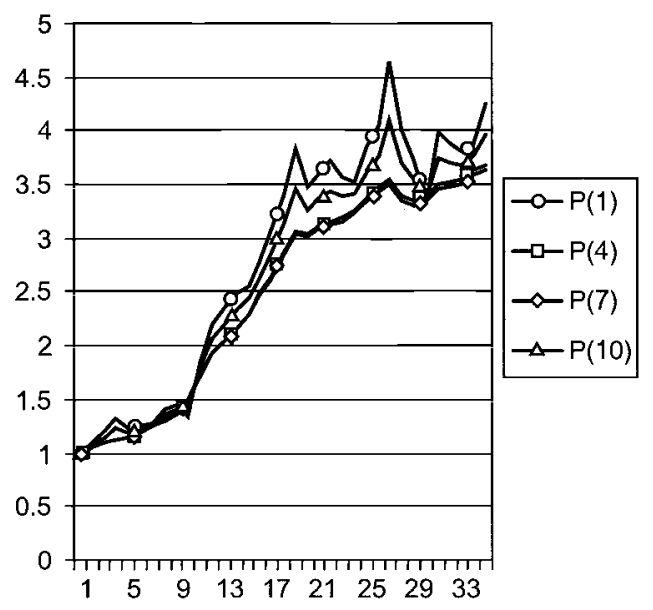

Fig. 12.1 Capital stock prices using ex post price changes

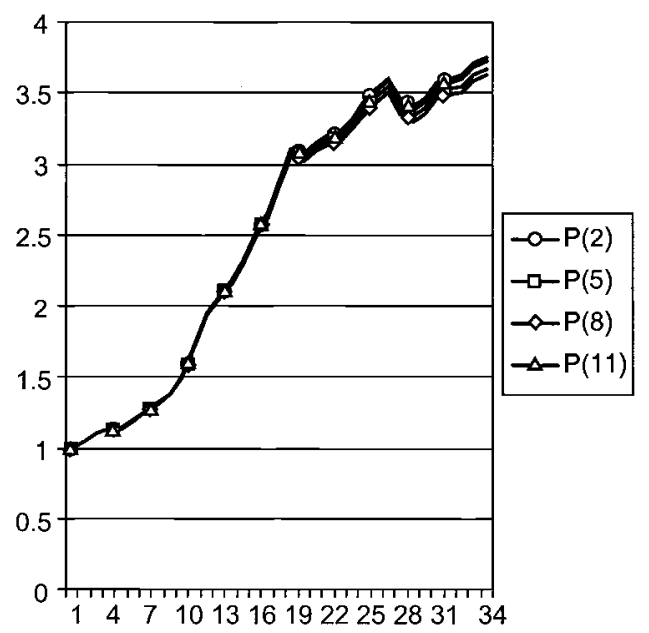

Fig. 12.2 Alternative stock prices with constant real interest rates

The one-hoss-shay and linear efficiency decline prices, $P(2)$ and $P(11)$, are virtually indistinguishable on the top, followed by the straight-line depreciation prices $P(5)$ and then followed very closely by the geometric stock prices $P(8)$.

Figure 12.3 plots the aggregate capital stock prices generated by our four depreciation and efficiency models, assuming that anticipated asset price changes are equal to smoothed ex post asset price changes. These stock price series smooth out considerably the much rougher series exhibited in 


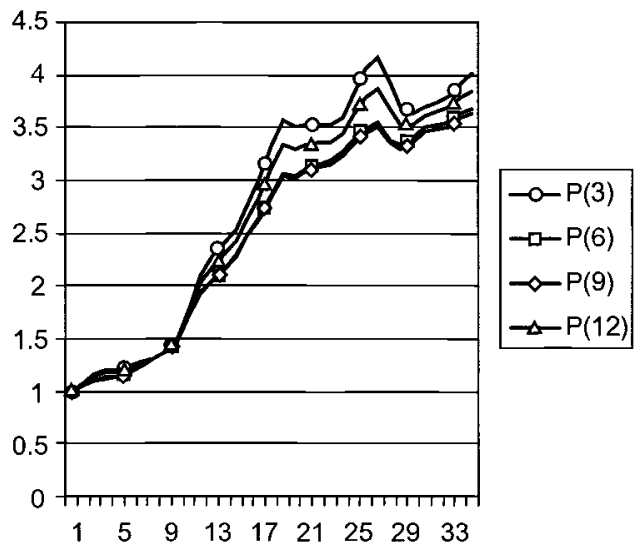

Fig. 12.3 Alternative stock prices using smoothed asset price changes

figure 12.1. The one-hoss-shay stock prices $P(3)$ are the highest, followed by the linear efficiency decline prices $P(12)$. The straight-line and geometric depreciation prices, $P(6)$ and $P(9)$, are the lowest and are very close to each other.

Figure 12.4 plots the aggregate capital stocks that correspond to the perfectly anticipated asset prices assumption for the four depreciation models. The one-hoss-shay capital stock curve $K(1)$ is the highest, followed by the straight-line depreciation curve $K(4)$, which in turn is followed by the geometric depreciation curve $K(7)$. The linear efficiency decline stock $K$ (10) is the lowest curve. These results are intuitively plausible: the onehoss-shay model has the least accelerated form of depreciation, followed by the straight-line model, followed by the geometric depreciation model, and the linear efficiency decline model generates the most accelerated form of depreciation. In an economy where investment is growing over time, the capital stocks corresponding to the least accelerated form of depreciation will grow the quickest, followed by the more accelerated forms, and the capital stock corresponding to the most accelerated form of depreciation will grow the slowest. Figures 12.5 and 12.6 plot the aggregate capital stocks that correspond to the constant real interest rate and the smoothed asset price models: the results are much the same as those exhibited in figure 12.4 .

Figure 12.7 plots the aggregate user costs generated by our four classes of depreciation and efficiency models, assuming that ex post asset price movements are perfectly anticipated. Note that the user cost series in figure 12.7 are even more volatile than the capital stock prices charted in figure 12.1. The one-hoss-shay and straight-line depreciation user costs, $u(1)$ and $u(4)$, are the highest, followed by the geometric depreciation and linear efficiency decline user costs, $u(7)$ and $u(10)$.

Figure 12.8 plots the aggregate user costs generated by our four classes 


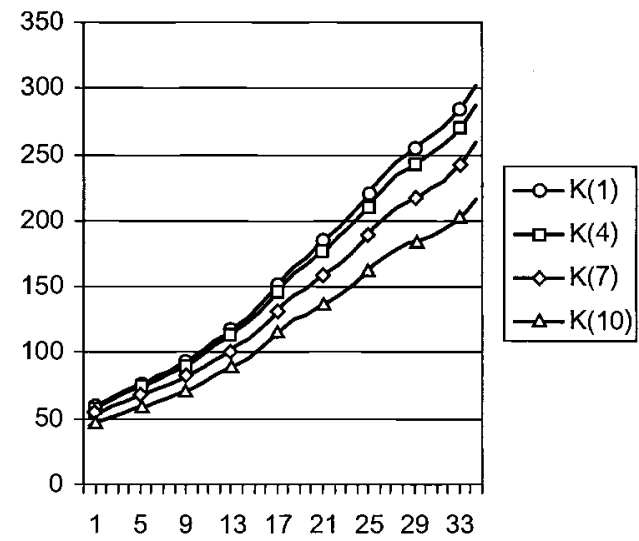

Fig. 12.4 Alternative capital stocks using ex post price changes

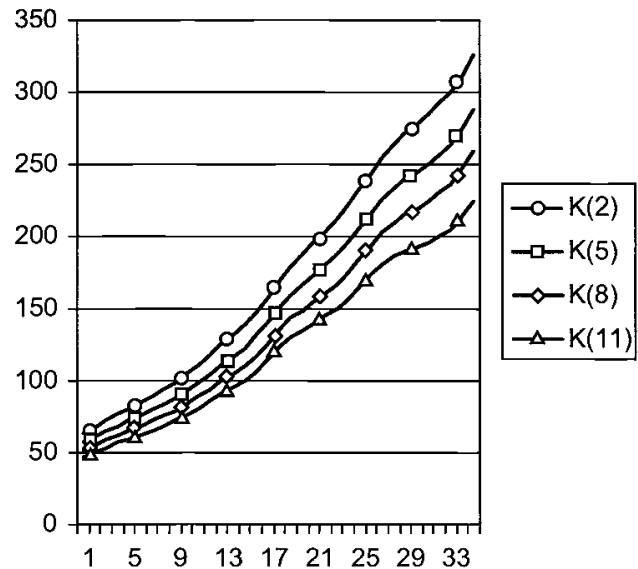

Fig. 12.5 Alternative capital stocks using constant real rates

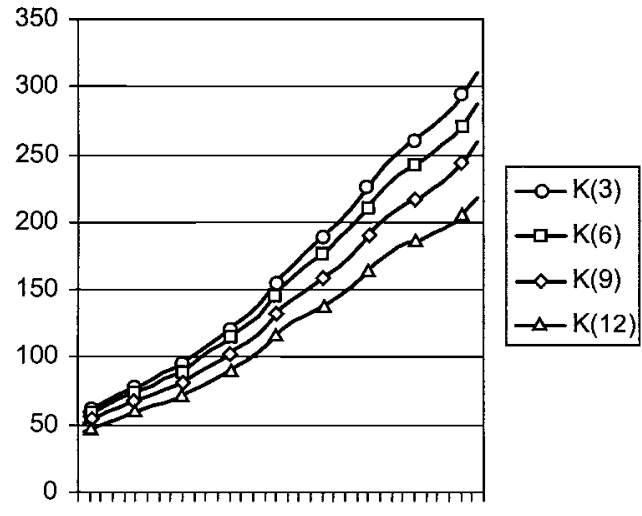

$\begin{array}{lllllllll}1 & 5 & 9 & 13 & 17 & 21 & 25 & 29 & 33\end{array}$

Fig. 12.6 Alternative capital stocks using smoothed asset price changes 


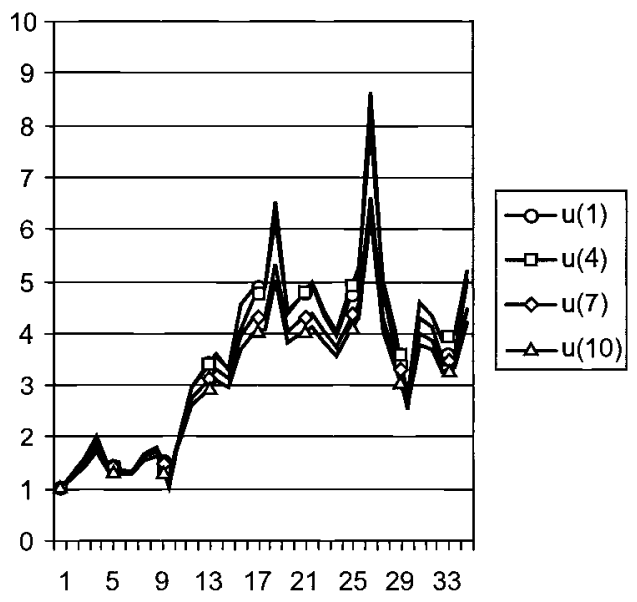

Fig. 12.7 Alternative user costs using ex post asset price changes

of depreciation and efficiency models, assuming that ex post asset price changes are equal to changes in the consumer price index. This model assumes a constant real interest rate of 4 percent. These user costs are much smoother than those exhibited in figure 12.7, and they are also much closer to each other. The straight-line depreciation user costs $u(5)$ are on top, followed by the one-hoss-shay, geometric, and linear efficiency decline user costs, $u(2), u(8)$, and $u(11)$, which are too close to each other to be distinguished visually.

Figure 12.9 plots the aggregate user costs generated by our four classes of depreciation and efficiency models, assuming that anticipated asset price changes are equal to smoothed ex post asset price changes. These user cost series smooth out considerably the much rougher series exhibited in figure 12.7. The straight-line and one-hoss-shay user costs, $u(6)$ and $u(3)$, are very close to each other on top; but near the end of our sample period, the one-hoss-shay user costs $u$ (3) dip below the straight-line depreciation user costs $u(6)$. The geometric depreciation and linear efficiency decline user costs, $u(9)$ and $u(12)$, are fairly close to each other on the bottom. These two models represent the most accelerated forms of depreciation.

Figures 12.10 and 12.11 plot the aggregate capital services that correspond to the perfectly anticipated asset price change and the constant real interest rate models. The aggregate services using ex post asset price changes plotted in figure 12.10 are more volatile and more widely dispersed than the aggregate services plotted in figures 12.11 and 12.12, as one might expect. The linear efficiency decline services are the top curve $k(10)$, followed by the geometric depreciation services $k(7)$, followed by the onehoss-shay services $k(1)$, and the straight-line depreciation capital services $k(4)$ are the bottom curve. The aggregate services using constant real 


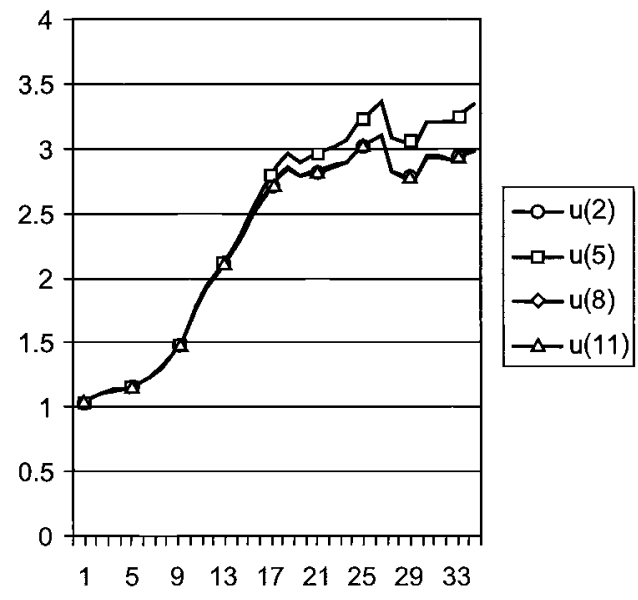

Fig. 12.8 Alternative user costs using constant real interest rates

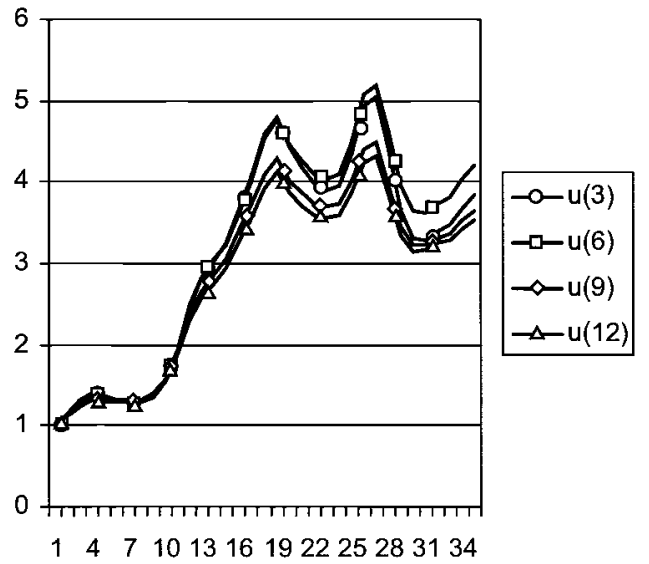

Fig. 12.9 Alternative user costs using smoothed asset price changes

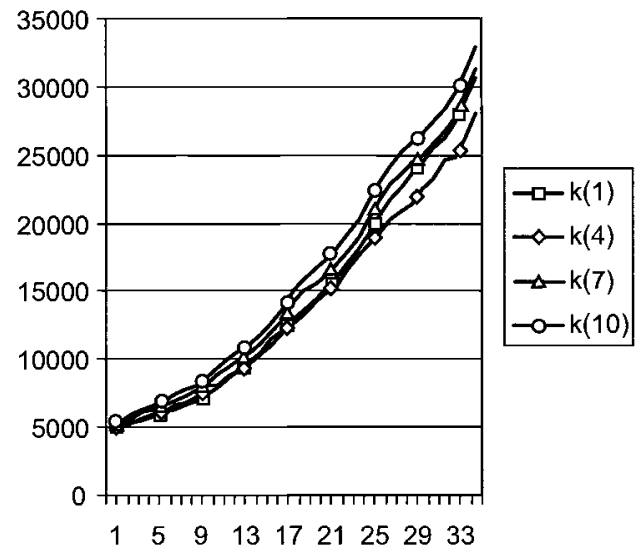

Fig. 12.10 Alternative capital services using ex post price changes 


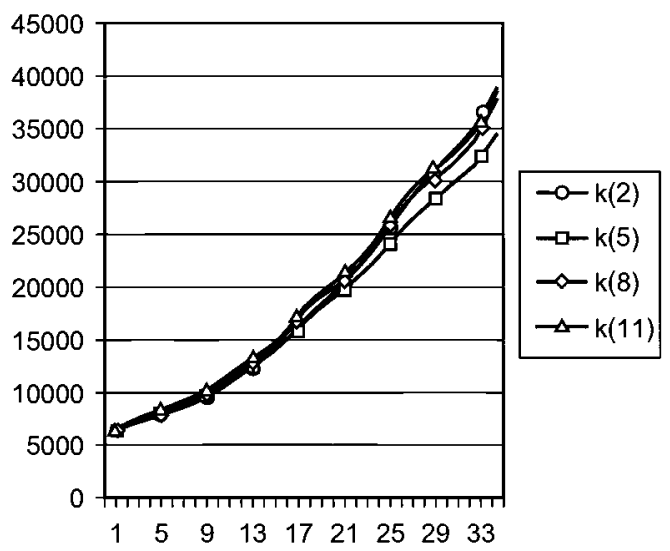

Fig. 12.11 Alternative capital services using constant real rates

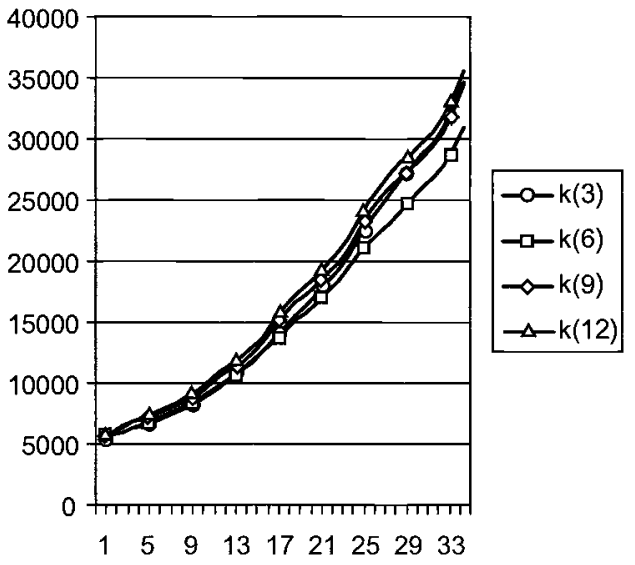

Fig. 12.12 Alternative capital services using smoothed asset price changes

interest rates plotted in figure 12.11 are fairly similar to the smoothed capital services exhibited in figure 12.12. For the constant real interest rate services in figure 12.11, the one-hoss-shay and linear efficiency decline services, $k(2)$ and $k(11)$, are at the top, followed very closely by the geometric depreciation services $k(8)$, and the straight-line depreciation capital services $k(5)$ are the bottom curve. Figure 12.12 plots the aggregate capital services that correspond to the smoothed asset price change model; that is, figure 12.12 is the quantity counterpart to figure 12.9. The linear efficiency decline capital services curve $k(12)$ is the highest, followed closely by the geometric depreciation and one-hoss-shay curves, $k(9)$ and $k(3)$, which are very close to each other. The straight-line depreciation curve $k(6)$ is the lowest curve and is well below the other three curves. Thus, overall, three 
of our four depreciation and efficiency models give rise to much the same measures of capital services, holding constant the assumptions about asset price changes and the reference interest rate. However, the straight-line depreciation capital services seem to be consistently below the corresponding services generated by the other three classes of models.

Our conclusion at this point is that both the form of depreciation that is assumed (lightbulb, straight line, geometric, or linear efficiency decline) and the assumptions on interest rates and price expectations (perfect foresight, constant real rate, or anticipated capital gains) matter. This means it will be necessary for statistical agencies to introduce surveys to determine when assets are retired or sold, and it will be necessary for economists to decide what is the best set of assumptions concerning the nominal opportunity cost of capital and anticipated asset price changes.

\subsection{The Treatment of Intangible Assets}

Since this volume is primarily concerned with the treatment of intangible assets, we devote this section to indicating how the above treatment of tangible assets can be modified to deal with intangible assets.

Examples of expenditures on intangible assets are advertising and marketing expenses and research and development expenditures. Both of these categories of expenditures have the character that the present-period outlays will create incremental revenues in the future for the firm that undertakes them. These current-period expenditures on intangible assets have a different character from expenditures on tangible durable inputs, which can be used for a number of periods and then sold to other users. ${ }^{65}$ The problem in this section is to determine how to allocate the cost outlays on intangible investments over future periods. Thus, the accounting problems in the present section have a different character from that of the previous sections, where a straightforward opportunity cost approach was used. In the present section, the approach taken is one of matching current costs with future expected revenues. ${ }^{66}$

To fix ideas, suppose that in period $t$, a firm has made expenditures on creating an intangible asset, which are equal to $C^{t}$ :

$$
C^{t} \equiv \sum_{m=1}^{M} P_{m}^{t} Q_{m}^{t},
$$

where $P_{m}^{t}$ is the period- $t$ price for the $m$ th type of input that is used to create the intangible asset and $Q_{m}^{t}$ is the corresponding quantity purchased.

65. In many cases, the stream of future revenues created by an intangible investment can be sold on the marketplace (e.g., patents, trademarks, and franchises), but this still does not solve the problem of how to distribute the intangible investment costs over future periods.

66. Paton and Littleton $(1940,123)$ argued that the primary purpose of accounting is to match costs and revenues. For an excellent early discussion on the importance of matching costs to future revenues, see Church (1917, p. 193). 
These expenditures in period $t$ are expected to generate a future stream of incremental revenues for the firm. Let $R_{0}^{t}$ denote the immediate period- $t$ incremental revenues (which could be zero), and let $R_{n}^{t}$ denote the incremental revenues that the period- $t$ expenditures $C^{t}$ are expected to generate $n$ periods from the present period $t$, for $n=1,2, \ldots$ Let $r^{t}$ be the (nominal) period- $t$ opportunity cost of financial capital. ${ }^{67}$ Then the discounted value of these expected incremental revenues is

$$
R^{t} \equiv R_{0}^{t}+\frac{R_{1}^{t}}{1+r^{t}}+\frac{R_{2}^{t}}{\left(1+r^{t}\right)^{2}}+\frac{R_{3}^{t}}{\left(1+r^{t}\right)^{3}}+\ldots
$$

The problem is to allocate the current-period cost $C^{t}$ over future periods. Thus, let $C_{n}^{t}$ be the allocation of $C^{t}$ to the accounting period that is $n$ periods after period $t$ for $n=0,1,2, \ldots$. At first sight, it seems reasonable that these future cost allocations $C_{n}^{t}$ should sum to $C^{t}$. However, this turns out not to be so reasonable: costs that are postponed to future periods must be escalated by the (nominal) interest rate $r^{t}$, so that the present value of discounted future costs is equal to the actual period- $t$ costs $C^{t}$. Thus, the intertemporal cost allocations $\mathrm{C}_{n}^{t}$ should satisfy the following equation:

$$
C^{t}=C_{0}^{t}+\frac{C_{1}^{t}}{1+r^{t}}+\frac{C_{2}^{t}}{\left(1+r^{t}\right)^{2}}+\frac{C_{3}^{t}}{\left(1+r^{t}\right)^{3}}+\ldots
$$

To see why discounting is necessary, consider the following simple example where we invest $C^{t}$ during the present period and anticipate the revenue $R_{2}^{t}$ two periods from now. The expected discounted profits that this investment will generate are

$$
\Pi \equiv-C^{t}+\frac{R_{2}^{t}}{\left(1+r^{t}\right)^{2}} .
$$

The period-by-period cash flows for this project are $-C^{t}, 0, R_{2}^{t}$. We want to match the period $t \operatorname{cost} C^{t}$ with the period- $t+2$ revenue flows. Thus, we want to convert the cash flow stream $-C^{t}, 0, R_{2}^{t}$ into an equivalent cash flow stream $0,0,-C_{2}^{t}+R_{2}^{t}$. If we choose

$$
C_{2}^{t} \equiv C^{t}\left(1+r^{t}\right)^{2},
$$

then it can be seen that these two cash flow streams have the same present value and $C_{2}^{t}$ is the "right" period- $t+2$ cost allocation. Put another way, if we simply carried forward the period- $t$ costs $C^{t}$ and set $C_{2}^{t}$ equal to $C^{t}$, we would be neglecting the fact that the costs took place in period $t$ while the return on the investment was deferred until period $t+2$; hence, we need to charge the opportunity cost of financial capital for two periods on the initial investment (for two periods) until it is expensed in period $t+2$.

How should the intertemporal cost allocations $C_{n}^{t}$ be chosen? It is natu-

67. Thus, for simplicity, we are making assumption (4) in section 12.2. 
ral to make these cost allocations proportional to the corresponding period anticipated revenues. Thus, choose the number $\alpha$ so that the following equation is satisfied:

$$
C^{t}=\alpha R^{t}
$$

Thus we set the observed period- $t$ cost associated with the intangible investment $C^{t}$ equal to the constant $\alpha$ times the discounted value of the anticipated incremental revenue stream $R^{t}$ that the investment is expected to yield. ${ }^{68}$

Typically, $\alpha$ will be equal to or less than one, since otherwise the period$t$ intangible investment expenditures $C^{t}$ should not be undertaken. If $\alpha$ is less than one, then there will be an expected profit above the opportunity cost of capital, which could be some form of monopoly profit or a reward for risk taking.

Once $\alpha$ has been determined by solving equation (77), then the intertemporal cost allocations $C_{n}^{t}$ can be defined to be proportional to the corresponding anticipated incremental revenues $R_{n}^{t}$ for future periods:

$$
C_{n}^{t} \equiv \alpha R_{n}^{t} \quad n=0,1,2, \ldots
$$

At this point, it is possible to use the algebra developed in sections 12.2 and 12.3 above with some slight modifications. We can convert the nominal cost allocation factors $C_{n}^{t}$ into constant- (period- $t$ ) dollar cost allocations $f_{n}^{t}$ as follows:

$$
\begin{aligned}
f_{n}^{t} & \equiv \frac{C_{n}^{t}}{\left(1+\rho^{t}\right)^{n}} \quad n=0,1,2, \ldots \\
& =\frac{\alpha R_{n}^{t}}{\left(1+\rho^{t}\right)^{n}}
\end{aligned}
$$

where $\rho^{t}$ is the period- $t$ consumer price inflation rate, which is expected to persist into the future. ${ }^{69}$ The $f_{n}^{t}$ s defined by equations (79) are the counterparts to the period- $t$ cross-sectional rental prices that were defined in section 12.2. Once these intertemporal constant-dollar cost allocation factors $f_{n}^{t}$ have been defined by equations (79), we can use equations (5) in section 12.2 to define the sequence of constant-dollar asset values, ${ }^{70} P_{0}^{t}, P_{1}^{t}$, $P_{2}^{t}, \ldots$, except that the period- $t$ expected rate of asset price change $i^{t}$ in equations (5) is replaced by the CPI inflation rate $\rho^{t}$. If we then make use of equation (18), which expresses the nominal interest rate $r^{t}$ in terms of the

68. Of course, the practical problem that the national income accountant will face is how to estimate the future stream of incremental revenues.

69. This expectational assumption could be relaxed at the cost of more notational complexity.

70. Note that $P_{0}^{t}$ is equal to $C^{t}$. 
real rate $r^{* t}$ and the CPI inflation rate $\rho^{t}$, so that $1+r^{t}=\left(1+\rho^{t}\right)\left(1+r^{* t}\right)$, then equations (5) simplify to the following equations:

$$
\begin{aligned}
& C^{t}=P_{0}^{t}=f_{0}^{t}+\frac{f_{2}^{t}}{\left(1+r^{* t}\right)^{2}}+\frac{f_{3}^{t}}{\left(1+r^{* t}\right)^{3}}+\ldots \\
& P_{1}^{t}=f_{1}^{t}+\frac{f_{2}^{t}}{\left(1+r^{* t}\right)^{2}}+\frac{f_{3}^{t}}{\left(1+r^{* t}\right)^{3}}+\ldots \\
& P_{2}^{t}=f_{2}^{t}+\frac{f_{2}^{t}}{\left(1+r^{* t}\right)^{2}}+\frac{f_{3}^{t}}{\left(1+r^{* t}\right)^{3}}+\ldots
\end{aligned}
$$

The sequence of constant-dollar "asset" values $C^{t}=P_{0}^{t}, P_{1}^{t}, P_{1}^{t}, \ldots$ shows how the period- $t$ intangible investment can be written down over time in constant period- $t$ dollars, and equations (10) and (12) in section 12.3 show how a sequence of constant-dollar depreciation rates $\delta_{n}^{t}$ for the intangible investment can be obtained from the sequence of constantdollar "asset" values, $P_{n}^{t}{ }^{71}$ These depreciation rates $\delta_{n}^{t}$ can also be applied to the investment components $Q_{m}^{t}$ to form estimated constant-dollar input stocks for the intangible investments. ${ }^{72}$ Thus, the assumptions made about the shape of the anticipated future period incremental revenues generated by the intangible investment, ${ }^{73}$ along with the matching of costs to revenues methodology, determine the pattern of depreciation that can be used to write down these costs associated with the intangible investment over time. ${ }^{74}$

The period- $t$ beginning-of-period and end-of-period user cost charges, $f_{0}^{t}$ and $u_{0}^{t}$ respectively, for the intangible investment have the following forms:

$$
\begin{aligned}
f_{0}^{t} & \equiv P_{0}^{t}-\left(\frac{1+\rho^{t}}{1+r^{t}}\right) P_{1}^{t} \\
& =P_{0}^{t}-\frac{P_{1}^{t}}{1+r^{* t}} \\
& =\frac{P_{0}^{t} r^{* t}+D_{0}^{t}}{1+r^{* t}},
\end{aligned}
$$

71. If the assumptions on the anticipated (real) incremental revenues are such that the $f_{n}^{t}$ decline at the geometric depreciation rate $\delta$, then this rate will carry over to $P_{n}^{t}$; that is, we will have $p_{n}^{t}=(1-\delta)^{n} C^{t}$ for $n=0,1,2, \ldots$ if $f_{n}^{t}=(1-\delta)^{n} f_{0}^{t}$ for $n=1,2, \ldots$

72. It is not necessary for the statistical agency to do this, but some users will be interested in the resulting $M$ asset stocks that form capital stock aggregates of the $Q_{m}^{t}$. Normal index number theory can be used to aggregate these $M$ stock components into an overall capital stock aggregate using the period- $t$ flow prices $P_{m}^{t}$ as price weights.

73. Thus the specific depreciation models presented in sections $12.7-12.10$ can be adapted to the present context.

74. It should be noted that the obsolescence problems discussed in section 12.5 do not occur in the present context because the asset inflation rate and the CPI inflation rate coincide. 


$$
\begin{aligned}
u_{0}^{t} & \equiv P_{0}^{t}\left(1+r^{t}\right)-\left(1+\rho^{t}\right) P_{1}^{t} \\
& =\left(1+\rho^{t}\right)\left[P_{0}^{t} r^{* t}+D_{1}^{t}\right]
\end{aligned}
$$

These two formulas show that the period- $t$ "user costs" for the intangible investment do not consist solely of a depreciation charge, $D_{0}^{t}$ : there are also real interest rate charges that must be added to the depreciation term.

It should be noted that the cost allocation model outlined above can be applied to other forms of "assets"; namely, deferred charges, prepaid expenses, ${ }^{75}$ and transfer fees when a reproducible asset is acquired. The onehoss-shay form of revenue matching is probably the preferred method for dealing with this type of "asset."

\subsection{Conclusion}

We have considered the problems involved in constructing price and quantity measures for both the capital stock and the flow of services yielded by the stock in an inflationary environment. In order to accomplish these tasks, the statistician will have to make decisions in a number of dimensions:

- What length of life $L$ best describes the asset?

- What form of depreciation or asset efficiency is appropriate?

- What assumptions should be made about the reference interest rate and the treatment of anticipated asset price change?

In this paper, we focused on the last two questions. We considered four classes of depreciation or efficiency and three types of assumption on the nominal interest rate $r^{t}$ and on the anticipated asset rate of price change, $i^{t}$, giving twelve models in all. We evaluated these twelve models using aggregate Canadian data on two asset classes over the period 1926-99. We found that the assumptions on the form of depreciation or asset efficiency by age were less important than the assumptions made about the reference interest rate and the treatment of anticipated asset price changes. ${ }^{76}$

We consider the third question first. In order to answer this question, it is necessary to ask about the purpose for which the capital data will be used. For some purposes, it may be useful to use ex post asset price changes

\footnotetext{
However, obsolescence problems can still occur when technical progress causes expectations about future incremental revenues to be revised downward.

75. Hatfield (1927, p. 16) gives several examples of this type of asset, including insurance payments that apply to multiple accounting periods, the stripping away of surface rock for a strip mine, and prepaid expenses. Hatfield (p. 18) notes that this type of asset is different from the usual sort of tangible asset since this type of asset cannot readily be converted into cash; i.e., it has no opportunity cost value.

76. Harper, Berndt and Wood (1989) also found that differing assumptions on $r^{t}$ and $i^{t}$ made a big difference empirically using U.S. data. However, they considered only geometric depreciation. Our paper can be viewed as an extension of their work to consider also variations in the form of depreciation.
} 
as anticipated price changes. For example, this approach may be useful in constructing estimates of taxable business income if capital gains are taxable. It may also be useful if we want to evaluate the ex post efficiency of a firm, industry, or economy. However, for most other uses, assuming that anticipated price changes are equal to actual ex post price changes is very unsatisfactory since it is unlikely that producers could anticipate all of the random noise that seems to be inherent in series of actual ex post asset price changes. Moreover, this approach generates tremendous volatility in user costs, and statistical agencies would face credibility questions if this approach were used.

Thus, we restrict our attention to the choice between assuming a constant real interest rate or using smoothed ex post asset price changes as estimates of anticipated asset price changes. The assumption of constant real interest rates has a number of advantages:

- The resulting price and quantity series tend to be very smooth.

- The estimates are reproducible; that is, any statistician given the same basic price and quantity data along with an assumed real interest rate will be able to come up with the same aggregate price and quantity measures.

However, the use of smoothed ex post asset price changes as measures of anticipated asset price changes has some advantages as well:

- Longer-run trends in relative asset prices can be accommodated.

- The anticipated obsolescence phenomenon can be captured.

Each individual statistical agency will have to weigh the costs and benefits of the two approaches in order to decide which approach to use. I think that for most assets, it would be quite acceptable to use the constant real interest rate model, and this would maximize reproducibility. However, with assets that have experienced rapid technical progress, I would prefer to use the smoothed expectations model, since this model will better capture obsolescence effects. I would also use the smoothed expectations model for land, since over long periods land prices tend to appreciate faster than the general price level.

We now discuss which of our four sets of assumptions on the form of depreciation or vintage asset efficiency decline is best.

The one-hoss-shay model of efficiency decline, while seemingly a priori attractive, does not seem to work well empirically; that is, vintage depreciation rates tend to be much more accelerated than the rates implied by the one-hoss-shay model. If maintenance costs are linearly rising over time, a "gross" one-hoss-shay model gives rise to a linearly declining efficiency model, ${ }^{77}$ which of course is a model that exhibits very accelerated depreciation. 
The straight-line depreciation model, while not as inconsistent with the data as the one-hoss-shay model, also does not generate the pattern of accelerated depreciation that seems to characterize many used asset markets. However, given the simplicity of this model (to explain to the public), it could be used by statistical agencies.

The geometric depreciation model seems to be most consistent with the empirical studies on used assets of the four simple classes of model that we considered. ${ }^{78}$ Of course, geometric depreciation has the disadvantage that it will never exhaust the full value of the asset. ${ }^{79}$

Finally, a good alternative to the geometric depreciation model is the linear efficiency decline model. However, this model may have a pattern of "overaccelerated" depreciation relative to the geometric model. What is required is more empirical work so that the actual pattern of depreciation can be determined. In particular, statistical agencies need to consider establishing capital asset surveys, which would ask firms not only what assets they purchased during the reference period but also what assets they sold or scrapped during the reference period. ${ }^{80}$

We conclude by noting some limitations of the analysis presented in this paper:

- We have not dealt in great detail with the problems posed by unique assets, although the model presented in the previous section could be used.

- We have not dealt with the problems posed by assets that depreciate by use rather than by age. ${ }^{81}$

- We have neglected property taxes, income taxes, and insurance premiums as additional components of user costs.

- We have neglected the problems posed by indirect commodity taxes on investment goods; this complication can lead to differences between investment prices and asset stock prices.

- We have neglected many forms of capital in our empirical work including inventories, land, knowledge capital (except for our brief discussion in the previous section), resource stocks, and infrastructure capital.

- We have not discussed the many complexities involved in making quality adjustments for new types of capital.

- We have not discussed the problems posed by establishment deaths on

78. See Hulten and Wykoff (1981a,b) and Jorgenson (1996a).

79. Some statistical agencies solve this problem by "scrapping" the depreciated value of the asset when it reaches a certain age. This solves one problem but it introduces two additional problems: (a) the truncation age has to be decided upon and (b) the theoretical simplicity of the model is lost.

80. The survey should also ask for information on what the age and initial purchase prices of the sold or scrapped assets was.

81. Our reason for neglecting use is simple: usually, the national statistician will not have data on the use of machines available. 
asset lives and depreciation rates. We would expect asset lives to decrease during recessions, but we have not spelled out exactly how to adjust for this factor.

However, we have provided a fairly comprehensive review of most of the issues surrounding the measurement of capital, including a method for forming intangible capital stocks.

\section{References}

Babbage, C. 1835. On the economy of machinery and manufactures. 4th ed. London: Charles Knight.

Beidelman, C. 1973. Valuation of used capital assets. Sarasota, FL: American Accounting Association.

- 1976. Economic depreciation in a capital goods industry. National Tax Journal 29:379-90.

Böhm-Bawerk, E. V. 1891. The positive theory of capital. Trans. W. Smart. New York: G. E. Stechert. (Orig. pub. 1888.)

Canning, J. B. 1929. The economics of accountancy. New York: Ronald Press.

Christensen, L. R., and D. W. Jorgenson. 1969. The measurement of U.S. real capital input, 1929-1967. Review of Income and Wealth 15:293-320.

1973. Measuring the performance of the private sector of the U.S. economy, 1929-1969. In Measuring economic and social performance, ed. M. Moss, 233-351. New York: Columbia University Press.

Church, A. H. 1901. The proper distribution of establishment charges, parts I, II, and III. The Engineering Magazine 21:508-17, 725-34, 904-12.

1917. Manufacturing costs and accounts. New York: McGraw-Hill.

Daniels, M. B. 1933. The valuation of fixed assets. The Accounting Review 8:302-16.

Diewert, W. E. 1974. Intertemporal consumer theory and the demand for durables. Econometrica 42:497-516.

1976. Exact and superlative index numbers. Journal of Econometrics 4: $115-45$.

1978. Superlative index numbers and consistency in aggregation. Econometrica 46:883-900.

1980. Aggregation problems in the measurement of capital. In The measurement of capital, ed. D. Usher, 433-528. Chicago: University of Chicago Press.

1992a. Fisher ideal output, input, and productivity indexes revisited. Journal of Productivity Analysis 3:211-48.

1992b. The measurement of productivity. Bulletin of Economic Research 44:165-98.

2004. Measuring capital. Discussion Paper 04-10. University of British Columbia, Vancouver, Department of Economics.

Diewert, W. E., and K. J. Fox. 1999. Can measurement error explain the productivity paradox? Canadian Journal of Economics 32:251-80.

Diewert, W. E., and D. A. Lawrence. 2000. Progress in measuring the price and quantity of capital. In Econometrics and the cost of capital: Essays in honor of Dale W. Jorgenson, ed. L. J. Lau, 273-326. Cambridge: MIT Press. 
Edwards, E. O., and P. W. Bell. 1961. The theory and measurement of business income. Berkeley: University of California Press.

Epstein, L. G. 1977. Essays on the economics of uncertainty. PhD diss., University of British Columbia.

Fisher, I. 1896. Appreciation and interest. New York: Macmillan.

1908. Are savings income? Publications of the American Economic Association, Third Series, 9:21-47. 1922. The making of index numbers. London: Macmillan.

Fox, Kevin J., and Ulrich Kohli. 1998. GDP growth, terms-of-trade effects, and total factor productivity. Journal of International Trade and Economic Development 7:87-110.

Garcke, E., and J. M. Fells. 1893. Factory accounts: Their principles and practice. 4th ed. London: Crosby, Lockwood, and Son. (Orig. pub. 1887.)

Griliches, Z. 1963. Capital stock in investment functions: Some problems of concept and measurement. In Measurement in economics, ed. C. Christ, 115-37. Stanford, CA: Stanford University Press.

Hall, R. E. 1971. The measurement of quality change from vintage price data. In Price indexes and quality change, ed. Z. Griliches, 240-71. Cambridge, MA: Harvard University Press.

Harper, M. J., E. R. Berndt, and D. O. Wood. 1989. Rates of return and capital aggregation using alternative rental prices. In Technology and capital formation, ed. D. W. Jorgenson and R. Landau, 331-72. Cambridge: MIT Press.

Hatfield, H. R. 1927. Accounting: Its principles and problems. Lawrence, KS: Scholars Book Co.

Hicks, J. R. 1939. Value and capital. Oxford: Clarendon Press.

Hill, P. 1999. Capital stocks, capital services, and depreciation. Paper presented at the third meeting of the Canberra Group on Capital Stock Statistics. 8-10 November, Washington, DC.

- 2000. Economic depreciation and the SNA. Paper presented at the 26th Conference of the International Association for Research on Income and Wealth. 27 August-2 September, Cracow, Poland.

Hill, R. J., and T. P. Hill. 2003. Expectations, capital gains, and income. Economic Inquiry 41:607-19.

Hotelling, H. 1925. A general mathematical theory of depreciation. Journal of the American Statistical Association 20:340-53.

Hulten, C. R. 1990. The measurement of capital. In Fifty years of economic measurement, ed. E. R. Berndt and J. E. Triplett, 119-52. Chicago: University of Chicago Press.

. 1996. Capital and wealth in the revised SNA. In The new system of national accounts, ed. J. W. Kendrick, 149-81. New York: Kluwer Academic.

Hulten, C. R., and F. C. Wykoff. 1981a. The estimation of economic depreciation using vintage asset prices. Journal of Econometrics 15:367-96.

. 1981b. The measurement of economic depreciation. In Depreciation, inflation, and the taxation of income from capital, ed. C. R. Hulten, 81-125. Washington, DC: Urban Institute Press.

1996. Issues in the measurement of economic depreciation: Introductory remarks. Economic Inquiry 34:10-23.

Jorgenson, D. W. 1989. Capital as a factor of production. In Technology and capital formation, ed. D. W. Jorgenson and R. Landau, 1-35. Cambridge: MIT Press. . 1996a. Empirical studies of depreciation. Economic Inquiry 34:24-42. 1996b. Tax policy and the cost of capital. Vol. 2 of Investment. Cambridge: MIT Press. 
Jorgenson, D. W., and Z. Griliches. 1967. The explanation of productivity change. Review of Economic Studies 34:249-83.

1972. Issues in growth accounting: A reply to Edward F. Denison. Survey of Current Business 52 (May): 65-94.

Kohli, Ulrich. 1982. Production theory, technological change, and the demand for imports: Switzerland, 1948-1974. European Economic Review 18:369-86.

Maddison, A. 1993. Standardized estimates of fixed capital stock: A six country comparison. Innovazione e materie prime (April): 1-29.

Matheson, E. 1910. Depreciation of factories, mines, and industrial undertakings and their valuations. 4th ed. London: Spon. (Orig. pub. 1884.)

Organization for Economic Cooperation and Development (OECD). 1993. Methods used by OECD countries to measure stocks of fixed capital. National Accounts Sources and Methods no. 2. Paris: OECD.

Oulton, N. 1995. Depreciation, obsolescence, and the role of capital in growth accounting. Bulletin of Economic Research 47:21-33.

Paton, W. A., and A. C. Littleton. 1940. An introduction to corporate accounting standards. Chicago: American Accounting Association.

Pigou, A. C. 1924. The economics of welfare. 2nd ed. London: Macmillan.

1935. Net income and capital depletion. The Economic Journal 45:235-41.

Scott, M. 1995. Depreciation, obsolescence, and the role of capital in growth accounting: A reply to Oulton. Bulletin of Economic Research 47:35-38.

Schmalenbach, E. 1959. Dynamic accounting. Trans. G. W. Murphy and K. S. Most. London: Gee and Company. (Orig. pub. 1919.)

Schreyer, P. 2001. OECD productivity manual: A guide to the measurement of industry-level and aggregate productivity growth. Paris: OECD.

Solomons, D. 1968. The historical development of costing. In Studies in cost analysis, 3-49. Homewood, IL: Richard D. Irwin.

Triplett, J.E. 1996. Depreciation in production analysis and in income and wealth accounts: Resolution of an old debate. Economic Inquiry 34:93-115.

Walras, L. 1954. Elements of pure economics. Trans. W. Jaffé. Homewood, IL: Richard D. Irwin. (Orig. pub. 1874.)

Comment Frank C. Wykoff

\section{Introduction}

Capital measurement continues to confound us. Official national income accountants from around the world are in 2004 trying to develop a consistent and coherent set of procedures for measuring capital accounts. This paper by Diewert is a major marker in progress toward this end. This was no doubt in Diewert's thinking as he wrote the paper, ${ }^{1}$ and it should be read with this in mind, because portions are responses to specific analysts involved in the international accounting effort.

Frank C. Wykoff is the Eldon Smith Professor of Economics at Pomona College.

1. Even though this paper is from a 2002 National Bureau of Economic Research Conference on Research in Income and Wealth conference, revisions were ongoing in 2004. 


\section{Roadmap to the Diewert Paper}

Diewert constructs specific steps that statisticians and national income accountants can follow in generating capital accounts. His model is based on capital theory accounting and on index number theory. He does not impose any one set of values, asset lives, depreciation patterns, discount rate, or expected inflation on accountants. Instead, Diewert illustrates, with Canadian data, the consequences of twelve different sets of parameter and form assumptions for each capital aggregate. Diewert assesses the relative importance of different assumptions by comparing his results. This will assist national income accountants to allocate scarce research resources.

The paper has two parts. The first part develops an internally consistent model for measuring aggregate capital stock quantity and price indexes and indexes for flow measures of capital services (quantities) and user costs (shadow costs or service prices) from historical data on investment flows. Diewert provides a specific solution for the problem that accountants must solve in order to produce capital accounts, because data on capital aggregates are rarely available; only historical data on investment flows are. Diewert assumes that investment deflators are available so that investment expenditures can be decomposed into price and quantity components, and that these deflators and quantities are for "constant quality assets." The assumption of a preexisting quality change correction is a strong one.

The Diewert model seems to derive from the Hall and Jorgenson (1967), Hall (1968, 1971), Jorgenson (1974), and Hulten (1990) neoclassical model of capital. ${ }^{2}$ The Diewert model is different in some important respects, though. I will comment on the differences in some detail.

Diewert provides a recipe for constructing capital aggregates. This contribution alone means that every national income accountant in the world should have this paper at their fingertips as they design their accounts. While the final capital accounting model that world national income accountants adopt may differ from the Diewert model, it should be close enough to make this paper a guidepost.

Diewert explains the algebraic relationships between asset prices, user costs, real and nominal rates of return, depreciation, revaluation, and inflation required in a coherent economic model of capital. He shows exactly how to use these relationships to construct capital aggregates from investment flow data. He also uses the model to critique several alternative approaches to capital accounting.

Second, Diewert applies his model to Canadian investment expenditures on two asset classes, machinery and equipment, and nonresidential

2. In this paper I am giving my interpretation of the HJH model. Hall, Jorgenson, and Hulten may have different understandings than mine, so any errors in presenting the model are mine, not theirs. I may be doing a disservice to Diewert and to Hall, Jorgenson, and Hulten pitting my view of $\mathrm{HJH}$ against Diewert. Still, I find this a useful deus ex machina. 


\begin{tabular}{lccc}
$\delta$-model $\backslash(\mathrm{r}, \pi)$-model & $\pi_{j}^{e}=\pi_{j}$ & $\mathrm{r}^{*}=4 \% \pi_{j}^{e}=\pi$ & $\pi_{j}^{e}=\pi_{j}^{s}$ \\
\hline$\varphi(\mathrm{s})=1$ & $\mathrm{~s} \leq \mathrm{L}$ & \\
$\delta(\mathrm{s})=1 / \mathrm{L}$ & $\mathrm{s} \leq \mathrm{L}$ & \\
$\delta(\mathrm{s})=\delta_{0}$ & $\mathrm{~s}$ & \\
$\varphi(\mathrm{s})=1 / \mathrm{L}$ & $\mathrm{s} \leq \mathrm{L}$ &
\end{tabular}

Fig. 12C.1 Diewart's twelve sets of assumptions

structures, from 1926 to 1999 . With these data he is able to construct capital aggregates for 1965 to 1999 . He assesses the consequences for each capital aggregate of the twelve different sets of assumptions.

The twelve assumptions are illustrated in the $4 \times 3$ array, figure 12C.1. Each row is one of four depreciation patterns - the one-hoss-shay efficiency function, linear depreciation pattern, geometric depreciation pattern, and linear-declining efficiency function. ${ }^{3}$ Each of the three columns is one of three expected asset-specific price changes and rates of returnperfect foresight, constant real rate of 4 percent, and an expected assetspecific price change equal to a smoothed ex post rate of asset-specific price change. ${ }^{4}$ The result is twelve pairs of different assumptions about two unknowns for which he produces each of the four capital aggregates. He then compares the different aggregate values and the stability over time of the aggregates. While both depreciation patterns and interest/expected inflation rates matter, differences associated with the latter are bigger. Finally, Diewert provides his own preferred pair of assumptions.

\section{The Hall-Jorgenson-Hulten Model}

To understand the Diewert model it helps to show how it differs from the Hall-Jorgenson-Hulten (HJH) model. Start with an age-time asset-price tableau in figure 12C.2. Each cell contains the acquisition price of an asset. ${ }^{5}$ The age of the asset is indexed from top to bottom starting with a new asset age 0 , down to ages $1,2,3, \ldots$. The year in which the asset is priced is indexed along the top left to right from year 1998 to 1999, 2000, 2001, ... . If we track the prices down a diagonal, we track the history or life experience of a particular asset. Down the principal diagonal we trace the life experience of a new, 1998 asset, $q(0,1998), q(1,1999), q(2,2000), \ldots$.

3. The difference between depreciation patterns and efficiency function patterns is explained by Diewert and by Hulten (1990). See also Wykoff (2002).

4. Diewert assesses several other assumptions but ends up comparing these twelve.

5. While I use the term "asset" here, when applied to actual data, each cell of the tableau will contain the average price of a cohort (given age and time) of assets. The capital theory model is virtually never applied to data on a single asset. It is ordinarily used to decompose expenditures on a cohort of heterogeneous assets. This has important implications for assessing different depreciation patterns for empirical work. 


\begin{tabular}{cccccc} 
Age $\downarrow$ & Year $\rightarrow$ & & & \\
\hline & 1998 & 1999 & 2000 & 2001 & 2002 \\
\hline 0 & $q(0,1998)$ & $q(0,1999)$ & $q(0,2000)$ & $q(0,2001)$ & $q(0,2002)$ \\
1 & $q(1,1998)$ & $q(1,1999)$ & $q(1,2000)$ & $q(1,2001)$ & \\
2 & $q(2,1998)$ & $q(2,1999)$ & $q(2,2000)$ & $q(2,2001)$ & \\
3 & $q(3,1998)$ & & & $q(3,2001)$ & \\
4 & $q(4,1998)$ & & & & $q(4,2002)$
\end{tabular}

Fig. 12C.2 Age-year price tableau

While the phrase "acquisition price" allows us to abstract in principle from whether the asset is actually marketed or not, the price is the equivalent of an explicit purchase price in a competitive market that one would pay to acquire one unit of the asset. To allow for the fact that most assets are not marketed once they are put into productive use, we may refer to this as the "shadow" or "acquisition" price. In any case, the four-row 2002column cell contains the (shadow) market price of "purchasing" one unit of a four-year-old asset in 2002.

The price tableau suggests one can disentangle forces operating on markets that cause changes in an asset's price as it moves down a diagonal over the course of its life. In a world without any changes in technology, perhaps Egypt for 3,000 years, this may be a relatively easy task. Hall (1968, 1971), however, wanted to analyze the implications of technological change on asset prices. Clearly, today technological change has been occurring in a lot of asset classes, and these changes influence the prices in figure 12C.2, so learning about technological change and capital is clearly an important goal.

A major insight of Hall's (1968) analysis was to recognize an identification impossibility. Let $s$ index age and let $t$ index time, so that $q(s, t)$ is the price of an age- $s$ asset in year $t$. Hall defines vintage to be the difference between time and age:

$$
v \equiv t-s
$$

Three types of effects influence the price of an asset throughout its history - vintage effects, age effects, and time effects. Equation (1) means that once we specify two of the three effects, the third is well defined by equation (1). In other words, 2 degrees of freedom do not allow identification of three unknowns. Hall's Impossibility Theorem is that an analyst can only identify two of the three terms from a price tableau. This theorem implies an important econometric constraint.

By definition, assume all forces influencing an asset's price throughout its life fall into one of the three categories: age, vintage, and time. Any effect on price is either age specific, vintage specific, or time specific. Because 
these are subtle distinctions often muddled in the literature, we explore each effect below.

\section{Age Effects}

We want to compare older to newer assets while holding vintage and time fixed. Assume away all vintage effects and compare assets of different ages at the same time. For example, suppose the asset is a 1-liter Egyptian water pot whose design never changes. In any time period, pots of different ages coexist. ${ }^{6}$ Some are new, some are a year old, and some are 100 years old. Would all pots have the same price? If not, what, in a competitive market, would cause their prices to differ?

Unless these pots are perpetuities, like the biblical widow's cruse, they are eventually going to stop holding liquids. Their lives are finite. An old pot, having delivered services for a long time, is closer to the end of life, so a market will price it below a newer pot. ${ }^{7}$ The old one simply retains less productive capacity. Triplett (1996), Griliches (cited in Triplett 1996), and Feldstein and Rothschild (1974) call this effect "exhaustion."

It is also possible that the in-use efficiency of the asset, even a simple pot, declines with age and use during its life. It may slowly wear out and thin out, so that water in a ten-year-old pot may evaporate more quickly, or the pot may spring a hairline fracture that leaks a bit, or it may become discolored and less attractive. Decline of in-use productive efficiency, which means a decline in marginal product, is called "decay." Note that decay and exhaustion are physical concepts. Obviously a lot of assets decay —old cars have lost some of their get-up-and-go, old computers become sluggish. When old, a machine may break down and need repairs - a pot might be patched up. This too is decay - the probability of breakdown rises, the likelihood of downtime increases, more frequent repairs are costly, and replacement parts become scarcer. Because of exhaustion and physical decay, old machines have lower prices than new machines. This price effect is called "deterioration."

\section{Vintage Effects}

Vintage effects cannot be illustrated with identical Egyptian pots. Consider instead French wines. Each specific year that a new wine is extracted from French grapes is a "vintage." Vintage does not just refer to year $t$ but to a specific date-2001. People do not pay vastly different prices for fiveversus six-year-old wines, but they do pay very different prices for superb

6. I use discrete time in this analysis. Hall (1968) worked in continuous time. Discrete time avoids the calculus but can result in (relatively uninteresting) complexities like beginning or end of the period and lumpy versus marginal changes.

7. This effect obviously is related to intensity of use. Rental agency cars are used up a lot faster than the car driven by the little old lady in Pasadena. The model can easily allow for this. In fact, age is really only a proxy here for intensity of use. Applying this distinction to data is harder. 
versus poor vintages. It is not that the wine is sold in a particular year. It is the specific vintage when the grapes ripened on the vines that matters to wine connoisseurs. ${ }^{8}$ The key is that each vintage is inherently uniquequality is embodied in the vintage wine. Furthermore, the quality of a superior vintage cannot be added on, embedded in, or retrofitted to a poorer vintage. Like wine, different vintages of machine can be different, and these differences may be embodied in the new machine and not available to the old. I define vintage effects so that they can only occur if technological change is embodied in new capital. There are several tricky points in transferring the vintage concept from wines to machines.

First, a vintage effect is different from a passage-of-time effect. A vintage effect is a difference between two assets; a time effect is a change in assets between two periods. While for wines vintage differences occur coincidentally with changes in time, this is not true for machines. In any given year or date, different kinds of a particular machine can be produced at the same time. This is not possible with wines, because the vintners define all wines produced in year $v$ to be vintage- $v$ wine. With capital, however, some new machines may embody new technologies and some may not.

Automobile producers, for instance, gradually adopt new technologies: automatic shift, power steering, air conditioning, safety air bags, radial tires, and navigation systems are all technological innovations that were at first embodied in a few top-of-the-line models of new cars. Eventually, successful innovations become standard equipment embodied in almost all cars. Consequently, while this is not true of wines, machines are often produced in any given year with a variety of the new technologies embodied in themthese are different "models." For this reason, the very concept of "vintage" capital becomes ambiguous compared to vintage wine. Most stocks of new assets are heterogeneous, creating conceptual and practical measurement difficulties, but heterogeneity also offers research opportunities.

Heterogeneity complicates the model in which a well-defined asset is being priced in the age-time tableau. How much and what types of heterogeneity do we allow in such a tableau? At first one might restrict the analysis to a homogeneous good, like the Egyptian pot or a single 75-watt light bulb, but this rules out technological change and vintage effects de facto. In theory we can imagine investment flows reflecting acquisition of only new vintages each year, but in applying the model to data we will have to contend with the reality that new assets in each year are heterogeneous. ${ }^{9}$

Do we apply the HJH model only to one simple 60-watt light bulb? Do

8. Exactly why this is true is controversial. Wine judges talk about mystical forces, like a vintner's wife having a new baby or lightning striking some oak trees, but different quality vintages more likely reflect weather conditions, especially timely rainfall and sunlight. See Ashenfelter, Ashman, and LaLonde (1995).

9. Heterogeneity of new production raises another difficult issue - heterogeneity of consumers and sorting could create serious identification problems with hedonic methods. This problem challenges the representative consumer model. 
we apply the model to only four-door sedan Chevrolets with standard features that never change? Do we apply the model to all laptop computers? When a new innovation comes on the scene, do we treat it as a new vintage even if many new assets do not embody the new innovation? More research is needed to answer these questions, and some problems only become evident when one applies the model to data.

I would make several points, though. First, unless we allow for heterogeneity of new assets when technological change occurs, we cannot, as Hall has shown, ever hope to identify vintage, age, and time effects. For example, price hedonic techniques, a widely used procedure in this literature, can only help us dig deeper into identification if new assets at a point in time are heterogeneous. ${ }^{10}$ Second, we must have heterogeneity in a price tableau if we want to estimate the consequences of embodied technological change. Third, once we allow for differences in technology embedded in different assets, we encounter the problem that our tableau is somehow defined for an arbitrarily defined set of assets. A closely related problem here is the definition of one unit of the asset. Consider the simplest example of a quality change - what does it mean to say we are pricing one box of crackers if a new box contains twice the crackers of an old box? How do we define one computer if a new one has twice the capacity along every dimension?

One way out of this conundrum would be to assume that assets, even with different technologies, are the same good if they are producing the same output, as long as we adjust for changes in productive capacity. We can identify asset quantities in equivalency units based on the output measure of each machine. A box with twice the crackers is equivalent to two of the smaller boxes. Even here we encounter problems, because some changes embodied in new goods permit qualitatively different kinds of output. For example, a four-wheel-drive SUV is still an SUV, but it can drive in off-road places where a two-wheel-drive SUV cannot. Furthermore, an SUV is still a car, even if it differs in some dimensions from other cars. A cell phone embodied with a computer or digital camera is still a cell phone, but it also allows one to take and view pictures. In principle the HJH model provides a coherent method for specifying units in terms of "vintageequivalents." Still, the model does not clearly draw the line between old

10. Hedonics encounters another problem from heterogeneity and identification of new technologies or "better" vintages. Faster processors in computers ordinarily are better processors, and faster processors are developed over time. For complex assets, though, some features are traded off in design. For example, heavier cars are safer cars, implying that weight increases improve quality. Lighter cars are more fuel efficient, lowering operating costs. This implies that weight reduces quality. This creates ambiguity in assessing the contribution of weight to "vintage" changes among periods. The example of changing prices of gasoline influencing the vintage effects raises complicated questions about capital aggregation. Many characteristics may be traded off, so that a change over time may be an embodied technological improvement in one period and yet be a lower quality effect in another. 
goods (cell phones and cameras) and an entirely new good (a cell phone with camera) or quality change of the old good (a cell phone with camera).

The idea of vintage machines here is that if two assets that are the same age in the same time period can embody different technologies, then they are different vintages. We could think of new, 2004 computers, with different RAM, different processors, different pixels per square inch, and so on. If we insist on asserting that all of these are just different assets instead of different vintages of the same asset, then we cannot proceed to analyze vintage effects for a class of assets. Vintages of processors are well defined-a Pentium I, II, III, and IV, for example. Vintages of RAM may be harder to specify, but the idea of "more" is still there.

Acknowledging practical ambiguities and problems, the key to vintage effects in this model is that new technology is embodied in a new vintage that remains unavailable to older vintages. For convenience I am going to assume that new vintages are superior to old. (This is obviously wrong for wines and may be wrong for some assets as well. For example, suppose critical components or resources, like black walnut, become unavailable. New furniture may not be as good as old.) $)^{11}$

What are the consequences of technological innovations in superior vintages for other new assets that do not have the superior features? The older vintages, while not aged by definition and with unchanged marginal products, will in a competitive market suffer a price decline. In the HJH model this price decline is "obsolescence." This definition of obsolescence depends only on vintage differences and does not result, strictly speaking, from the passage of time. I will explain that Diewert approaches many of these problems differently from $\mathrm{HJH}$.

\section{Time Effects}

Now consider time effects. Time effects are all effects that occur between periods that do not reflect aging and are not specific to vintage. Following $\mathrm{HJH}$, time effects result in "capital gains (losses)." One might ask, why isolate vintage from time effects? After all, as a general rule, new vintages of capital are adopted over time. Isn't isolation of vintage effects arbitrary? The answer has to do with the purpose for these models in the first place. An important issue in economics concerns specification of the capital input in production and the effects of technological change on the production function. For example, Solow (1970) modeled the vintage production function to show how growth models could account for embodied technological change. Isolation of vintage effects in this model and identifying "obsolescence" as resulting from vintage effects allows us to study the consequences of embodied technological change.

In any case, time change generates many effects besides aging and vin-

11. See also caveats in notes 8 and 9 . 
tage. Excluding age and vintage effects, it seems immediately clear that there are two very distinct types of price changes that occur between periods. First is a change in the value of the numeraire (the unit of accountthe dollar, yen, or euro). This effect is "inflation." By definition, inflation is a change in the unit of account that leaves relative prices unchanged.

Most economists would acknowledge that the classical dichotomychanges in output and other real variables are independent of the price level and other nominal variables - applies in the long run. Thus, defining velocity, $V$, as $P Q / M$ where $P$ is the price level, $Q$ is real output, and $M$ is the quantity of money, most economists would agree that in the long run

$$
d M=\alpha+\pi+d Q,
$$

where $d M$ is the time rate of change in the nominal money supply, $\alpha$ is a constant (reflecting secular trend changes in velocity), $\pi$ is the rate of inflation, and $d Q$ is the change in output. Holding $Q$ constant, then, equation (2) implies

$$
d m \equiv d M-\pi=\alpha .
$$

The change in the real money supply equals the rate of change in velocity. If velocity is a constant, then in the static long run, no change in output, inflation equals the growth rate of the money supply so that the real money supply is constant. This model implies that the sole cause of inflation is growth in the nominal money supply. Even if this is not the case, inflation is a monetary phenomenon, unrelated intellectually to relative changes in prices. As such, inflation is a distinct phenomenon.

The second set of forces in the capital gains (losses) term is relative price changes that reflect changes in either demand for or supply of the capital good, excluding vintage and age effects. Capital goods are inputs, and so their demands are derived demands. For example, suppose a new substitute for gasoline comes on line. Oil tankers are a capital input to gasoline production, and oil tanker prices, ceteris paribus, will fall. The vintage of the oil tanker is not relevant, unless a new vintage embodies unique technology that accommodates the new energy substitute. All oil tankers will fall in price. This effect, in the absence of embodied technological differences, would leave asset prices relative to age or vintage unchanged.

Changes in prices or technology of complements can have complicated effects over time on capital goods. Consider a laptop computer. Software is a complement in production to a laptop computer. Suppose new software is introduced for which old laptops are ill suited. This is a change in technology, not of the computer but of the software complement to the computer. Such a change in HJH results in obsolescence of earlier vintages of software, because the change is embodied in the new software. If no change has been embodied in the new computer, then the new software will 
have the same effect on new and old capital. It will not, however, make the old asset obsolete relative to the new vintage.

For new software to render an old computer worth less relative to a new one-that is, to have nonproportional effects on different vintages of capital-the new software must be accompanied by some innovation embodied in the new computer. ${ }^{12}$ If new computers are different, then this effect is captured by our definition of obsolescence, because it is vintage specific. If new technology is not embodied in a new asset, demand for the old asset relative to the new asset will not change its relative price. ${ }^{13}$ This means that software innovations are not changes in computer depreciation per se.

We have now defined age, vintage, and time effects on productive capacity of assets. We define deterioration, obsolescence, and capital gain (loss) as the price changes that result from each of these respective physical effects. We are now prepared to see, using figure 12C.2, how these combine to influence the price during the life of an asset. In figure 12C.2 in one year the price of an asset moves down the diagonal one cell. The total price change is

$$
\Delta q(s, t) \equiv[q(s+1, t+1)-q(s, t)] .
$$

The figure suggests we can decompose this total price change into two steps: (a) a vertical move down one column, $(q[s, t]-q[s+1, t])$, and (b) a horizontal move across one row from left to right, $(q[s+1, t+1]-q[s+1$, $t])$.

"Depreciation," as defined in the HJH model, is the vertical move down a column of an age-time tableau. "Revaluation" is the horizontal move from left to right across a row. The total price change is depreciation minus revaluation:

$$
\Delta q(s, t)=[q(s, t)-q(s+1, t)]-[q(s+1, t+1)-q(s+1, t)] .
$$

Decomposing the diagonal move into two steps, depreciation and revaluation, is not enough to identify three effects, age, vintage, and time. Depreciation is

$$
\left.\frac{\Delta q}{\Delta s}\right|_{\Delta t=0} \equiv[q(s+1, t)-q(s, t)] .
$$

Equation (6) advances the age index while holding the time index constant, so by equation (1) the vintage index is also advanced. The price

12. Feenstra and Knittel (2004) develop an innovative model in which expectations can cause consumers to purchase more computer capacity than they need in anticipation of future software developments. Analyzing synergies among software, hardware, and expectations by Feenstra and Knittel suggests an important area of new research.

13. I argue below that this distinction has important implications for the definition of depreciation. 
change we track down the vertical involves a one-year-old asset that is a one-year-earlier vintage. Depreciation is the sum of deterioration resulting from age (exhaustion and decay) plus obsolescence resulting from vintage effects (embodied technological change).

Revaluation is

$$
\left.\frac{\Delta q}{\Delta t}\right|_{\Delta s=0} \equiv[q(s+1, t+1)-q(s+1, t)] .
$$

By this definition, revaluation advances the time index and not the age index, so by equation (1) the price change we track from left to right is to an asset one year later and a one-year-newer vintage. Revaluation is the sum of obsolescence (embodied technological change) plus capital gain or loss (inflation and shifts in supply and demand). Both depreciation and revaluation are polluted by vintage effects. ${ }^{14}$

\section{Analysis of the Diewert Model}

The HJH model helps to clarify the Diewert model. First, the prices in figure 12C.2 are not the prices Diewert uses. Figure 12C.2 prices are market "shadow" prices, without adjustments, of one unit of an asset in the relevant cell. Diewert assumes that the prices in the tableau have already been modified by statisticians to remove quality differences, so a Diewert cell would contain prices of a "constant-quality" asset. A statistical agency is assumed to have already solved the problem of extracting price changes due to quality change from market prices to produce a series of prices (or a price index) of a constant-quality capital good. For example, the Diewert tableau prices Egyptian pots or computers that, like Egyptian pots, are identical. This strikes me as a strong assumption for a model intended to estimate depreciation. In particular, if capital goods' prices are corrected for quality change, then vintage effects are assumed away, but it seems to me that vintage effects have to drop from the analysis and are not known a priori.

Nonetheless, making such corrections to investment flow data is common practice in statistical agencies. Diewert, who works with statistical agencies worldwide, is making an assumption that his principal target audience, statistical agency economists, finds natural. The advantage to the assumption is that Diewert can later define an explicit term, $i^{*}$, for changes in asset prices between periods to capture effects that drive used asset prices down. Diewert calls this effect "obsolescence." This differs from my definition of obsolescence as a pure vintage effect.

14. Hall (1971) shows how to use hedonics to isolate obsolescence. I apply Hall's model in Wykoff (2002) to show how to extract the obsolescence component of depreciation from the revaluation term. 
Next Diewert defines two possible concepts of depreciation. Neither one is the definition from the HJH model. Diewert defines "cross-section depreciation" to be the changes in prices moving down a vertical in a Diewert price tableau. Because he has assumed away vintage effects, his "crosssection depreciation" corresponds to "deterioration" in the HJH model. Recall that deterioration was the decline in price from aging, holding both the vintage and time indexes constant, leaving two forces that change asset quantities: exhaustion and in-use decay. ${ }^{15}$ Diewert defines "time series depreciation" to be movements along the diagonal in his quality-corrected price tableau. ${ }^{16}$

It turns out that Diewert pits his two definitions of depreciation against one another, arguing that time series depreciation is vitiated by two types of time effects - inflation and "asset-specific price changes." He points out that one must strip inflation out of time series depreciation. Diewert also distinguishes ex ante from ex post time series depreciation. While this at first struck me as an unnecessary complication, it turns out that Diewert makes it because some accountants, using time series depreciation, think only ex ante asset-specific price changes should be included with deterioration in capital measures. This is why it is important to realize that this paper is addressing national and international agency accountants at this time. Ultimately his position on these two concepts of depreciation is that the correct concept should consist of "cross-section depreciation" plus ex ante asset-specific price increases, corrected for inflation expectations, that imply a fall in used asset prices relative to new ones. He calls this assetspecific intertemporal effect excluding deterioration "obsolescence."

Diewert argues that his concept of obsolescence is broader than the $\mathrm{HJH}$ concept, because $i^{*}$ allows for asset-specific, real price effects between periods in addition to vintage effects. That is, Diewert argues that his concept of obsolescence is broader than price changes caused by capital-embodied technological changes. In the language of the HJH model, Diewert defines depreciation to allow for deterioration, obsolescence, and inflationcorrected capital gain (loss). Recall that capital gain (loss) consists of real time effects on asset-specific prices apart from vintage effects.

15. In contrast to Diewert here, Dunn et al. (2004) in estimating depreciation of personal computers rule out in-use decay a priori, so if they were to use quality-adjusted prices their depreciation would only allow for exhaustion. They report very large estimated obsolescence effects.

16. Things tend to get very cloudy here, in part because Diewert is so thorough, perhaps to a fault. He allows in his model for interest rates to vary, for differences between beginningand end-of-period user costs, nominal asset-specific inflation, and real asset-specific inflation. He also allows for ex ante and ex post time series depreciation. He may know that some readers need these concepts spelled out, but I find they clutter the analysis. Diewert can work through the thicket himself, but I think some simplification by ignoring a few issues like beginning- and end-of-period user costs, varying interest rates with term structures, and so forth would clarify the exposition. However, in the context of the debate in 2004 among world national income accountants, Diewert obviously felt these details were necessary. 
Evidently, Diewert's distinction between ex ante and ex post obsolescence is the difference between expected and realized inflation. If one is going to distinguish ex ante from ex post inflation, why not distinguish ex ante from ex post technological change? ${ }^{17}$

I am not sure depreciation deductions should cover real asset-specific time effects. I think depreciation should consist only of deterioration plus obsolescence as defined in $\mathrm{HJH}$. The reason for this is subtle but worth discussion. In addition to deterioration, only vintage-specific changes cause prices of old assets to fall relative to new ones. All other time changes in supply of or demand for assets will influence new and old assets proportionally and leave depreciation rates unchanged.

This point is arguable. My view is this: capital goods are inputs, and thus their demands are derived from production processes. A shock to the market for a capital input only alters the relative prices of different versions of the inputs, if different vintages embody different technologies. A new software "killer application" changes old relative to new asset prices (depreciation) only if the new computer embodies a technological innovation that can exploit the killer application. ${ }^{18}$ This capital-embodied innovation is a pure vintage effect captured by the "narrow" definition of obsolescence.

There is one more important difference between Diewert and HJH. The conversion of historical investment flows into capital aggregates is usually thought of as a problem of choosing weights, $\omega_{i}$, in the following equation:

$$
K_{t}=\sum_{i=1}^{i=L} \omega_{i} I_{t-i}
$$

$K$ is capital, $I$ investment corrected for inflation, and $L$ the life of the oldest asset. The HJH analysis produces estimates of weights, $\omega_{i}$, of past investment flows in determining the period- $t$ capital aggregates like equation (8) for the stock of capital. The quantity weights are relative productive capacities (estimated from relative asset prices based on duality) in measuring the capital stock and relative efficiencies (estimated from relative user costs based on duality) for capital services.

Diewert says that equation (8) arbitrarily imposes linear aggregation. He assumes, after constructing individual price and quantity indexes, that he still has the problem of decomposing capital aggregates into price and quantity components. He assumes that nominal capital aggregates in each period - say, $N_{t}$ for the nominal capital stock - are some function, or index, of his price and quantity indexes, so that

17. Admittedly, this would be much more complex and require more than an inflationforecasting model. It would require a formal expectations-generating model, such as rational expectations, of both economics and technological change.

18. The working paper by White et al. (2004) is an excellent illustration of the complexities involved in constructing price indexes from hedonics when synergies are occurring between capital innovations, software innovations, and marketing innovations. 


$$
N_{t}=P\left[p_{1}, p_{2}, \ldots, p_{L}\right] Q\left[q_{1}, q_{2}, \ldots, q_{L}\right] .
$$

Diewert uses index number theory to construct aggregate price, quantity, user costs, and services indexes. Diewert appears to be basing this analysis of designing capital accounts in part on utility theory. This may help explain why his model differs from $\mathrm{HJH}$, which is based on neoclassical capital theory.

\section{Conclusion}

Diewert has designed a solution to an important problem now confronting world national income accountants - how to construct capital accounts from historical investment flow data. While unique in some respects, Diewert's model is built on solid economic theory and provides a defensible solution to virtually all practical problems the accountants will encounter. Diewert has identified the information required to construct capital accounts. Some aspects of the model will be contentious; nonetheless, this is a major advance in clarifying the issues, providing a guide, and setting a future research agenda.

\section{References}

Ashenfelter, Orley, David Ashman, and Robert LaLonde. 1995. Wine vintage quality and the weather. Chance 8 (4): 7-14.

Dunn, Wendy E., Mark E. Domes, Stephen D. Oliner, and Dan E. Sichel. 2004. How fast do personal computers depreciate? Concepts and new estimates. NBER Working Paper no. 10521. Cambridge, MA: National Bureau of Economic Research.

Feenstra, Robert C., and Christopher R. Knittel. 2004. Re-assessing the U.S. quality adjustment to computer prices: The role of durability and changing software. Paper presented at CRIW Conference on Index Theory and Measurement of Price and Productivity. 28-29 June, Vancouver, B.C.

Feldstein, Martin, and Michael Rothschild. 1974. Towards an economic theory of replacement investment. Econometrica 42 (May): 393-423.

Hall, Robert E. 1968. Technical change and capital from the point of view of the dual. Review of Economics and Statistics 35 (January): 35-46.

. 1971. The measurement of quality change from vintage price data. In Price indexes and quality change, ed. Zvi Griliches, 240-71. Cambridge, MA: Harvard University Press.

Hall, Robert E., and Dale W. Jorgenson. 1967. Tax policy and investment behavior. American Economic Review 57 (3): 391-414.

Hulten, Charles R. 1990. The measurement of capital. In Fifty years of economic measurement: The jubilee of the Conference on Research in Income and Wealth, ed. Ernst R. Berndt and Jack E. Triplett, 119-58. Chicago: University of Chicago Press.

Jorgenson, Dale W. 1974. The economic theory of replacement and depreciation. In Econometrics and economic theory, ed. W. Sellekraets, 189-221. New York: MacMillan.

Solow, Robert A. 1970. Growth theory: An exposition. Oxford: Clarendon. 
Triplett, Jack. 1996. Depreciation in production analysis and economic accounts. Economic Inquiry 31 (1): 93-115.

White, Alan G., Jaison R. Abel, Ernst R. Berndt, and Cory W. Monroe. 2004. Hedonic price indexes for personal computer operating systems and productivity suites. NBER Working Paper no. 10427. Cambridge, MA: National Bureau of Economic Research.

Wykoff, Frank C. 2002. Obsolescence in economic depreciation from the point of view of the revaluation term. Working paper for National Bureau of Economic Research and Conference on Research in Income and Wealth productivity workshop. 28-30 June, Cambridge, Massachusetts. 